John Peter Oyardo Manrique

\title{
Reconstrução do espectro de fótons de aceleradores lineares clínicos com base na curva de transmissão e no algoritmo de recozimento simulado generalizado "Versão corrigida"
}


John Peter Oyardo Manrique

\section{Reconstrução do espectro de fótons de aceleradores lineares clínicos com base na curva de transmissão e no algoritmo de recozimento simulado generalizado "Versão corrigida"}

Dissertação apresentada à Faculdade de Filosofia, Ciências e Letras de Ribeirão Preto da Universidade de São Paulo para obtenção do título de Mestre em Ciências. Área de concentração: Física Aplicada à Medicina e Biologia

Orientador: Prof. Dr. Alessandro Martins da Costa 
AUTORIZO A REPRODUÇÃO E DIVULGAÇÃO TOTAL OU PARCIAL DESTE TRABALHO, POR QUALQUER MEIO CONVENCIONAL OU ELETRÔNICO, PARA FINS DE ESTUDO E PESQUISA, DESDE QUE CITADA A FONTE.

FICHA CATALOGRÁFICA

Manrique, John Peter Oyardo.

Reconstrução do espectro de fótons de aceleradores lineares clínicos com base na curva de transmissão e no algoritmo de recozimento simulado generalizado. Ribeirão Preto, 2015.

103 p.: il.; $30 \mathrm{~cm}$

Dissertação de Mestrado, apresentada à Faculdade de Filosofia, Ciências e Letras de Ribeirão Preto/USP. Área de concentração: Física Aplicada à Medicina e Biologia.

Orientador: Costa, Alessandro Martins da.

1. Radioterapia. 2. Espectrometria. 3. Fótons. 4. Problema inverso. 5. Funções generalizadas. 


\section{FOLHA DE APROVAÇÃO}

John Peter Oyardo Manrique

Reconstrução do espectro de fótons de aceleradores lineares clínicos com base na curva de transmissão e no algoritmo de recozimento simulado generalizado

Dissertação apresentada à Faculdade de Filosofia, Ciências e Letras de Ribeirão Preto da Universidade de São Paulo para obtenção do título de Mestre em Ciências. Área de concentração: Física Aplicada à Medicina e Biologia.

Aprovado em:

Banca Examinadora

Prof. Dr.

Instituição:

Assinatura:

Prof. Dr.

Instituição:

Assinatura:

Prof. Dr.

Instituição: Assinatura: 


\section{DEDICATÓRIA}

Dedicado às pessoas que me permitiram lograr meus sonhos, e àquelas que perseguem um, não desistam deles, pois o caminho é longo e ainda não terminou. 


\section{AGRADECIMENTOS}

Ao meu orientador, Prof. Dr. Alessandro Martins da Costa. A todo o pessoal, docentes, funcionários e companheiros de Laboratório, do Departamento de Física, Faculdade de Filosofia Ciências e Letras de Ribeirão Preto, Universidade de São Paulo. Aos Físicos do Serviço de Radioterapia do Hospital das Clínicas da Faculdade de Medicina de Ribeirão Preto, Universidade de São Paulo. À Coordenação de Aperfeiçoamento de Pessoal de Nível Superior pelo apoio financeiro. E finalmente, a todos que contribuíram de maneira direta o indireta na realização deste trabalho. 
"O mundo me é dado apenas uma vez, não como um registro e sim como uma percepção. Sujeito e objeto são apenas um. A barreira entre eles não pode ser discriminada, porque essa barreira não existe." 


\section{Resumo}

A distribuição espectral de raios $X$ de megavoltagem utilizados em departamentos de radioterapia é uma grandeza fundamental a partir da qual, em princípio, todas as informações requeridas relevantes para tratamentos de radioterapia podem ser determinadas. A medição direta é difícil de realizar clinicamente, e a análise da transmissão é um método indireto clinicamente viável para determinar espectros de fótons de aceleradores lineares clínicos. Neste método, os sinais de transmissão são adquiridos após o feixe passar através de diferentes espessuras de atenuadores. $O$ objetivo deste trabalho foi o estabelecimento e a aplicação de um método indireto que utilizou um modelo espectral baseado no algoritmo de recozimento simulado generalizado para determinar o espectro de fótons de aceleradores lineares clínicos com base na curva de transmissão. A análise dos espectros obtidos foi feita por determinação analítica de grandezas dosimétricas e parâmetros relacionados. 


\section{Abstract}

The spectral distribution of megavoltage $X$-rays used in radiotherapy departments is a fundamental quantity from which, in principle, all relevant information required for radiotherapy treatments can be determined. The direct measurement is difficult to achieve clinically and analyzing the transmission is a clinically viable indirect method for determining clinical linear accelerators photon spectra. In this method, transmission signals are acquired after the beam passes through different thicknesses of attenuators. The objective of this work was the establishment and application of an indirect method that used a spectral model based on generalized simulated annealing algorithm to determine the spectrum of clinical linear accelerators photons based on the transmission curve. Analysis of the spectra was made by analytical determination of dosimetric quantities and related parameters. 


\section{Sumário}

1 Introdução $\quad$ p. 12

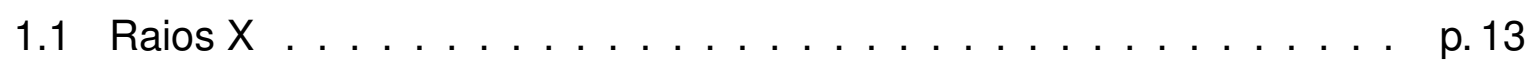

1.1.1 Produção de raios $X \ldots \ldots \ldots \ldots \ldots \ldots$. . . . . . . . . .

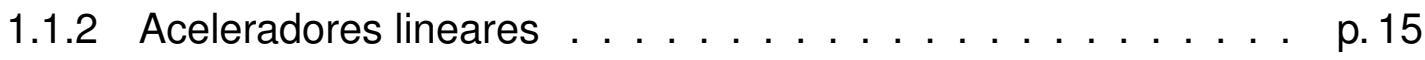

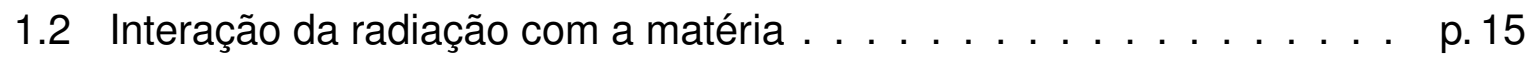

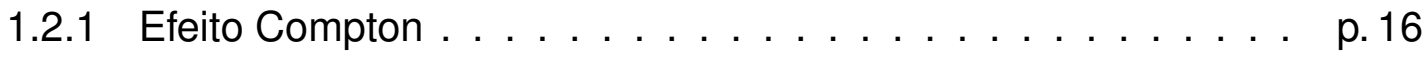

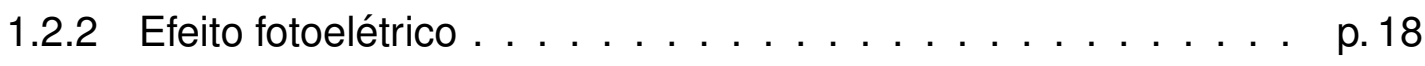

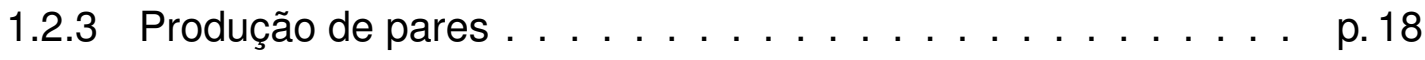

1.2.4 Espalhamento Rayleigh . . . . . . . . . . . . . . p. 19

1.2 .5 Interações fotonucleares $\ldots \ldots \ldots \ldots \ldots$

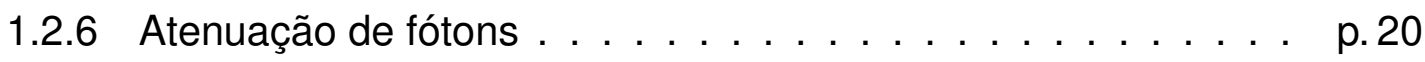

1.3 Grandezas para um feixe de fótons . . . . . . . . . . . . p. 21

1.3.1 Fluência de fótons $\ldots \ldots \ldots \ldots \ldots \ldots \ldots \ldots$

1.3.2 Fluência em energia de fótons $\ldots \ldots \ldots \ldots \ldots$. . . . . . . . .

1.3 .3 Kerma . . . . . . . . . . . . . . . . . p. 22

1.3.4 Dose absorvida . . . . . . . . . . . . . . . . . . . . p. 22

1.3.5 Relação entre kerma e fluência de fótons $\ldots \ldots \ldots \ldots$. . . . 22

1.4 Qualidade de um feixe de raios $X$ de energia alta $\ldots \ldots \ldots$. . . . . 23

2 Materiais e métodos $\quad$ p. 25

2.1 Método de recozimento simulado generalizado $\ldots \ldots \ldots \ldots \ldots$

2.2 Metodo GSA na reconstrução do espectro de fótons . . . . . . . . . p.35 
2.2.1 Medição das Curvas de Transmissão de fótons . . . . . . . . p p.35

2.2.2 Algoritmo para a Reconstrução do Espectros de fótons . . . . p.39

3 Resultados e discussões $\quad$ p. 46

4 Conclusões $\quad$ p. 57

$\begin{array}{ll}\text { Referências } & \text { p.58 }\end{array}$

Apêndice A - Mecânica estatística e critério de Metropolis p.62

A.1 Algoritmo de Metropolis . . . . . . . . . . . . . . . p.64

A.2 Critério de Metropolis generalizado . . . . . . . . . . . p. 65

A.3 Funções Generalizadas . . . . . . . . . . . . . . . . . . . . p.67

A.4 Generalização dos Operadores Algébricos . . . . . . . . . . p. 68

A.5 Convergência do método de GSA $\ldots \ldots \ldots \ldots \ldots$

Apêndice B - Método de reconstrução dos espectros $\quad$ p.70

Apêndice C - Critérios para obtenção de soluções de ensaio GSA p.73

C.1 Pseudo-Código para o Método de Box-Müller Generalizado . . . . . p p.73

C.2 Regularização de Tikhonov . . . . . . . . . . . . . . . . . p.74

Apêndice D - Reconstrução e refinamento dos espectros p.75

Apêndice E - Dados para obtenção curva de transmissão p.77

E.1 Coeficiente de atenuação $\ldots \ldots \ldots \ldots \ldots \ldots$. . . . . . . . .

Apêndice F - Distribuições de probabilidade e universo soluções para

$6 \mathrm{MV}$

F.1 Distribuições . . . . . . . . . . . . . . . . . p. 83 
Apêndice G - Espectros obtidos pela técnica GSA com base nas curvas $\begin{array}{ll}\text { de transmissão } & \text { p.90 }\end{array}$

G.1 Validação da reconstrução do espectro de fluência de fótons $\ldots$. . . . p.90

G.2 Espectro de fluência de fótons de $6 \mathrm{MV} \ldots \ldots \ldots \ldots$ p.97

G.3 Espectro de fluência de fótons de $15 \mathrm{MV} \ldots \ldots \ldots \ldots \ldots$ p.97 


\section{Introdução}

A radioterapia é uma técnica clínica usada para o tratamento de pacientes com câncer mediante radiação ionizante (1), entregando doses suficientemente altas com o objetivo de destruir as células tumorais e reduzir ou eliminar os tumores. Mas, ao entregar altas doses de radiação deve-se preservar o tecido sadio circundante à zona tratada que, em alguns pacientes, pode comprometer órgãos vitais críticos afetando sua saúde.

A distribuição espectral de raios $\mathrm{X}$ de megavoltagem utilizados em departamentos de radioterapia é uma grandeza fundamental a partir da qual, em princípio, todas as informações requeridas relevantes para tratamentos de radioterapia podem ser determinadas. A melhor descrição da qualidade de um feixe permite cálculos acurados das razões entre os poderes de freamento para melhorar a dosimetria de fótons de energias altas (2-4) e, se medida regularmente, fornece meios para um controle de qualidade periódico e para otimização dos portais eletrônicos dos aceleradores lineares clínicos.

Mais recentemente, têm aparecido sistemas de planejamento de tratamento tridimensionais que usam poderosos algoritmos de convolução ou baseados em Monte Carlo que exigem o conhecimento exato do espectro de fluência de fótons de raios $X$ do feixe completo da máquina de tratamento o acelerador linear em questão, para realizar adequadamente cálculos de dose sofisticados para o paciente em tratamentos com radioterapia que envolvem heterogeneidades, falta de equilíbrio de partículas carregadas e dispositivos modificadores de feixe (5-8).

A medição direta dos espectros de megavoltagem é difícil de realizar, devido às taxas de doses elevadas entregues por máquinas clínicas que levam a um empilhamento de pulsos nos detectores e saturação induzida pelo tempo morto, e devido também aos grandes intervalos de energia dos fótons produzidos que levam a uma eficiência baixa do detector. A energia alta dos fótons também dita o uso de um de- 
tector de espessura impraticável do qual o custo e a necessidade de uma calibração sofisticada coloca o método fora do alcance da maioria dos físicos nos serviços de radioterapia. Além disso, o tempo de máquina necessário para tais medições pode não estar disponível para a maioria dos serviços de radioterapia. Por estas razões poucos espectros medidos têm aparecido na literatura.

A análise da transmissão é um método indireto clinicamente viável para determinar espectros de fótons de aceleradores lineares clínicos. Neste método, os sinais de transmissão são adquiridos após o feixe passar através de diferentes espessuras de atenuadores. Estudos anteriores sobre a análise de transmissão na faixa de energia megavoltagem incluem os métodos de pares de transformadas de Laplace (9), inversão de matriz direta (10), redes neurais (11), e algoritmos iterativos, como por exemplo, o algoritmo de recozimento simulado (12).

O objetivo deste trabalho é o estabelecimento e a aplicação de um método indireto que utilizará um modelo espectral baseado no algoritmo de recozimento simulado generalizado $(12,13)$ para determinar o espectro de fótons de aceleradores lineares clínicos com base na curva de transmissão. A análise dos espectros obtidos será feita por determinação analítica de grandezas dosimétricas e parâmetros relacionados e a validação experimental por meio de medições realizadas com câmaras de ionização.

\subsection{Raios X}

Os raios $\mathrm{X}$ podem ser produzidos pela transição eletrônica entre a camada externa e interna de um átomo quando este passa de um estado excitado para seu estado fundamental de configuração de mínima energia. Também se produz raios $X$ pela desaceleração de elétrons de alta energia perto dos núcleos dos átomos de um meio material, conhecidos como fótons de raios $X$ de bremsstrahlung, (1) (14).

\subsubsection{Produção de raios $X$}

Raios $\mathrm{X}$ de bremsstrahlung podem ser produzidos quando um feixe de elétrons de alta energia é freado ao passar próximo do núcleo de um material de alto numero atômico, experimentando interação coulombiana, a qual reduz sua energia e produz fótons num espectro contínuo cuja energia máxima é igual a energia cinética máxima dos elétrons incidentes (1). 


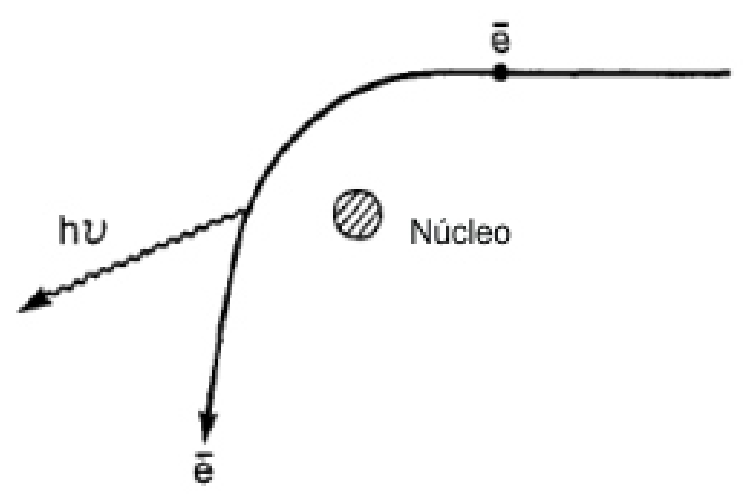

Figura 1: llustração do processo de bremsstrahlung (1), onde um elétron é freado ao passar próximo de um núcleo atômico, sua direção muda e se produz um fóton de energia $h v$.

A direção em que os fótons de bremsstrahlung são emitidos depende da energia e da direção dos elétrons incidentes e do número atômico $Z$ do material alvo, com a maior probabilidade dos raios $X$ serem emitidos na mesma direção dos elétrons incidentes. A energia é dada pela diferença de potencial de aceleração dos elétrons dada pelo tubo acelerador.

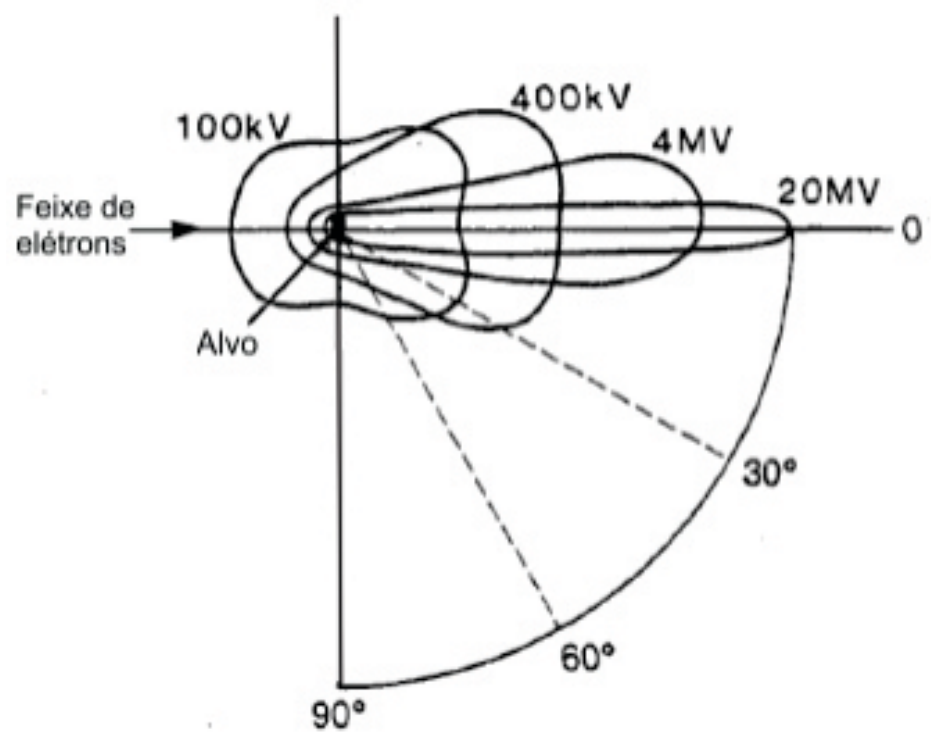

Figura 2: Distribuição espacial dos fótons de bremsstrahlung (1), em função do potencial de aceleração dos elétrons para um alvo de numero atômico $Z$.

Raios X característicos ou de fluorescência são produzidos pela transição eletrônica entre a camada externa e uma camada interna no átomo quando este passa de seu estado excitado a seu estado fundamental de mínima energia. A energia dos raios $\mathrm{X}$ é a diferença da energia das camadas do átomo. 


\subsubsection{Aceleradores lineares}

O acelerador linear é um equipamento que usa ondas eletromagnéticas de alta frequência para acelerar partículas carregadas, por exemplo elétrons a altas energias através de um tubo linear (tubo acelerador). O principio de funcionamento do acelerador baseia-se num gerador de alta potência de corrente contínua que alimenta o modulador o qual gera pulsos de alta voltagem de curta duração $(\mu \mathrm{s})$, que vão para o canhão de elétrons e para a klystron. Os pulsos de micro-ondas gerados na klystron são injetados no tubo acelerador via um guia de ondas. Os elétrons são injetados pelo canhão de elétrons na estrutura do tubo acelerador em forma de pulso de elétrons, e estes ganham energia quando se produz a ressonância com o pulso de micro-ondas dado pela klystron. Finalmente elétrons de alta energia emergem do tubo acelerador e são levados ao cabeçote de tratamento onde o alvo produz os raios $\mathrm{X}$.

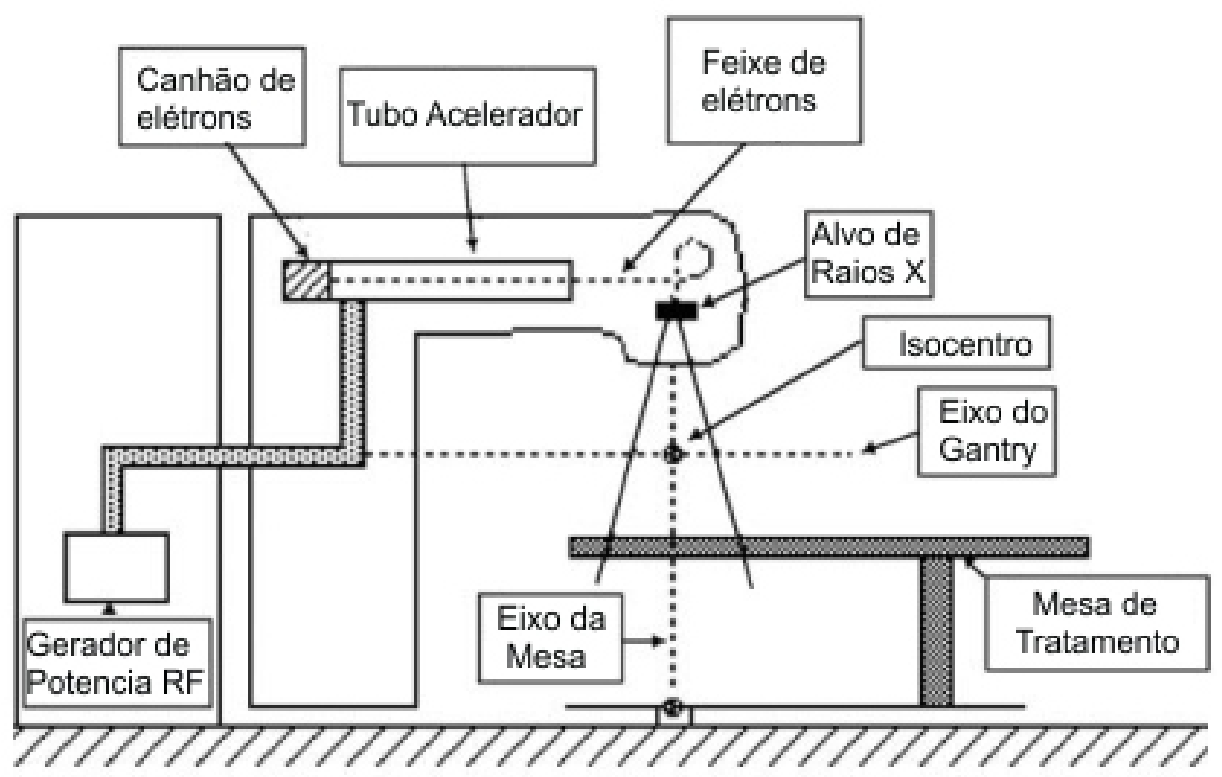

Figura 3: Diagrama esquemático para um acelerador linear clínico isocêntrico (15) com seus principais componentes.

\subsection{Interação da radiação com a matéria}

No processo de interação da radiação com a matéria, a transferência de energia entre a radiação e o meio geralmente se dá mediante absorção ou espalhamento, processos os quais são mais ou menos importantes dependendo do tipo de partícula, sua energia e do meio material que atravessa. 
Quando uma partícula de radiação ionizante interage com um meio material produz-se uma transferência de energia da radiação para os átomos e moléculas do meio o qual a radiação atravessa. A transferência de energia da radiação para o meio pode ocorrer principalmente por ionização ou excitação; o processo de ionização resulta na remoção de um elétron do átomo, transformando-o em um íon positivo, no processo de excitação, se produz uma adição de energia ao átomo, passando de seu estado normal de energia ao um estado de excitação. Ainda podemos classificar a radiação como diretamente ionizante (partículas carregadas) e indiretamente ionizantes (fótons e nêutrons).

No caso da interação de fótons (raios $\mathrm{X}$ ) com a matéria a energia é transferida para o meio em um processo de duas etapas. Na primeira etapa, a energia radiante dos fótons se transfere para as partículas secundárias carregadas (elétrons) por meio dos processos de interação (efeito fotoelétrico, efeito Compton, produção de pares, etc.). $\mathrm{Na}$ segunda etapa, a transferência da energia das partículas carregadas para o meio é por meio de excitações atômicas e ionização. De acordo com Attix(14) existem 5 tipos de processos de interação da radiação com a matéria que devem ser considerados em física radiológica:

- Efeito Compton;

- Efeito fotoelétrico;

- Produção de pares;

- Espalhamento Rayleigh (coerente);

- Interações fotonucleares.

\subsubsection{Efeito Compton}

Compton, em 1922, propôs um modelo do espalhamento Compton, onde um fóton de energia $h v$ colide com um elétron orbital fracamente ligado ao átomo $\left(E_{l} \simeq 0\right)$ estacionário e livre (pode-se considerar um elétron livre quando a energia do fóton incidente é muito maior do que a energia de ligação do elétron ao átomo, $h v \gg E_{l}$ ). A figura 4 mostra o processo de interação Compton.

Inicialmente, um fóton com energia $h v$ colide com um elétron livre do meio, e como resultado da interação e com base as leis de conservação da energia e do momento, 


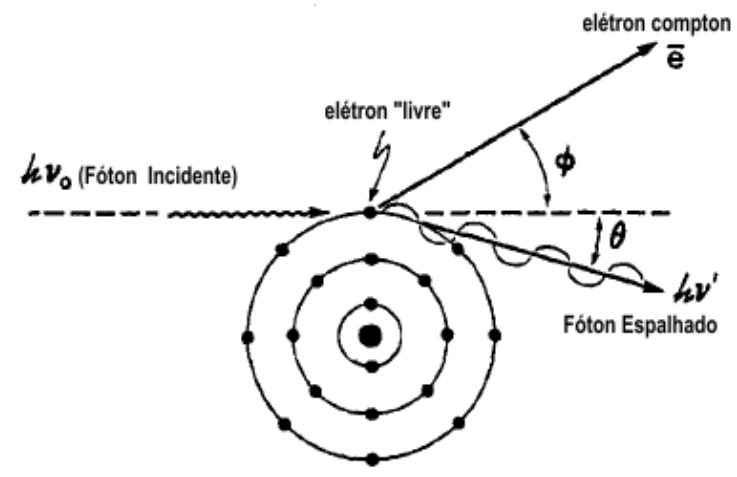

Figura 4: Diagrama ilustrando a cinemática do efeito Compton (1).

produz-se um fóton espalhado com menor energia $h v^{\prime}$ em um ângulo $\theta$ em relação à direção do fóton incidente, dada por

$$
h v^{\prime}=\frac{h v}{1+\alpha(1-\cos \theta)},
$$

em que $\alpha=h v /\left(m_{0} c^{2}\right)$.

O elétron liberado adquire uma energia cinética $T$ e denominado elétron Compton, é espalhado num ângulo $\phi$ com relação à direção do feixe incidente com energia cinética $T=h v-h v^{\prime}$.

A seção de choque diferencial por elétron para o efeito Compton (14) é dada por

$$
\frac{d_{e} \sigma_{K N}(\theta)}{d \Omega}=\frac{r_{e}^{2}}{2}\left(\frac{h v^{\prime}}{h v}\right)^{2}\left[\frac{h v^{\prime}}{h v}+\frac{h v}{h v^{\prime}}-\sin \theta^{2}\right] .
$$

A probabilidade de interação para o efeito Compton é dada pela seção de choque de Klein-Nishina por elétron e pode se obter pela integração da Eq.(1.2) e é representada pela equação

$$
{ }_{e} \sigma_{K N}=2 \pi r_{e}^{2}\left(\frac{1+\alpha}{\alpha^{2}}\left[\frac{2(1+\alpha)}{1+2 \alpha}-\frac{\ln (1+2 \alpha)}{\alpha}\right]+\frac{\ln (1+2 \alpha)}{2 \alpha}-\frac{1+3 \alpha}{(1+2 \alpha)^{2}}\right) .
$$

A seção de choque de Klein-Nishina por átomo (14) é dada por: ${ }_{a} \sigma_{K N}=Z_{e} \sigma_{K N}$ e o correspondente coeficiente de atenuação mássico de Compton é

$$
\frac{\sigma}{\rho}=\frac{N_{A} Z}{A}{ }_{e} \sigma
$$


em que $\frac{\sigma}{\rho}$ é dado em $\mathrm{cm}^{2} / \mathrm{g}, N_{A}=6,022 \times 10^{23} \mathrm{~mol}^{-1}$ é a constante de Avogadro, $Z$ é o numero atômico, $A$ é o peso molecular ou peso atômico e $\rho$ é a densidade em $\mathrm{g} / \mathrm{cm}^{3}$.

\subsubsection{Efeito fotoelétrico}

O efeito fotoelétrico é uma forma de interação na qual toda a energia $E_{\gamma}$ do fóton é transferida para um elétron geralmente da camada $\mathrm{K}$, arrancando-o do átomo. A energia excedente depois que o elétron e removido do átomo é transferido para o elétron em forma de energia cinética $E_{c}$. $O$ efeito fotoelétrico é predominante para baixas energias. A energia do fóton incidente $E_{\gamma}$ no material deve ser maior do que a energia de ligação dos elétrons $W_{e}$. A figura 5 mostra a cinemática do efeito fotoelétrico.

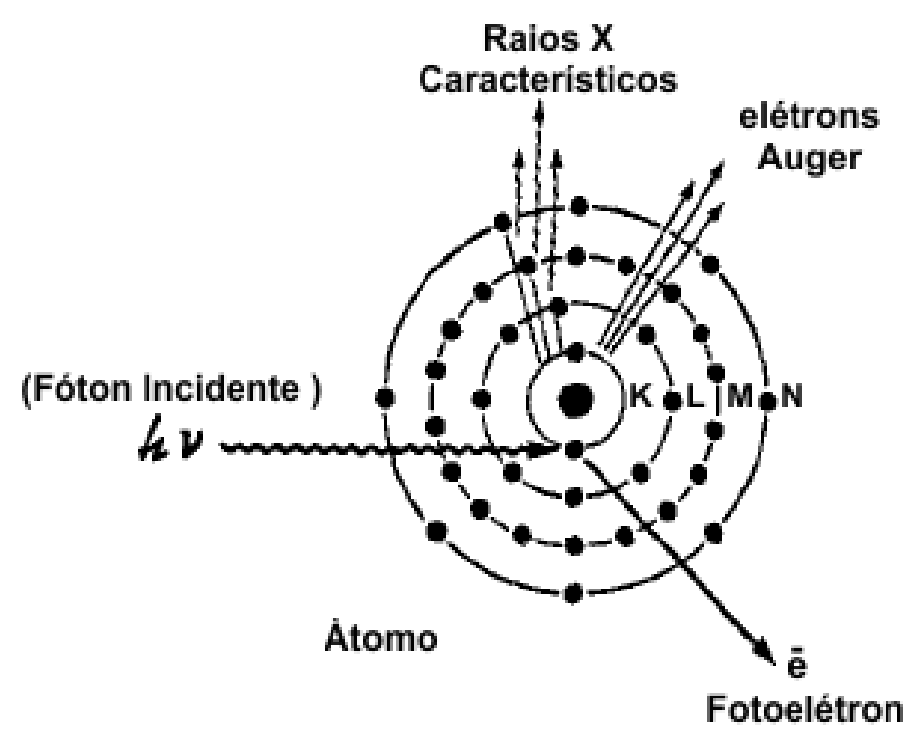

Figura 5: Diagrama ilustrando a cinemática do efeito fotoelétrico (1).

A energia cinética obtida pelo elétron é igual a energia do fóton incidente $E_{\gamma}$ menos a energia de ligação do elétron $W_{e}$ e é dada pela equação

$$
E_{c}=E_{\gamma}-W_{e}
$$

\subsubsection{Produção de pares}

Quando um fóton com energia superior a $1,022 \mathrm{MeV}$ interage nas vizinhanças do núcleo de um átomo, ele pode desaparecer e em seu lugar surgir um par elétron e pósitron. A energia excedente ao limiar de produção de pares dado acima é transferido às partículas formadas. Quanto maior a energia do fóton, maior será a energia 
cinética das partículas, que irão perder sua energia no meio. Quando o pósitron praticamente não tiver mais energia, irá se aniquilar com um elétron livre qualquer do meio, originando duas radiações eletromagnéticas. A cinemática do efeito de produção de pares é dada na figura 6 .

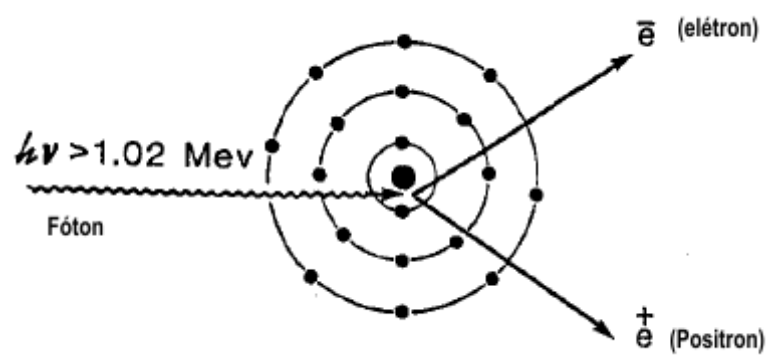

Figura 6: Ilustração do processo de produção de um par elétron-pósitron (1)

\subsubsection{Espalhamento Rayleigh}

O espalhamento Rayleigh (coerente) pode ser entendido considerando a natureza da radiação eletromagnética (1), em que um fóton de certa frequência passa perto de um elétron de um átomo colocando ele em oscilação. O elétron oscilante re-irradia a energia a mesma frequência que o fóton incidente (Figura 7). No espalhamento Rayleigh não se produz transferência de energia ao meio.

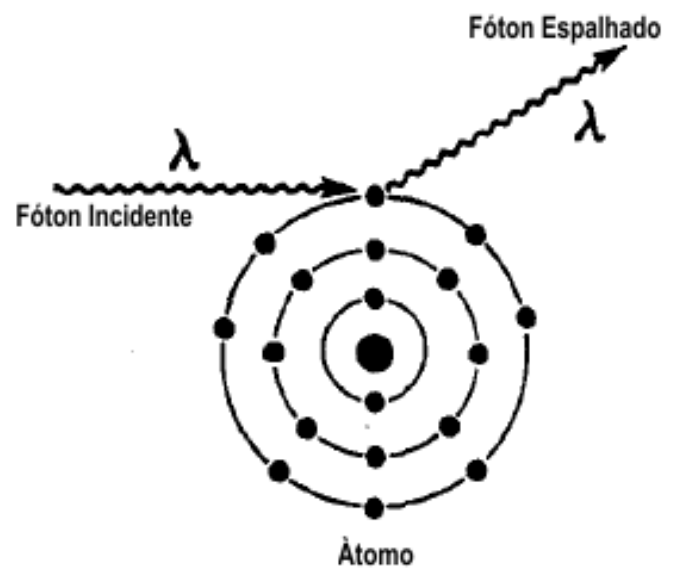

Figura 7: Ilustração do efeito Rayleigh o fóton espalhado tem o mesmo comprimento de onda que o fóton incidente (1) 


\subsubsection{Interações fotonucleares}

Em uma interação fotonuclear um fóton energético de uns poucos $\mathrm{MeV}$ entra e excita um núcleo o qual então emite um próton ou um nêutron $(\gamma, p$ ou $\gamma, n)$, estes eventos contribuem diretamente ao kerma mas a quantidade relativa de produção permanece menor que o $5 \%$ da produção de pares de modo que não se consideram dosimetricamente (14). Para o caso de fótons produzidos a $15 \mathrm{MV}$ a produção de nêutrons chega a ser importante mas sem afetar a proteção radiológica do paciente e os trabalhadores ocupacionalmente expostos (16), (17), quando são adotadas as medidas de segurança no desenho da instalação para o acelerador linear, considerando uma adequada blindagem para neutrons e um adequado sistema de ventilação com troca de ar para extrair os produtos de ativação como o nitrogênio-13, e oxigênio-15 assim como outros produtos ativados gerados.

\subsubsection{Atenuação de fótons}

Um feixe de radiação de fótons, ao passar através de um material experimenta uma diminuição de sua intensidade que é dada pela lei do decaimento exponencial, devido a que alguns fótons conseguem passar sem interagir com o material e não são absorvidos porém outros experimentam espalhamento ou são absorvidos totalmente deixando toda sua energia no material. Se consideremos um feixe estreito com um numero $N$ relativamente grande de fótons que incidem sobre uma pequena espessura $d l$ de material, então a variação no número de fótons, $d N$, devido à absorção que atravessam a espessura dada é proporcional a $N$, e à probabilidade de que um fóton interaja na espessura $\mu d l$

$$
d N=-N \mu d l .
$$

Para um feixe estrito que tem inicialmente $N_{0}$ fótons que atravessam uma placa de espessura $L$ a equação diferencial acima tem solução dado por:

$$
N=N_{0} e^{-\mu L},
$$

em que $\mu$ é conhecido como coeficiente de atenuação linear ou simplesmente coeficiente de atenuação (14). Considerando a densidade do material $\rho$, podemos obter o coeficiente de atenuação mássico $\mu / \rho$, e o coeficiente de absorção de energia mássico $\mu_{e n} / \rho$. 


\subsection{Grandezas para um feixe de fótons}

Para parametrizar o feixe de radiação se usam grandezas radiológicas e dosimétricas (14).

\subsubsection{Fluência de fótons}

A fluência de fótons, $\phi$, e definida como a razão entre o valor esperado do número de fótons $d N_{e}$ incidentes sobre uma esfera infinitesimal de área transversal $d A$ em torno de um ponto $p$,

$$
\phi=\frac{d N_{e}}{d A}
$$

A unidade da fluência é $\mathrm{m}^{-2}$.

\subsubsection{Fluência em energia de fótons}

Define-se a fluência em energia de fótons $\psi$ como a razão entre o valor esperado da energia radiante $d R$ incidente sobre uma esfera de área infinitesimal transversal $d A$.

$$
\psi=\frac{d R}{d A}
$$

A unidade da fluência em energia e $\mathrm{J} / \mathrm{m}^{2}$.

Para um feixe monoenergético a energia radiante $R$ pode ser calculada como o produto da energia de um fóton $E$ pelo número de fótons $N_{e}$ e a fluência em energia pode ser calculada a partir da seguinte equação:

$$
\psi=\frac{d R}{d A}=\frac{d\left(E N_{e}\right)}{d A}=\phi E .
$$

Para feixes polienergéticos se define o espectro de fluência de fótons diferencial $\phi^{\prime}$, e o espectro de fluência em energia de fótons diferencial $\psi^{\prime}$. Como

$$
\phi^{\prime}=\frac{d \phi}{d E}, \quad \psi^{\prime}=\frac{d \psi}{d E}
$$




\subsubsection{Kerma}

O kerma é uma grandeza não estocástica relevante para campos de radiação indiretamente ionizantes (fótons ou nêutrons). O Kerma é definido num dado ponto $P$ num meio de volume $V$ como o valor esperado da energia média transferida $d\left(\bar{E}_{t r}\right)_{e}$ das partículas não carregadas (radiação indiretamente ionizante) a partículas carregadas (elétrons) do meio por unidade de massa $\mathrm{dm}$.

$$
K=\frac{\left(d \bar{E}_{t r}\right)_{e}}{d m},
$$

cuja unidade é o Gray $(1 \mathrm{~Gy}=1 \mathrm{~J} / \mathrm{kg})$

\subsubsection{Dose absorvida}

A dose absorvida é definida num dado ponto $P$ num meio de volume $V$ como o valor esperado da energia depositada $d E$ pela radiação ionizante por unidade de massa $d m$ correspondente ao volume $d V$.

$$
D=\frac{d E}{d m} .
$$

A unidade de dose também é o Gray.

\subsubsection{Relação entre kerma e fluência de fótons}

Para um feixe monoenergético de energia $E$ num meio de numero atômico $Z$ temse a seguinte relação:

$$
K=\psi\left(\frac{\mu_{t r}}{\rho}\right)_{(E, Z)} .
$$

Para um espectro de fluência em energia de fótons:

$$
K=\int_{0}^{E_{\max }} \psi^{\prime}\left(\frac{\mu_{t r}}{\rho}\right)_{(E, Z)} d E,
$$

em que $\psi^{\prime}$ e a distribuição diferencial de fluência em energia de fótons, em $\mathrm{J} / \mathrm{m}^{2} \cdot \mathrm{KeV}$ ou $\mathrm{erg} / \mathrm{cm}^{2} \cdot \mathrm{KeV}, \mu_{t r}$ é o coeficiente de transferência de energia linear, dado $\mathrm{em}^{\mathrm{cm}}{ }^{-1}$ 
ou $\mathrm{m}^{-1}$, e o coeficiente de transferência de energia mássico $\mu_{t r} / \rho_{(E, Z)}$ é dado em $\mathrm{m}^{2} / \mathrm{kg}$ ou cm $\mathrm{cm}^{2} / \mathrm{g}$. O coeficiente de transferência de energia mássico $\mu_{t r} / \rho$ está relacionado com o coeficiente de absorção de energia mássico $\mu_{e n} / \rho$ pela equação

$$
\frac{\mu_{e n}}{\rho}=\frac{\mu_{t r}}{\rho}(1-g),
$$

em $g$ representa a fração média de perda radiativa da energia dos elétrons secundários. O kerma pode ser subdivido em kerma de colisão $K_{c}$ e kerma radiativo $K_{r}$ em que $K=K_{c}+K_{r}$.

A fração média da energia transferida aos elétrons que é perdida por meio de processos radiativos é representada pelo fator $\bar{g}$ chamado fator de perda radiativa,

$$
K_{c}=K(1-\bar{g})
$$

Então o em kerma de colisão $K_{c}$ pode ser obtido por

$$
K_{c}=\psi\left(\frac{\mu_{e n}}{\rho}\right)_{(E, Z)},
$$

em que $\left(\mu_{e n} / \rho\right)_{(E, Z)}$ é o coeficiente de absorção de energia mássico para um feixe de fótons de energia $E$ num meio de número atômico $Z$.

\subsection{Qualidade de um feixe de raios X de energia alta}

A especificação da qualidade de um feixe de fótons tem sido objeto de inúmeros estudos devido a sua relevância na dosimetria de radiações. Não obstante, não se encontrou um descritor de qualidade do feixe que satisfaça todos os requisitos possíveis pra ser um descritor único para todo a faixa de energias de fótons utilizado em radioterapia e para todos os tipos de aceleradores usados em hospitais e laboratórios de calibração. Neste contexto,pode-se adotar a razão tecido-phantom $T P R_{20,10}$ como um descritor adequado da qualidade do feixe, ou a $P D D(10)_{x}$, proposta no protocolo de dosimetria da $A A P M$ (3). Muitos protocolos de dosimetria, baseados em padrões de kerma no ar e em padrões de dose absorvida na água, têm recomendado a $T P R_{20,10}$ como descritor da qualidade de um feixe de fótons de energia alta (4). Define-se a $T P R_{20,10}$ como a razão entre as doses absorvidas na água, no eixo do feixe, nas profundidades de $20 \mathrm{~cm}$ e $10 \mathrm{~cm}$ num objeto simulador de água, obtidas com uma distância 
fonte-detector $(S D D)$ constante de $100 \mathrm{~cm}$ e um tamanho de campo de $10 \times 10 \mathrm{~cm}^{2}$ na posição do detector. O parâmetro $T P R_{20,10}$ é uma medida do coeficiente de atenuação efetivo, que descreve o decréscimo aproximadamente exponencial de uma curva de dose em profundidade de fótons além da profundidade de dose máxima (4), que é independente da contaminação eletrônica do feixe incidente. 


\section{Materiais e métodos}

\subsection{Método de recozimento simulado generalizado}

Existem muitos métodos para encontrar o mínimo global de uma função custoenergia, como o método de Newton, método de descida de gradiente, método de mínimos quadrados (18) (19), assim também, podemos usar um método de busca local iterada (20). Por exemplo podemos usar o método de Newton ou o método de descida de gradiente para minimizar uma função que possui um único mínimo (função convexa) dentro de seu domínio, mas se a função é não convexa (múltiplos mínimos locais) a maioria destes métodos falha em encontrar o mínimo global devido a que o sistema pode ficar capturado num mínimo local. O método de recozimento simulado generalizado, GSA (do inglês, Generalized Simulated Annealing), tem provado sua eficiência em encontrar o mínimo global de uma função de custo-energia não convexa que tem uma configuração de energia com muitos mínimos locais (13).

A partir do princípio de máxima entropia formulado por Jaynes(21), qual foi derivado usando critérios de inferência estatística na teoria da informação e a partir de leis da mecânica estatística se postula que um sistema esta em equilíbrio quando sua entropia e maxima, isso foi usado por Tsallis e Saltorio (13) para propor uma nova distribuição de probabilidade para o ensemble canônico (distribuição de probabilidade de visitação) e assim ó método de recozimento simulado generalizado, GSA, com base ao uso de um parâmetro de generalização $q$, para a re-formulação da entropia de Shannon-Gibss. Assim surge o uso do termino estatística generalizada de Tsallis que é considerado uma extensão da estatística de Boltzmann Gibbs para situações de quasi-equilíbrio, e estritamente segue a estatística de quase equilíbrio de Boltzmann Gibbs.

O GSA é um método estocástico formulado a partir da estatística generalizada de Tsallis usado para encontrar o mínimo global de uma função de custo-energia não necessariamente convexa definida num espaço $D$ dimensional contínuo (13). Baseado 
no trabalho de Tsallis sobre a generalização da entropia e ao incorporar a proposta de funções generalizadas (22), com o parâmetro de generalização $\tilde{q}$, obtemos o $\tilde{q}$-GSA (recocido simulado generalizado de parâmetro q) que é baseado no uso da função de distribuição de probabilidade $\tilde{q}$-Normal (23).

O método GSA baseia-se em simular o recozimento de um material metálico qual é esquentado até uma alta temperatura e logo esfriado lentamente fazendo que o metal fundido alcance seu estado cristalino ou configuração para a qual a energia é mínima (mínimo global). A temperatura atua como fonte de estocasticidade (esquema de esfriamento da temperatura) para fazer saltar a solução do mínimo local na qual se encontra capturada usando um método de Subida de Montanha (Hill Climbings) (20). Ao encontrar-se próximo do final do processo o sistema tem a maior probabilidade de estar próximo ao mínimo global da solução (para sistemas com degeneração que tem mais de um mínimo global o sistema se encontrara perto a um mínimo global se existe mais de um) (13).

O algoritmo GSA é um algoritmo de pesquisa do mínimo global (algoritmo de busca iterativa) (20) que usa um recozimento mais rápido de modo tal de fazer um rápido esfriamento da temperatura preservando a probabilidade de finalizar num mínimo global igual a um (apêndice A.5), quando a temperatura e próxima de zero. As primeiras soluções para o método neste caminho foram dadas em 1983 por Kirkpatrick, Gellat e Vecchi(24) para sistemas clássicos e foi estendida em 1986 por Ceperley e Alder(25) para sistemas quânticos.

Em 1996 Tsallis and Saltorio [ (13)] usarem o parâmetro $q \in \mathbb{R}$ para a generalização da entropia de de Shanon-Gibbs e assim propuseram usar um parâmetro de generalização para o esquema de esfriamento da temperatura $q_{A} \in \mathbb{R}$, e um parâmetro de generalização para a distribuição de probabilidade de visitação a usar $q_{V} \in \mathbb{R}$, dependendo dos valores de estes parâmetros eles classificarem o esquema proposto por Kirkpatrick, Gellat e Vecchi(24) com parâmetros $\left(q_{A}, q_{V}\right)=(1,1)$ como maquina de Boltzmann (Recozimento Simulado Clássico CSA) qual usa uma distribuição de visitação Gaussiana, e um esquema resfriamento da temperatura geométrico, Geman e Geman(26) mostrarem que uma condição necessaria e suficiente para que o CSA tenha probabilidade de finalizar num mínimo global igual a um é que a temperatura decresça logaritmicamente com o tempo (13). O esquema proposto por Szu and Hartley,[(27)], foi chamado a Maquina de Cauchy (Recozimento Simulado Rapido FSA) com parâmetros $\left(q_{A}, q_{V}\right)=(1,2)$ qual usa uma distribuição de visitação Cauchy- 
lorentz ademais um mais rápido esquema de esfriamento da temperatura que desce com a inversa do tempo com o objetivo de acelerar o Esquema de Esfriamento sem incrementar a probabilidade de ficar preso num mínimo local. (mantendo a probabilidade de encontrar o mínimo global igual a 1).

Com base na introdução do parâmetro de generalização $q$, a definição das funções $q$-logaritmo e $q$-exponencial,$(28,29)$ dadas por

$$
\ln _{q} x \equiv \frac{x^{1-q}-1}{1-q}, \quad \exp _{q} x \equiv \begin{cases}{[1+(1-q) x]^{1 /(1-q)}} & \text { Se } 1+(1-q) x \geq 0 \\ 0 & \text { outro. }\end{cases}
$$

onde $\lim _{q \rightarrow 1} \ln _{q} x=\ln x$, e, $\lim _{q \rightarrow 1} e_{q}^{x}=e^{x}$, além do uso das inversas $e_{q}^{\ln _{q} x}=\ln _{q} e_{q}^{x}=x$, e usando a entropia de Shannon-Gibbs, construimos a entropia generalizada de Tsallis [ (13), (29)], cuja expressão se apresenta na equação

$$
s_{q}=-k_{B} \sum_{i} p_{i}^{q} \ln _{q} p_{i}
$$

onde $k_{B}$ e a constante de Boltzmann a qual posteriormente é renormalizada fazendo $k_{B}=1$ para trabalhar em unidades adimensionais, $p_{i}$ e a probabilidade de um sistema encontra-se num estado de energia $E_{i}$.

Quando $q=1$, recuperamos a entropia de Shanon-Gibbs dada por

$$
s_{k}=-k_{B} \sum_{i} p_{i} \ln p_{i}
$$

Tsallis e Stariolo(13) também propuseram uma generalização do ensemble canônico, através da distribuição de probabilidade generalizada

$$
p_{i}=\frac{\left[1-\beta(1-q) E_{i}\right]^{1 /(1-q)}}{Z_{q}},
$$

e a correspondente função de partição

$$
Z_{q}=\sum_{i}\left[1-\beta(1-q) E_{i}\right]^{1 /(1-q)}
$$

em que o parâmetro $\beta \equiv 1 / k T$ e $E_{i}$ é a energia do sistema no estado $i$. Pode-se verificar que quando $q \rightarrow 1$ se recupera a distribuição de Boltzmann como caso particular onde $\left.p_{i}=\exp \left(-\beta E_{i}\right) / Z_{1} \operatorname{com} Z_{1} \equiv \sum_{i} \exp \left(-\beta E_{i}\right)\right]$. 
No algoritmo GSA se usa o parâmetro $q_{V}$, para a gerar novas soluções candidatas $X_{\text {new }} \in \mathbb{R}$ a partir de uma solução anterior $X_{\text {old }} \in \mathbb{R}$, dentro do domínio $D$ de uma função da custo-energia $f(x)$. Assim, Tsallis e Stariolo(13), propõem o uso de uma nova distribuição de probabilidade generalizada $g_{q_{V}}$ construída a partir da Distribuição de probabilidade da equação 2.4 , dada na equação

$$
g_{q_{V}}=\left(\frac{q_{V}-1}{\pi}\right)^{1 / 2} \frac{\Gamma\left(\frac{1}{q_{V}-1}\right)}{\Gamma\left(\frac{1}{q_{V}-1}-\frac{1}{2}\right)} \times \frac{\left[T_{V}^{(t)}\right]^{-1 /\left(3-q_{V}\right)}}{\left[1+\left(q_{V}-1\right) \frac{x^{2}}{\left[T_{V}^{(t)}\right]^{2 /\left(3-q_{V}\right)}}\right]^{1 /\left(q_{V}-1\right)}} .
$$

Um novo critério para aceitar o rejeitar as soluções $X_{\text {new }}$ geradas com a distribuição de probabilidade de visitação 2.6 a partir da solução anterior $X_{\text {old }}$ que unifica os critérios de aceitação do recozimento simulado clássico (máquina de Boltzmann) e o recozimento simulado rápido (máquina de Cauchy) usando o parâmetro $q_{A}$, e dado na equação

$$
P_{q_{A}}\left(X_{\text {old }} \leftarrow X_{\text {new }}\right)= \begin{cases}1, & \text { se } \Delta f \leq 0, \\ \frac{1}{\left[1+\left(q_{A}-1\right) \Delta f / T_{q_{A}}^{A}\right]^{1 /\left(q_{A}-1\right)},}, & \text { se } \Delta f>0,\end{cases}
$$

em que $\Delta f=f\left(X_{\text {new }}\right)-f\left(X_{\text {old }}\right)$ e $T_{q_{A}}^{A}>0$ é a temperatura de aceitação

Além disso propuseram uma generalização para o cronograma de resfriamento da temperatura

$$
T_{V}^{(t)}=T_{V}^{(t)} \frac{2^{q_{V}-1}-1}{(1+t)^{q_{V}-1}-1}
$$

em que $T_{V}^{(t)}$ é a temperatura de visitação na iteração $t$.

O algoritmo proposto (13) para encontrar o mínimo global de uma função de custoenergia $E(x)$ é:

1. Defina $\left(q_{A}, q_{V}\right)$. Inicie $t=1 \mathrm{com}$ um valor arbitrário de $x_{1}$ e um valor suficientemente alto de $T_{q V}(1)$, calcule $E\left(x_{1}\right)$.

2. Aleatoriamente gere $x_{t+1}$ a partir de $x_{t}$ considerando a distribuição de probabilidade dada na equação 2.6 para determinar o tamanho do passo $\Delta x$, e determinar sua direção.

3. Calcular $E\left(x_{t+1}\right)$ :

Se $E\left(x_{t+1}\right)<E\left(x_{t}\right)$, substituir $x_{t}$ por $x_{t+1}$. 
Se $E\left(x_{t+1}\right) \geq E\left(x_{t}\right)$, gerar um numero aleatório $r \in[0,1]$ com distribuição uniforme: Se $r>P_{q_{A}}$ [Equação 2.7] com $T_{q_{A}}^{A}(t)=T_{q_{V}}^{V}(t)$, mantenha $x_{t}$; de outro modo mude $x_{t}$ por $x_{t+1}$.

4. Calcule a nova temperatura $T_{q_{V}}^{V}(t)$ da equação 2.8 e ir ao item[2] até que o mínimo $E(x)$ seja alcançado com a precisão decidida.

Baseado nos trabalhos de Arruda et al.(30), Martinez, González e Terçariol (22), reformula-se as funções $\tilde{q}$-logaritmo e $\tilde{q}$-exponencial,[apêndice A.3, A.4] usando o parâmetro de generalização $\tilde{q}$, cuja equivalência ao parâmetro $q$ de Tsallis é $\tilde{q}=1-q$. A função $\tilde{q}$ - logaritmo, $\ln _{\tilde{q}} x$ e definida como a área sob a curva $f(t)=1 / t^{1-\tilde{q}}$ no intervalo entre $t \in[1, x]$ é dada por

$$
\ln _{\tilde{q}} x=\left\{\begin{array}{cc}
\frac{x^{\tilde{q}}-1}{\tilde{q}}, & \text { se } \tilde{q} \neq 0 \\
\ln (x), & \text { se } \tilde{q}=0
\end{array}\right.
$$

A função $q$-exponencial é definida como

$$
\exp _{\tilde{q}}(x)= \begin{cases}0, & \text { se } \tilde{q} x<-1 \\ \lim _{\tilde{q}^{\prime} \rightarrow \tilde{q}}\left(1+\tilde{q}^{\prime} x\right)^{1 / \tilde{q}^{\prime}}, & \text { se } \tilde{q} x \geq-1\end{cases}
$$

Na figura 8, observa-se o $\tilde{q}$-logaritmo e na figura 9 a $\tilde{q}$-exponencial para diferentes valores do parâmetro $\tilde{q}$ obtidas com um programa em $\mathrm{C}++$ a partir da definições anteriores e usando o pacote de gráficos origin8.

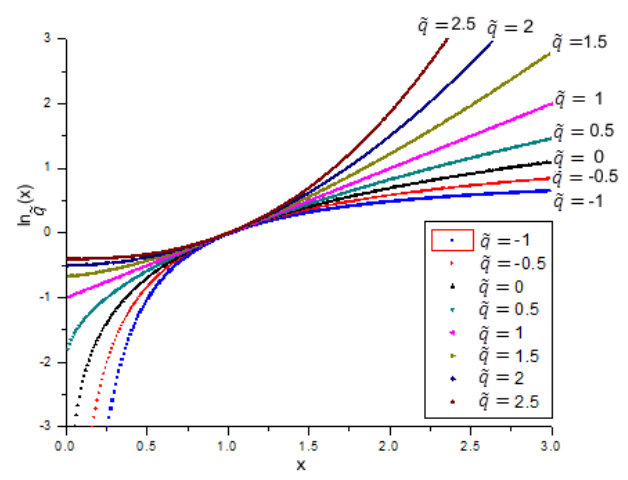

Figura 8: Função logaritmo generalizado em função de $\tilde{q}$

Usando o $\tilde{q}$-logaritmo e $\tilde{q}$-exponencial, reescrevemos a probabilidade $p\left(x_{i}\right)$ de encontrar o sistema na configuração $x_{i}$, dada na equação 2.4 como

$$
p\left(x_{i}\right)=\frac{\exp _{\tilde{q}}\left[-\beta f\left(x_{i}\right)\right]}{\sum_{i=1}^{n} \exp _{\tilde{q}}\left[-\beta f\left(x_{i}\right)\right]} .
$$




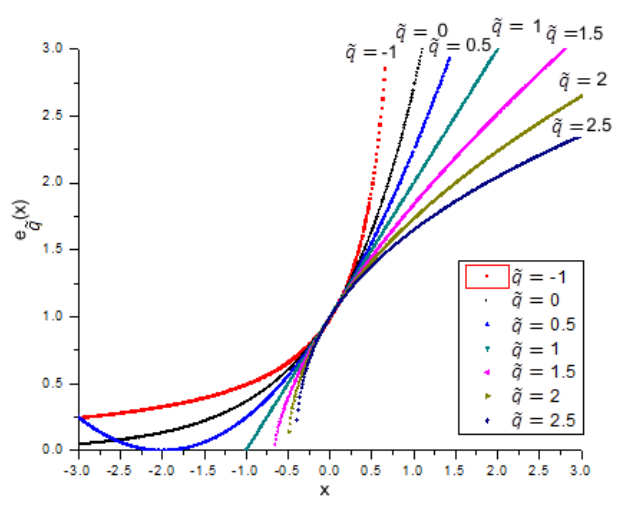

Figura 9: Função exponencial generalizada em função de $\tilde{q}$

Sendo $T_{a}$ e a temperatura de aceitação, e fazendo o parâmetro $\beta=1 / T_{a}$, para nosso caso, podemos usar a probabilidade $p\left(x_{\text {new }}\right)$ de encontrar o sistema em a configuração $x_{\text {new }}$, e probabilidade $p\left(x_{\text {old }}\right)$ de encontrar o sistema em a configuração $x_{\text {old }}$, para calcular a probabilidade de aceitar uma nova solução $x_{\text {new }}$, a partir da solução anterior $x_{\text {old }} p_{\tilde{q}_{a}}\left(x_{\text {new }} \leftarrow x_{\text {old }}\right)=p\left(x_{\text {new }}\right) \oslash_{\tilde{q}_{a}} p\left(x_{\text {old }}\right),[(31)]$ dada como

$$
p_{\tilde{q}_{a}}\left(x_{\text {new }} \leftarrow x_{\text {old }}\right)=\exp _{\tilde{q}_{a}}\left[-\frac{f\left(x_{\text {new }}\right)}{T_{a}}\right] \oslash_{\tilde{q}_{a}} \exp _{\tilde{q}_{a}}\left[-\frac{f\left(x_{\text {old }}\right)}{T_{a}}\right] .
$$

Fazendo uso dos operadores algébricos generalizados [apêndice A.4], usando a expressão [A.37]

$$
\exp _{\tilde{q}}(a) \oslash_{\tilde{q}} \exp _{\tilde{q}}(b)=\exp _{\tilde{q}}(a-b)
$$

se obtém

$$
p_{\tilde{q}_{a}}\left(x_{\text {new }} \leftarrow x_{\text {old }}\right)=\exp _{\tilde{q}_{a}}\left[-\frac{f\left(x_{\text {new }}\right)-f\left(x_{\text {old }}\right)}{T_{a}}\right],
$$

O qual produz o critério de metropolis q̃-generalizado, dado no [apêndice A.2], que é usado por Menin(23), para expressar a nova probabilidade de aceitação de soluções como

$$
p_{\tilde{q}_{a}}\left(x_{\text {new }} \leftarrow x_{\text {old }}\right)= \begin{cases}1, & \text { se } f\left(x_{\text {new }}\right) \leq f\left(x_{\text {old }}\right), \\ \exp _{\tilde{q}_{a}}\left(-\frac{\Delta f}{T_{a}}\right), & \text { se } f\left(x_{\text {new }}\right)>f\left(x_{\text {old }}\right),\end{cases}
$$

em que $\Delta f=f\left(x_{\text {new }}\right)-f\left(x_{\text {old }}\right)$. o critério de metropolis clássico e recuperado para $\tilde{q}_{a}=0$.

Para gerar cada nova solução $x_{n e w}$ cada elemento $x_{\text {old }}^{k}$ da solução anterior e atualizado um de cada vez transformando-se em un novo elemento de $x_{\text {new }}^{k}$ de acordo com a distribuição de probabilidade de visitação $G_{\tilde{q}_{v}}(x)$, é a partir da equação 


$$
x_{\text {new }}^{k}=x_{\text {old }}^{k}+T_{v} G_{\tilde{q}_{v}}(x),
$$

Sendo, que $T_{v}$ é a temperatura de visitação e usando as funções generalizadas para simplificar a expressão da probabilidade de Tsallis da equação 2.6, pode-se obter a distribuição de probabilidade $\tilde{q}$-gaussiana (22), e assim a partir dessa distribuição de probabilidade, fazer a geração de novas soluções como foi proposto por Menin(23), que uso a distribuição de probabilidade de visitação q -gaussiana padrão dada por

$$
G_{\tilde{q}_{v}}(x)=\sqrt{\frac{\tilde{q}_{v}}{2 \pi}} \frac{\Gamma\left(1 / \tilde{q}_{v}\right)}{\Gamma\left(1 / \tilde{q}_{v}-\frac{1}{2}\right)} \exp _{-\tilde{q}_{v}}\left(-\frac{x^{2}}{2}\right)
$$

onde $\tilde{q}_{v}$ o parâmetro de generalização da distribuição de visitação. de acordo com Martinez et al (22). devido a simetria todos os momentos ímpares se anulam e a distribuição tem momentos pares dada por:

$$
\left\langle x^{2 n}\right\rangle_{\tilde{q}, a, 1 / 2}=\left(\frac{2 a^{2}}{\tilde{q}}\right) \frac{\Gamma(1 / 2+n) \Gamma(1 / \tilde{q}-1 / 2-n)}{\sqrt{\pi} \Gamma(1 / \tilde{q}-1 / 2)}
$$

e desvio padrão finito solo para $\tilde{q}<2 / 3$ :

$$
\sigma_{\tilde{q}, a}^{2}=\left\langle x^{2}\right\rangle_{\tilde{q}, a}=\frac{2 a^{2}}{2-3 \tilde{q}}
$$

A figura 10 ilustra o comportamento da pdf $\tilde{q}$-gaussiana, o $\tilde{q}$-Normal, dada pela Eq. 2.16, para diferentes valores do parâmetro q̃ obtida com um programa em $\mathrm{C}++\mathrm{e}$ usando o pacote de gráficos origin8.

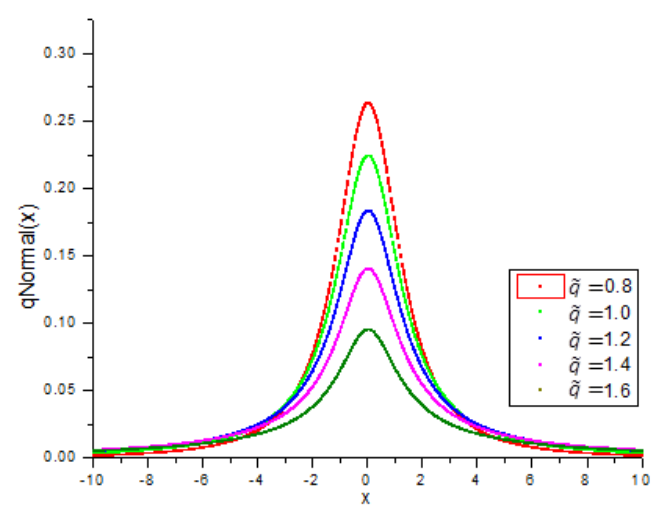

Figura 10: Função q̃-Normal em função do parâmetro $\tilde{q}$

Neste ponto devemos ressaltar que para o desenvolvimento do nosso programa de reconstrução de espectros de aceleradores lineares clínicos escrito em $\mathrm{C}++$ qual 
chamamos GSA-1.0, adotamos o método teórico q̃-SA proposto por Menin(23) em sua teses de doutorado, agradecendo a ajuda dada pelo Dr. Olavo Menin na derivação do algoritmo usado qual se disponibiliza aqui, e assim que nos preferimos realizar poucas mudanças, na estrutura do procedimento teórico do $\tilde{q}$-SA, devido ao tempo corto para a realização deste trabalho, mais também argumentamos que o programa GSA-1.0 foi construído independentemente, e significo um reto de programação para nos.

Depois de esquentar a amostra de material a alta temperatura, se procede a esfriar lentamente com a finalidade de alcançar o estado de minima energia para o sistema. São usados dois esquemas de esfriamento um para a temperatura de aceitação $T_{a} \mathrm{e}$ outro para a temperatura de visitação $T_{v}$, a estocasticidade do processo de otimização e controlada pelo cronograma de resfriamento das temperaturas $T_{a}$ e $T_{v}$, Menin(23), que sao função do tempo e são dadas por

$$
\begin{aligned}
T_{a}^{(t)} & =T_{a}^{(0)} \frac{\ln _{\tilde{q}_{a}}(2)}{\ln _{\tilde{q}_{a}}(t+1)} \\
T_{v}^{(t)} & =T_{v}^{(0)} \frac{\ln _{\tilde{q}_{v}}(2)}{\ln _{\tilde{q}_{v}}(t+1)}
\end{aligned}
$$

em nosso casso nos optamos pelo resfriamento geométrico para a temperatura de aceitação, $T_{a}$ dada por

$$
T_{a}^{(t)}=\alpha^{t} T_{a}^{(0)}
$$

onde $T_{a}^{(0)}$ e a temperatura inicial $(\mathrm{em} \mathrm{t}=0)$ e $\alpha \in(0,1)$ e a taxa de resfriamento.

Dependendo da escolha adequada das temperaturas iniciais de aceitação e visitação o desempenho do algoritmo sera mais o menos ótimo. A temperatura inicial de visitação $T_{v}^{(0)}$, deve ser definida de forma que, no início do processo de otimização, o algoritmo consiga explorar o espaço de soluções completo em conseqüência deve-se conhecer de um modo alternativo o espaço de soluções para definir adequadamente essa temperatura em função a um parâmetro do domínio da função de custo o que dependerá das especificidades do problema. Para garantir que o processo consiga escapar de bacias de mínimos locais, a temperatura inicial de aceitação, $T_{a}^{(0)}$, deve ser da ordem da profundidade da bacia de mínimo local mais profundo esse conseguisse fazendo correr a simulação em um corto numero de passos prévio para assim conhecer a maxima variação da função de custo $\Delta f_{\text {prev }}=\max \left(f\left(x_{i}\right)-\min \left(f\left(x_{i}\right)\right)\right)$, com $x_{i} \in D$ e $i=1, . . n$, onde $n$ e o numero de passos prévios para exploração do espaço de soluções. Então a probabilidade iniciai de aceitar novas soluções $p_{0}$ e dada por

$$
p_{0}=\exp _{\tilde{q}_{a}}\left(-\Delta f_{\text {prev }} / T_{a}^{(0)}\right)
$$


E a temperatura de aceitação iniciai se calcula como:

$$
T_{a}^{(0)}=-\frac{\Delta f_{\text {prev }}}{\ln _{\tilde{q}_{a}}\left(p_{0}\right)}
$$

O algoritmo de recozimento simulado generalizado,pode ser escrito como:

1. Introduzir os parâmetros da simulação: $k, t_{\max }, n_{r}, \tilde{q}_{a}, \tilde{q}_{v}$ e $\alpha$;

2. Definir a temperatura iniciai $T_{v}^{(0)}$ com base a um critério adequado;

3. Gerar $n$ soluções aleatórias previas $x_{i}$ e calcule a função de custo $f\left(x_{i}\right)$;

4. Calcular $\Delta f_{\text {prev }}=\max \left(f\left(x_{i}\right)-\min \left(f\left(x_{j}\right)\right)\right)$, com $i, j=1,2, \ldots, n$;

5. Calcular a temperatura de aceitação iniciai $T_{a}^{(0)}$ da Eq. 2.23;

6. Gerar uma solução iniciai $x_{\text {old }}$;

7. Calcule o valor de função objetivo $f\left(x_{\text {old }}\right)$;

8. para $t$ de 1 até $t_{\max }$ faça:

a repetir $n_{r}$ vezes

- Gerar uma solução candidata $x_{\text {new }}$ com base na Equ. 2.15.

- Calcular $f\left(x_{\text {new }}\right)$

- Se $\delta=f\left(x_{\text {new }}\right)-f\left(x_{\text {old }}\right)<0$

- $x_{\text {old }} \leftarrow x_{\text {new }}$

- $\operatorname{Sef}\left(x_{\text {old }}\right)<f\left(x_{\min }\right) \Rightarrow x_{\min } \leftarrow x_{\text {old }}$

- else

- gerar $x \in[0,1]$ aleatório

- Se $x<\exp _{\tilde{q}_{a}}\left(-\delta / T_{a}\right)$

- $x_{\text {old }} \leftarrow x_{\text {new }}$

- $\operatorname{Sef}\left(x_{\text {old }}\right)<f\left(x_{\min }\right) \Rightarrow x_{\min } \leftarrow x_{\text {old }}$

b Diminuir a temperatura $T_{a}^{(t)}$ da Eq. 2.21;

c Diminuir a temperatura $T_{v}^{(t)}$ da Eq. 2.20;

9. Calcule as quantidades requeridas; 
Antes de realizar a reconstrução dos espectros com a técnica GSA verificamos o correto funcionamento do algoritmo de $\tilde{q}$-SA mediante a minimização de diferentes funções na qual realizamos provas numéricas da obtenção do mínimo global; se observo que nosso algoritmo escrito em $\mathrm{C}++$ supero todas as provas numéricas realizadas.

Prova Numérica 1. Uma função interessante é dada no trabalho de Tsallis e Stariolo(13), a qual possui vários mínimos locais, então o objetivo e encontrar o mínimo absoluto. Essa função é da dada na equação

$$
E(x)=\sum_{i=1}^{4}\left(x_{i}^{2}-8\right)^{2}+5 \sum_{i=1}^{4} x_{i}+E_{0}
$$

No trabalho de Tsallis, se considera o valor para $E_{0} \approx 57.3276$ de modo $E(x) \geq 0 \forall x$. Nos verificamos com nosso algoritmo GSA os resultados obtidos para essa função, que possui quinze mínimos locais e um mínimo global dados na tabela 1 :

Tabela 1: Mínimos locais encontrados para a função $E(x)$ da Eq. 2.24

\begin{tabular}{cccccc}
\hline x1 & x2 & $x 3$ & $x 4$ & $E$ & Degeneração \\
\hline 2,75 & 2,75 & 2,75 & 2,75 & 113,0932 & 1 \\
2,75 & 2,75 & 2,75 & $-2,9$ & 84,8199 & 4 \\
2,75 & $-2,9$ & 2,75 & $-2,9$ & 56,5466 & 6 \\
2,75 & $-2,9$ & $-2,9$ & $-2,9$ & 28,2733 & 4 \\
$-2,9$ & $-2,9$ & $-2,9$ & $-2,9$ & 0 & 1 \\
\hline
\end{tabular}

Prova Numérica 2. Outra função interessante para propósitos de minimização foi a função "six-hump camel back", do Matlabß dada na equação

$$
Z=4 x^{2}-2.1 x^{4}+x^{6} / 3+x y-4 y^{2}+4 y^{4}
$$

definida para $x \in[-2,2], y \in[-1,1]$, onde se sabe que todos os mínimos locais caem na região $x, y \in[-3,3]$ e pode observar-se na figura 11. Para essa função nos encontramos usando nosso algoritmo GSA o mínimo global em $(x=-0.0898, y=0.7127)$ e a função no mínimo de $f_{\min }=-1.0316$.

Prova Numérica 3. Para finalizar os testes numéricos de nosso algoritmo foi usada uma função $Z=f(x, y)$ dada por

$$
Z=\left(x^{2}-y^{2}\right) \exp \left[-0.5\left(x^{2}+y^{2}\right)\right]
$$




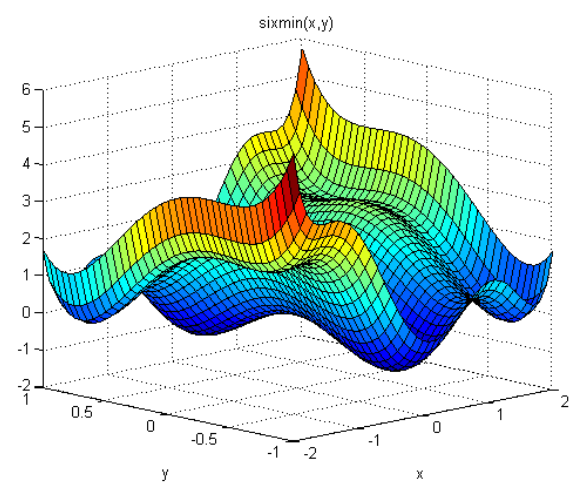

Figura 11: Camel invertida

definida para $x, y \in[-5,5]$, e que tem dois máximos nos pontos $(x=-1.4142, y=0)$, $(x=1.4142, y=0)$. Com nosso algoritmo GSA podemos verificar que tem dois mínimos nos pontos $(x=0, y=-1.4142),(x=0, y=1.4142)$ e como se mostra na figura 12

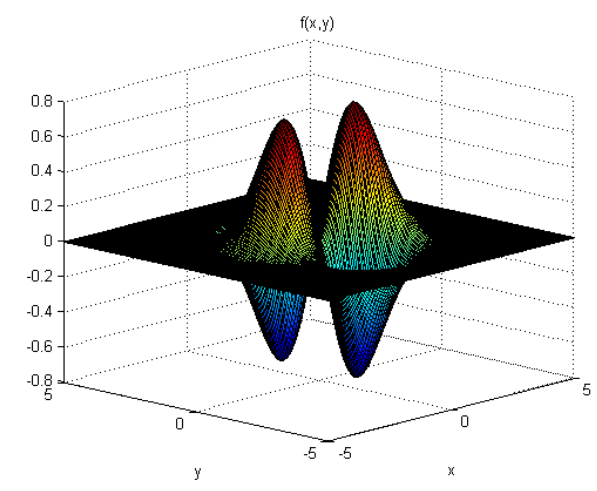

Figura 12: Função com dois mínimos

Para cada uma dessas funções foi implementado um programa em $\mathrm{C}++_{+}$, e para propósitos de visualização foi levado ao Matlab.

\subsection{Metodo GSA na reconstrução do espectro de fótons}

\subsubsection{Medição das Curvas de Transmissão de fótons}

Foram medidas os dados das curvas de transmissão para fótons no acelerador linear ONCOR de energia nominal de $6 \mathrm{MV}$ e $15 \mathrm{MV}$ usando blocos de alumínio, cobre e chumbo previamente preparados para o experimento na oficina mecânica do departamento de Física da FFCLRP-USP. As curvas de transmissão foram medidas de acordo com o esquema de medição que se observa na figura 13, com uma câmara 
de ionização FARMER $F C 65$ - $G$ unida a um eletrômetro IBA-DOSE1 calibrados e que são usados em medidas de controle de qualidade no Serviço de Radioterapia do Hospital das Clinicas da Faculdade de Medicina de Ribeirão Preto, registrando a leitura do eletrômetro para a carga produzida na câmara de ionização em nC depois de que o feixe transmitido passa a través dos diferentes espessuras de atenuadores de cada material. Logo se fizeram os gráficos normalizadas da transmissão. Posteriormente obtivemos os coeficientes de atenuação mássico e coeficientes de atenuação mássico em energia que foram previamente medidos pelo National Institute of Standards and Technology - NIST. As medidas de transmissão foram normalizadas e inseridas num arquivo de dados "atenua.dat" para se processado pelo nosso programa GSA-1.0 escrito em $\mathrm{C}_{++}$qual realiza o ajuste da transmissão medida e a transmissão calculada para logo obter o espectro de fluência de fótons com base a algoritmo de GSA.

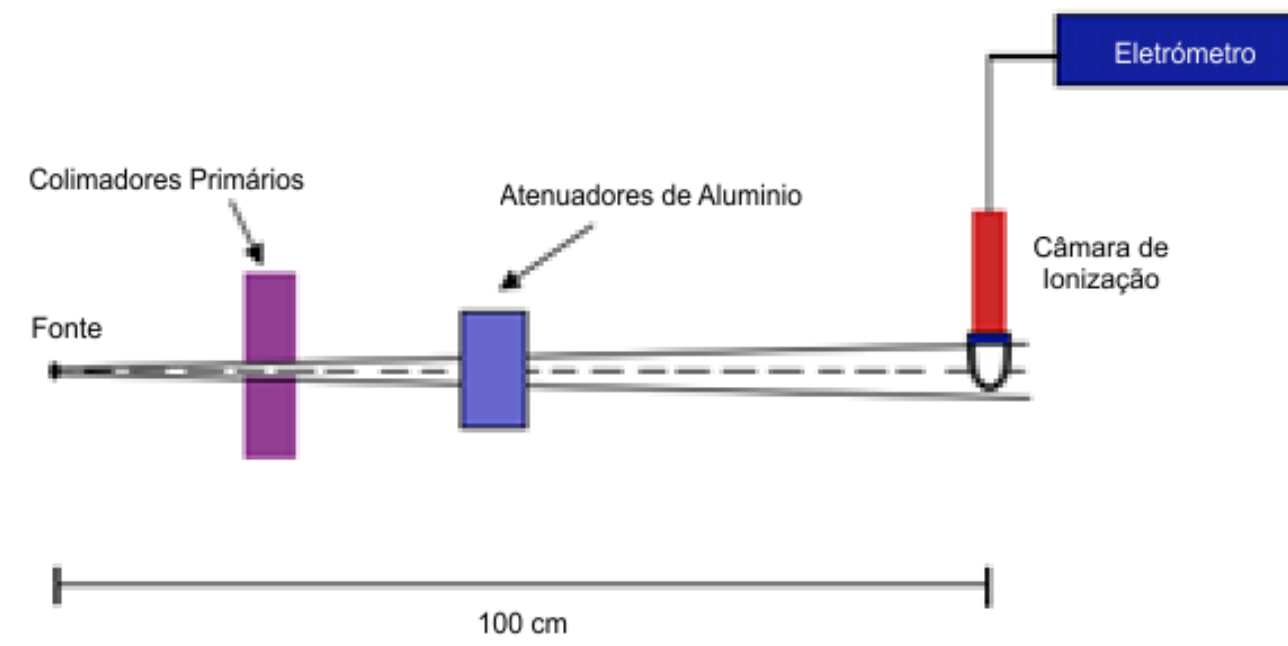

Figura 13: Diagrama esquemático da medida de transmissão relativa $T_{x}$ em alumínio para fótons com a câmara de ionização FARMER e o eletrômetro IBADOSE1

Na tabela 2, observa-se as leituras da câmara de ionização FARMER $F C 65-G$ no eletrômetro IBA-DOSE1 em unidades de carga elétrica Coulomb [C], e sua correspondente normalização, estas medidas foram tomadas como a transmissão de alumínio $T_{x}$ para fótons de $6 \mathrm{MV}$ no acelerador linear Siemens-ONCOR, e relaciona a intensidade do feixe transmitido $I_{x}$, em função da espessura $x(\mathrm{~cm})$ dos atenuadores de alumínio, cujo gráfico se observa na figura 14. Na figura 15 observa-se os dados de transmissão medidos para a energia de $15 \mathrm{MV}$ do mesmo acelerador dados na tabela 3 , usando as mesmas condições de medição. 
Estas curvas foram obtidos usando o pacote de gráficos origin8 que permite fazer o ajuste de acordo com a necessidade do usuário, em nosso casso se observo o comportamento exponencial dos dados, mais para propósito de visualização dos dados obtidos da medição das tabelas 2 é 3 , as curvas solo se representam pela union de pontos consecutivos com uma linha recta. No [apêndice E], pode-se observar as diferentes curvas de transmissão obtidas para as dois energias do acelerador ONCOR de $6 \mathrm{MV}$, e $15 \mathrm{MV}$, para Alumínio, Cobre e chumbo e sua respectiva comparação. A partir do processado destes dados medidos que nos construímos o método para a reconstrução de espectros correspondentes a cada energia do acelerador.

Tabela 2: Dados de transmissão para fótons de $6 \mathrm{MV}$ em alumínio

\begin{tabular}{cccccc}
\hline $\begin{array}{c}\text { Espess. } \\
\text { de Al }\end{array}$ & Leitura & Transm. & $\begin{array}{c}\text { Espess. } \\
\text { de Al }\end{array}$ & Leitura & Transm. \\
\hline (cm) & $(\mathrm{nC})$ & (relativa) & $(\mathrm{cm})$ & $(\mathrm{nC})$ & (relativa) \\
\hline 0 & 16,9 & 1 & 10 & 5,62 & 0,3329 \\
01 & 16,7 & 0,9876 & 15 & 3,38 & 0,2002 \\
0,2 & 16,5 & 0,9751 & 16 & 3,06 & 0,1813 \\
0,3 & 16,3 & 0,9639 & 20 & 2,08 & 0,1233 \\
1 & 15 & 0,8886 & 21 & 1,89 & 0,1121 \\
1,1 & 14,8 & 0,8786 & 25 & 1,29 & 0,0761 \\
1,2 & 14,7 & 0,8685 & 30 & 0,818 & 0,0485 \\
1,3 & 14,5 & 0,859 & 35 & 0,523 & 0,031 \\
5 & 9,56 & 0,5662 & 40 & 0,341 & 0,0202 \\
6 & 8,57 & 0,5076 & 45 & 0,224 & 0,0133 \\
\hline
\end{tabular}

Tabela 3: Dados de transmissão para fótons de $15 \mathrm{MV}$ em alumínio

\begin{tabular}{cccccc}
\hline $\begin{array}{c}\text { Espess. } \\
\text { de Al }\end{array}$ & Leitura & Transm. & $\begin{array}{c}\text { Espess. } \\
\text { de Al }\end{array}$ & Leitura & Transm. \\
\hline$(\mathrm{cm})$ & $(\mathrm{nC})$ & (relativa) & $(\mathrm{cm})$ & $(\mathrm{nC})$ & (relativa) \\
\hline 0 & 16,04 & 1 & 10 & 6,932 & 0,4321 \\
0,1 & 15,93 & 0,9929 & 15 & 4,641 & 0,2893 \\
0,2 & 15,78 & 0,9835 & 16 & 4,282 & 0,2669 \\
0,3 & 15,65 & 0,9754 & 20 & 3,146 & 0,1961 \\
1 & 14,72 & 0,9175 & 21 & 2,904 & 0,181 \\
1,1 & 14,59 & 0,9094 & 25 & 2,144 & 0,1337 \\
1,2 & 14,47 & 0,9019 & 30 & 1,474 & 0,0919 \\
1,3 & 14,34 & 0,8938 & 35 & 1,022 & 0,0637 \\
5 & 10,45 & 0,6513 & 40 & 0,7188 & 0,0448 \\
6 & 9,612 & 0,5991 & 45 & 0,5081 & 0,0317 \\
\hline
\end{tabular}

Uma vez obtidos os dados de transmissão o seguinte passo é obter os dados de coeficiente de atenuação mássico e coeficiente de atenuação mássico em energia do National Institute of Standards and Technology- NIST (32). Na figura 16 observa-se o 


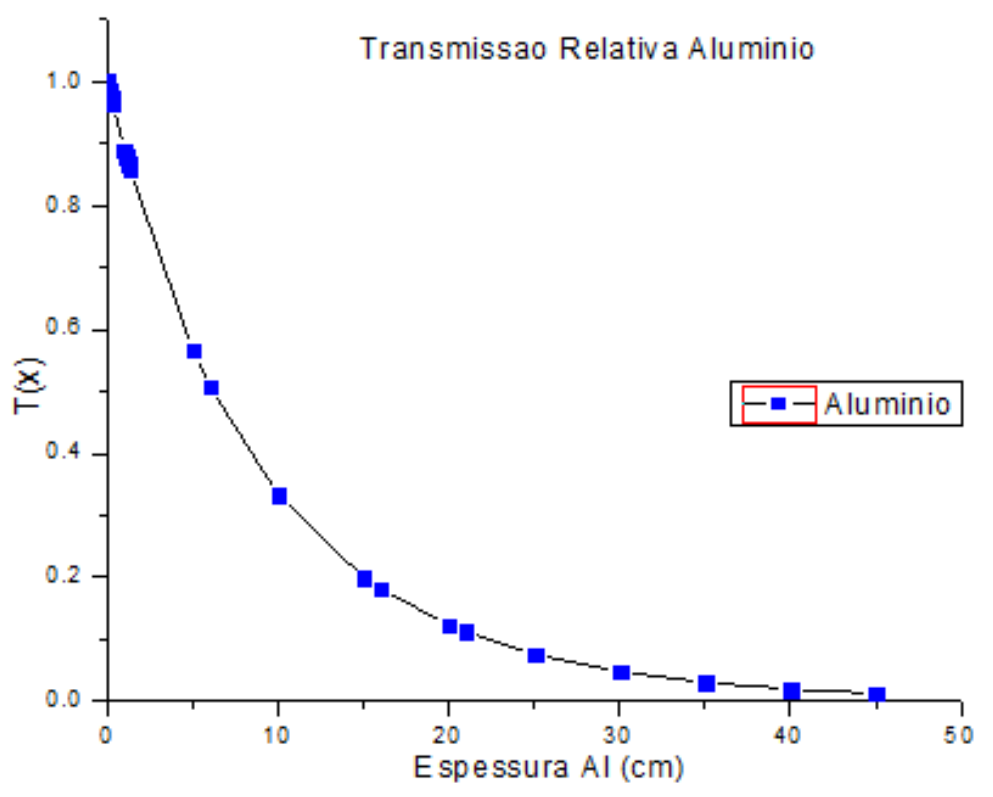

Figura 14: Transmissão relativa $T_{x}$ em alumínio em função da espessura $x(\mathrm{~cm})$ de alumínio para fótons de $6 \mathrm{MV}$ que foram medidas com a câmara de ionização FARMER e o eletrômetro IBADOSE1

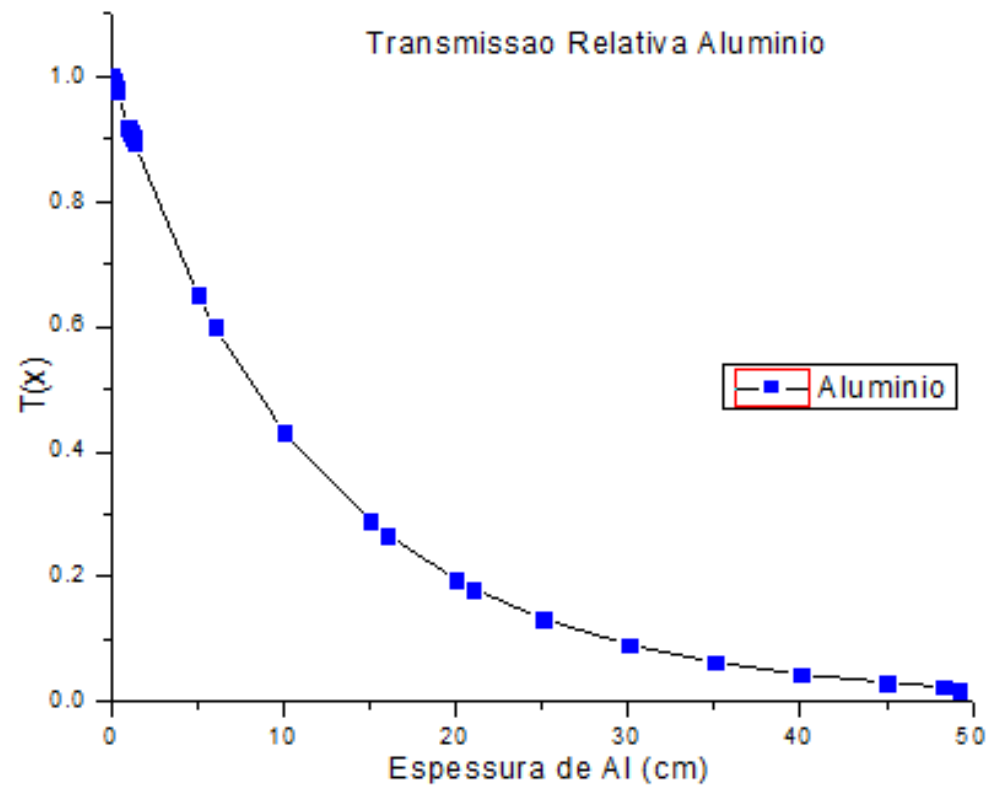

Figura 15: Transmissão relativa $T_{x}$ em alumínio em função da espessura $x(\mathrm{~cm})$ de alumínio para fótons de $15 \mathrm{MV}$ que foram medidas com a câmara de ionização FARMER e o eletrômetro IBADOSE1 
coeficiente de atenuação mássico $\mu / \rho$ e coeficiente de atenuação mássico em energia $\mu_{e n} / \rho$ para alumínio obtido de 32.

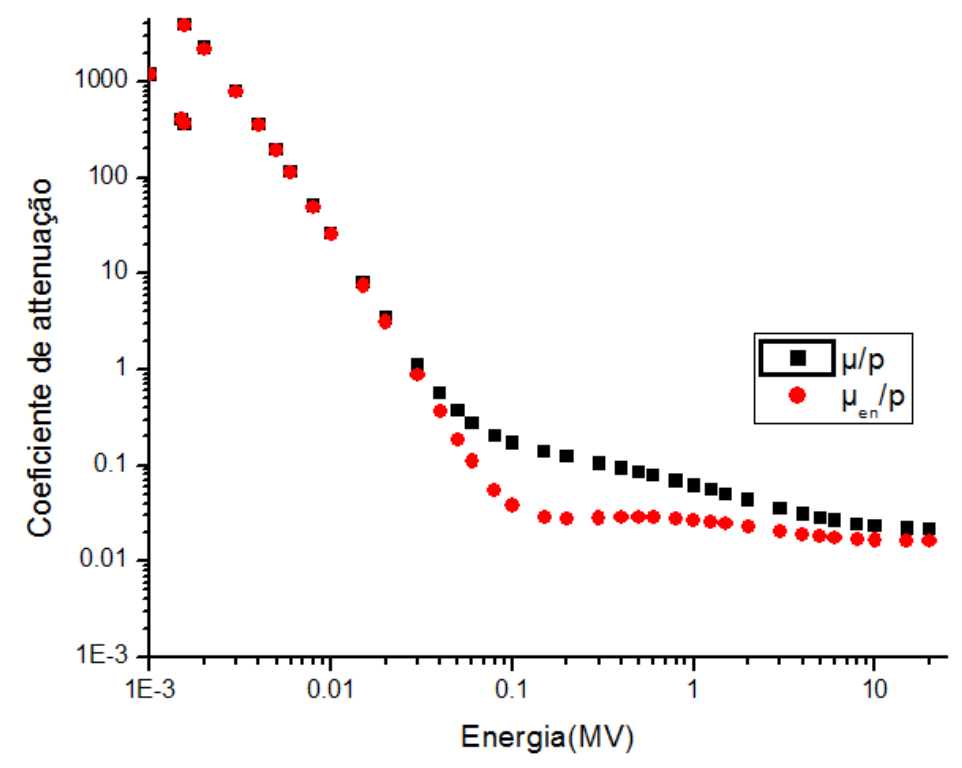

Figura 16: Coeficiente de atenuação $\mu / \rho$, e coeficiente de atenuação mássico $\mu_{e n} / \rho$, para alumínio em função da energia do fóton $h v$ na faixa de 0 a $20 \mathrm{MV}$.

\subsubsection{Algoritmo para a Reconstrução do Espectros de fótons}

Com o propósito de construir o programa para reconstruir o espectro de fótons do acelerador linear, nos baseamos no método proposto por Nisbet et al.(12), com o objetivo de obter a função de custo para ser minimizada com o método GSA, qual para nosso caso e ó erro quadrático médio entre a transmissão medida e a transmissão calculada. Nisbet et al.(12) faz uso de um método de caráter inverso para obter o espectro de fluência de fótons a partir da doses absorvida no meio [apêndiceB]. Também usamos o algoritmo do método q̃-SA proposto por Menin(23), adaptado para a reconstrução de fótons de alta energia com o que construímos o Programa GSA-1.0 em $\mathrm{C}++$. A continuação damos o detalhe teórico para a obtenção do algoritmo.

Consideramos então que a doses absorvida num meio, $D_{m e d}$ (12) pode se expressar como:

$$
D_{m e d}=\int_{E=0}^{E_{\max }} E \Phi^{\prime}(E)\left(\mu_{e n} / \rho\right) d E
$$

em que $\left(\mu_{e n} / \rho\right)$ é o coeficiente de absorção em energia mássico do material atenuador, $\Phi^{\prime}$ é a fluência de fótons, é $E$ é sua energia. A doses absorvida ao meio pode 
se expressar como:

$$
D_{m e d}=M N_{K} C_{w, \lambda}
$$

em que $M$ é a leitura da câmara de ionização, $N_{K}$ é o fator de calibração da câmara em termos de kerma no ar, $C_{w, \lambda}$ é o fator de conversão de doses a kerma. Então a leitura da câmara pode se obter como:

$$
M=\frac{1}{N_{K} C_{w, \lambda}} \int_{E=0}^{E_{\max }} \Phi^{\prime}(E)\left(\mu_{e n} / \rho\right) E d E .
$$

A fração $T_{x}$ do feixe fe fótons primário transmitido através de uma espessura $x$ do material atenuador, e dado por

$$
T_{x}=\frac{M_{x}}{M_{0}},
$$

onde $M_{x}$, e a leitura da câmara para um feixe atenuado pó uma espessura $x$ de material atenuador, e $M_{0}$ e a leitura da câmara para um feixe sem atenuação.

As medições de atenuação foram feitas em condições de feixe estreito de maneira que a contribuição do espalhamento não e considerada. Ademais a fluência de fótons diferencial $\Phi^{\prime}(E)$ para um feixe de fótons atenuado por uma espessura $x$ de material, pode se expressar como o produto da fluência de fótons diferencial para um feixe de fótons não atenuado $\Phi^{\prime}(E)_{0}$ e a atenuação exponencial devido ao material atenuador.

$$
\Phi^{\prime}(E)=\Phi^{\prime}(E)_{0} \exp \left[-(\mu / \rho)_{a t t} x \rho\right]
$$

em que $(\mu / \rho)_{\text {att }}$ é o coeficiente de atenuação para o material atenuador e $\rho$ é a densidade.

Assim mesmo se a atenuação através da parede da câmara e a capa de equilíbrio eletrônico(build-up) e tomada em conta, e se $n$ medidas com diferentes espessuras de material atenuador são feitas, a fluência de fótons diferencial se expressa como

$$
\Phi^{\prime}(E)_{x}=\Phi^{\prime}(E)_{0} \exp \left(-\left\{\left(\frac{\mu}{\rho}\right)_{a t t} x_{n}+\sum_{i=1}^{h}\left[-\left(\frac{\mu}{\rho}\right)_{\text {med }_{i}} \rho_{\text {med }_{i}} t_{\text {med }_{i}}\right]\right\}\right)
$$

em que $x_{n}=\sum_{j=0}^{n} \rho_{j} t_{j}$ é a suma dos produtos densidade $\rho_{j}$ é a espessura $t_{j}$ de cada folha de material atenuante formando o material atenuador; $(\mu / \rho)_{\text {med }}$ é o coeficiente de atenuação mássico para o meio i-ésimo na parede da câmara (e capa de buildup), e $\rho_{\text {med }}$ e $t_{m e d}$ são a densidade e espessura do meio i-ésimo respetivamente, $h$ é o 
numero de diferentes meios, sendo dois, a parede de grafito da câmara e o material da capa de build-up de Perspex(acrilico).

Usando as equações 2.29, 2.30, 2.32, e fazendo discreto o domínio da energia, em $k$ canais de energia, onde $E(s)$ e o limite inferior e $E(s+1)$, e o limite superior do canal de energia $s$, Nisbet et al.(12), obtém a transmissão para uma leitura particular da câmara de ionização $T_{n}$ dada como

$$
T_{n}=\frac{\sum_{s=0}^{k-1} a_{n, s} \tilde{\Phi}^{\prime}(s)_{0}}{\sum_{s=0}^{k-1} a_{0, s} \tilde{\Phi}^{\prime}(s)_{0}}, \text { para } n=0,1, \ldots, m-1
$$

onde $m$ e o numero de medidas de atenuação.

O coeficiente $a_{n, s}$ e dado como:

$$
a_{n, s}=\int_{E(s)}^{E(s+1)}\left(\frac{\mu_{e n}}{\rho}\right) \exp \left(-\left\{\left(\frac{\mu}{\rho}\right)_{a t t} \sum_{j=0}^{n} \rho_{j} t_{j}+\sum_{i=1}^{h}\left[\left(\frac{\mu}{\rho}\right)_{\text {med }_{i}} \rho_{\text {med }_{i}} t_{\text {med }_{i}}\right]\right\}\right) E d E
$$

e o coeficiente $a_{0, s}$ :

$$
a_{0, s}=\int_{E(s)}^{E(s+1)}\left(\frac{\mu_{e n}}{\rho}\right) \exp \left(-\left\{\sum_{i=1}^{h}\left[\left(\frac{\mu}{\rho}\right)_{\text {med }_{i}} \rho_{\text {medi }_{i}} t_{\text {med }}\right]\right\}\right) E d E
$$

O objetivo e resolver a equação 2.33 para os termos de fluência na equação matricial usando a técnica de GSA é reconstruir o espectro de fluência para o feixe de fótons. Para fazer isso o espectro e dividido em um numero de $k-1$ canais para os que cada um dos elementos $a_{n, s}$, e $a_{0, s}$ são calculados por integração numérica. De acordo com a proposta de Nisbet et al.(12) nos construímos uma função de custo dada pela equação 2.36, definida como o erro entre a transmissão experimental e a transmissão calculada mais um termo qual é dado por uma função de regularização de Tikhonov[ (33), (34)], multiplicada por um parâmetro de regularização $\lambda$ :

$$
f\left(\phi_{\text {trial }}\right)=\frac{1}{m} \sum_{n=0}^{m-1}\left[T^{(n)}-S^{(n)}\right]^{2}+\frac{\lambda}{k-2} \sum_{s=1}^{k-1}\left|\hat{\phi}_{\text {trial }}^{(s)}-\hat{\phi}_{\text {trial }}^{(s-1)}\right|
$$

Onde a para construir a função de custo $f\left(\phi_{\text {trial }}\right)$, usamos $\hat{\phi}_{\text {trial }}$ que e uma fluência de ensaio normalizada dada por Menin(23), obtida a partir de dividir cada um dos elementos de $\phi_{\text {trial }}$ pelo máximo calculado $\max \left(\phi_{\text {trial }}\right) . T^{(n)}$ e a transmissão calculada na equação 2.33 e $S^{(n)}$ e a transmissão medida, $\lambda$ e um parâmetro de regularização, 
$m$ e o numero de medidas feitas de transmissão, e $k$ e o número de canais de energia para a reconstrução do espectro.

Devido a que a temperatura controla a estocasticidade do processo de otimização GSA, foram usados dois esquemas de resfriamento. O resfriamento geométrico para a temperatura de aceitação $T_{a}$, dado pela equação

$$
T^{(t)}=\alpha^{t} T_{a}^{(0)}
$$

em que $\alpha \in(0,1)$ e a taxa de esfriamento. E outro esquema de resfriamento da temperatura visitante dada pela equação 2.38 , onde $\ln _{\tilde{q}_{v}}$ e a função logaritmo generalizado.

$$
T_{v}^{(t)}=T_{v}^{(0)} \frac{\ln _{\tilde{q}_{v}}(2)}{\ln _{\tilde{q}_{v}}(t+1)}
$$

A temperatura inicial de aceitação, $T_{a}^{(0)}$, se calculo fazendo correr a simulação em um corto numero $n$ de passos prévio, para exploração do espaço de soluções, e para assim conhecer a maxima variação da função de custo da equação 2.36 , com $\Delta f_{\text {prev }}=$ $\max \left(f\left(x_{i}\right)-\min \left(f\left(x_{i}\right)\right)\right)$, com $x_{i} \in D$ e $i=1, . . n$, e logo usando a equação 2.22 para calcular a probabilidade iniciai de aceitar novas soluções $p_{0}$, calculamos a temperatura de aceitação iniciai dada por

$$
T_{a}^{(0)}=-\frac{\Delta f_{\text {prev }}}{\ln _{\tilde{q}_{a}}\left(p_{0}\right)}
$$

Então considerando um numero $n_{r}$ de repetições em cada temperatura, o algoritmo de recozimento simulado generalizado,pode ser escrito como (23):

1. Introduzir os parâmetros da simulação: $k, t_{\max }, n_{r}, \tilde{q}_{a}, \tilde{q}_{v}$ e $\alpha$;

2. Definir a temperatura iniciai $T_{v}^{(0)}$ usando um critério adequado;

3. Gerar $n$ soluções aleatórias previas $x_{i}$ e calcule a função de custo $f\left(x_{i}\right)$;

4. Calcular $\Delta f_{\text {prev }}=\max \left(f\left(x_{i}\right)-\min \left(f\left(x_{j}\right)\right)\right)$, com $i, j=1,2, \ldots, n$;

5. Calcular a temperatura de aceitação iniciai $T_{a}^{(0)}$ da Eq. 2.23;

6. Gerar uma solução iniciai $x_{\text {old }}$;

7. Calcule o valor de função objetivo $f\left(x_{\text {old }}\right)$;

8. para $t$ de 1 até $t_{\max }$ faça:

a repetir $n_{r}$ vezes 
- Gerar uma solução candidata $x_{\text {new }}$ com base na Equ. 2.15.

- Calcular $f\left(x_{\text {new }}\right)$

- Se $\delta=f\left(x_{\text {new }}\right)-f\left(x_{\text {old }}\right)<0$

- $x_{\text {old }} \leftarrow x_{\text {new }}$

- $\operatorname{Sef}\left(x_{\text {old }}\right)<f\left(x_{\min }\right) \Rightarrow x_{\text {min }} \leftarrow x_{\text {old }}$

- else

- gerar $x \in[0,1]$ aleatório

- Se $x<\exp _{\tilde{q}_{a}}\left(-\delta / T_{a}\right)$

- $x_{\text {old }} \leftarrow x_{\text {new }}$

- $\operatorname{Se} f\left(x_{\text {old }}\right)<f\left(x_{\min }\right) \Rightarrow x_{\min } \leftarrow x_{\text {old }}$

b Diminuir a temperatura $T_{a}^{(t)}$ da Eq. 2.21;

c Diminuir a temperatura $T_{v}^{(t)}$ da Eq. 2.20;

9. Calcule as quantidades requeridas;

O algoritmo pode ser observado no diagrama de blocos da figura 17. Para propósitos de visualização no algoritmo usamos $s$ em lugar de $x_{\text {new }}$, assim as novas soluções $x_{\text {new }}$ são geradas a partir de uma solução de ensaio inicial $x_{\text {old }}$, fazendo inicialmente $s_{0}=x_{\text {old }}$ para calcular o tamanho de passo $\Delta s=s-s_{0}$, e usando a distribuição de probabilidade de visitação $\tilde{q}$-gaussiana padrão $G_{\tilde{q}_{v}}(\Delta s)$ (22) dada pela equação

$$
G_{\tilde{q}_{v}}(x)=\sqrt{\frac{\tilde{q}_{v}}{2 \pi}} \frac{\Gamma\left(1 / \tilde{q}_{v}\right)}{\Gamma\left(1 / \tilde{q}_{v}-\frac{1}{2}\right)} \exp _{-\tilde{q}_{v}}\left(-\frac{x^{2}}{2}\right),
$$

Sendo $\tilde{q}_{v}$ o parâmetro de generalização da distribuição de visitação. O critério de aceitação para as soluções passa por o critério de Metropolis (13) qual esta implementado no algoritmo acima.

A temperatura inicia $T_{v}^{(0)}$ foi calculada a partir do Kerma (23), baseado em critérios geométricos considerando que o kerma $K$, e a area de um triângulo com base $\left(E_{\max }-\right.$ $\left.E_{\min }\right)$ é altura $T_{v}^{(0)}$, de acordo com a equação

$$
T_{v}^{(0)}=\frac{2 K}{\left(E_{\max }-E_{\min }\right)}
$$

Onde $K$ e o kerma para um fóton (o em seu defeto kerma por elétron, quando o espectro de fluência de fótons e dada em unidades, numero de photons por MeV por 


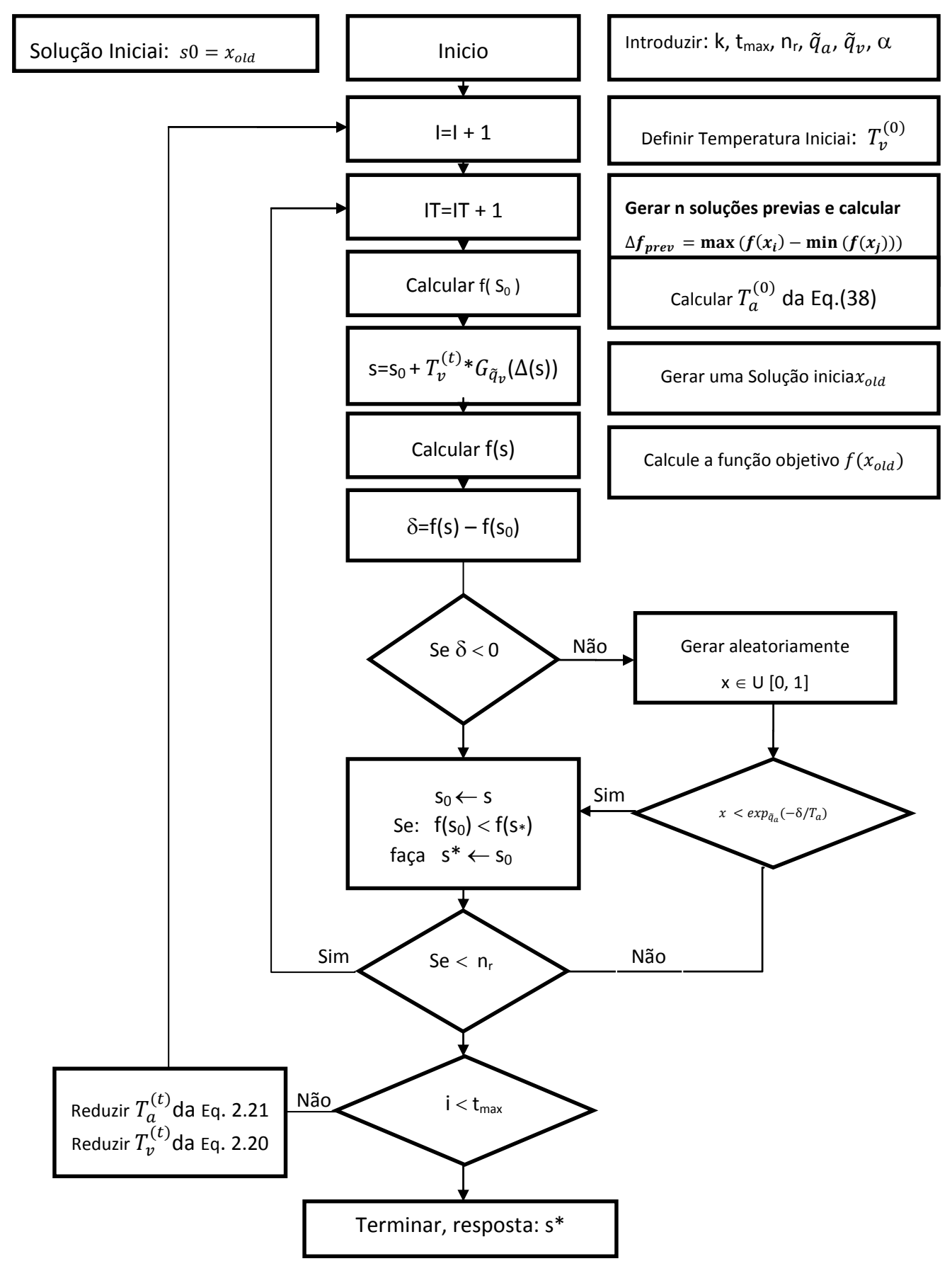

Figura 17: Algoritmo GSA usado neste trabalho para o minimização de funções custo. 
elétron incidente (35)), e deve ser calculado considerando o numero de fótons que fazem kerma na câmara de ionização. Para o calculo do kerma consideramos a medida da dose absorvida em condições de referencia de $\mathrm{D}=0.787$ Gy (obtida da medição da doses absorvida em agua usando o protocolo de medição da doses (4))aplicando o fator de conversão kerma a doses $C_{w \lambda}$ dado na equação

$$
C_{w \lambda}=(1-g) k_{a t t} k_{m}\left(S_{w, a i r}\right) P_{u}
$$

em que $g$ é a fração de energia das partículas carregadas secundarias pela perda como bremsstrahlung no ar, $k_{a t t}$ é o fator de correção para atenuação e espalhamento, $k_{m}$ é o fator que toma em conta a atenuação devido ao material da camera, $\left(S_{w, a i r}\right)$ é razão entre os poderes de freado para agua e ar é $P_{u}$ é o fator para correção pela perturbação da fluência de elétrons devido ao phantom de agua.

Usando o fator de conversão de kerma para dose obtemos o valor do kerma para a energia de $6 \mathrm{MV}$ de $0,733 \mathrm{~Gy}$. Logo fazendo calculo estimado da energia media do espectro em $2 \mathrm{MeV}$ e considerando o volume da camera de ionização $\left(0.6 \mathrm{~cm}_{3}\right)$ a densidade do ar $1.2922 \mathrm{Kg} / \mathrm{m}_{3}$ que o numero de fótons que contribuem ao kerma na câmera de ionização é de $n_{f}=1856582$ fótons então o kerma por fóton e de $K=0.733 / 1856582=3.95 E-7 G y$. Então usando a equação 2.41 obtemos $T_{v}^{(0)}=31.21$. Mas para o caso da energia de $6 \mathrm{MV}$ elegemos $T_{v}^{(0)}=25$, e em algumas outros casos usamos $T_{v}^{(0)}=25$; cálculos similares para o caso de $15 \mathrm{MV}$ derem uma temperatura de $T_{v}^{(0)}=20$; para a reconstrução do espectro e um bom começo.

A geração de soluções convidadas a partir da distribuição q̃-gaussiana padrão dada na equação 2.40 foi feita usando o método de Box-Müller generalizado como uma função $\mathrm{C}++$, dada no [apêndice C.1]. Assim mesmo foi implementada uma função de regularização como restrição a ser imposta para nossa função de transmissão a ser minimizada de forma a produzir um problema de aproximação bem-comportado a partir do método de Regularização de Tikhonov [ (33), (34)] dado no [apêndice C.2]. Nós também usamos uma geração de soluções alternativa baseada no método de Deng, Chang e Yang(36) em conjunto com a função de regularização de Tikhonov. 


\section{$3 \quad$ Resultados e discussões}

Antes de usar nosso programa GSA-1.0, construído en $\mathrm{C}_{++}$, na reconstrução de espectros de aceleradores lineares de uso clinico, nos fizemos diferentes provas numéricas como pode-se observar na seção de materiais e métodos [capitulo 2], para varias funções custo-energia, seguidamente obtivemos as curvas de transmissao medidas para Alumínio para as energias de 6MV e 15MV no Acelerador ONCOR, dadas nas tabelas [2, 3], assim mesmo podemos observar no [apêndice E], os dados medidos das curvas de transmissão para Alumínio, cobre e Chumbo no acelerador ONCOR para as mesmas energias, e sua respectiva comparação. Também podemos dizer que ó presente método de reconstrução foi melhor implementado para atenuadores de Alumínio devido a que seu coeficiente de atenuação decresce monotonicamente apresentando um gradiente suave é de valor único, como especificam alguns autores en trabalhos similares [ (10), (37)].

Seguindo com as provas, testamos a capacidade de nosso programa é nosso método de geração de números aleatórios de produzir diferentes distribuições de probabilidade, como e dado no [apêndice F], e selecionamos para nosso programa o gerador de números pseudo-aleatórios Mersenne Twister dado no artigo de Matsumoto e Kurita (38). seguidamente testamos o programa na reconstrução de espectros obtidos da literatura a partir de suas curvas de transmissão simuladas como se observa na seção [no apêndice G], Validação da reconstrução do espectro de fluência de fótons, é finalmente apresentamos os resultados obtidos para nosso caso no acelerador SIEMENS ONCOR de 6MV e 15MV para diferentes parâmetros de entrada, com a finalidade de apresentar a suficiente evidencia do correto funcionamento de nosso programa. A continuação nesta seção damos os resultados mais específicos de nosso trabalho.

Na tabela 4 observa-se os parâmetros que foram usados no programa GSA-1.0 para reconstruir os espectros: $k$ e o número de canais, $t_{\max }$ e o numero de iterações máximo, $n_{r}$ e o número de soluções de ensaio em cada iteração, $\tilde{q}_{v}$ e o valor do 
parâmetro de generalização, $\lambda$ e o parâmetro de regularização, e $\alpha$ o coeficiente da taxa de esfriamento. Assim também temos resumido o cálculo da energia media para o espectro do acelerador ONCOR de energia nominal $6 \mathrm{MeV}$, que deu como resultado $2 \mathrm{MeV}$, que e um valor muito próximo a energia media obtida do espectro do Planejador TPS que deu o valor de 2,1 MV. Além disso esta dizer que a discordância que se observa entre os espectro simulado por GSA e obtido do TPS para os parâmetros dados se devem à flutuação estocástica do método.

\begin{tabular}{lcc} 
Tabela 4: Parâmetros para reconstrução do espectro de 6 MV. & Representação & Valor \\
\hline Item & $\mathrm{k}$ & 33 \\
\hline Número de canais & $t_{\max }$ & 200 \\
Numero de iterações & $n_{r}$ & 100 \\
Número de soluções de ensaio & $\tilde{q}_{v}$ & 1,6 \\
Parâmetro de generalização & $\lambda$ & 2000 \\
Parâmetro de regularização & $\alpha$ & 0,9 \\
Coeficiente de resfriamento & $\alpha$ & \\
\hline Energia média (MV) & \multicolumn{2}{c}{2,0} \\
\hline
\end{tabular}

Como um método para observar a eficiência do processo de GSA podemos considerar o ajuste da transmissão inicial dada na figura 18, e o ajuste da transmissão ao final do processo de calculo com o programa GSA1.0, dada na figura 19. Observa-se, que ao inicio do processo existe uma grande diferença entre a transmissão calculada com a equação 2.33, para um espectro inicial $\tilde{\Phi}^{\prime}(s)_{0}=[0, \ldots, 0,1,0]$, cuja longitude e dada por $k$, e a transmissão medida cujos dados se apresenta na tabela 2; depois de correr o programa usando os parâmetros dados na tabela 4 se obtive a figura 19 onde observa-se que ao final do processo de ajuste, a transmissão medida e a transmissão calculada sao praticamente iguais, o que e um indicador do desempenho do programa.

Na figura 20 observa-se em linha com pontos cor azul o espectro de fluência de fótons normalizado para um Acelerador Linear de $6 \mathrm{MV}$ em função da energia do fóton $E$, obtido pela técnica de GSA usando o programa GSA1.0, o espectro foi reconstruído usando os dados da curva de transmissão para alumínio dados na tabela 2 e usando os parâmetros de ajuste dados da tabela 4. Em seguida, o espectro passa por um método de refinamento que usa o método de Levenberg-Marquardt (19), implementado em Matlabß, a partir do uso da formula analítica melhorada de Schiff (apêndiceD).

A figura 21 mostrasse o efeito do refinamento como o suavizado dos dados obtidos para o espectro, onde mostra-se a comparação entre o espectro obtido pelo programa 


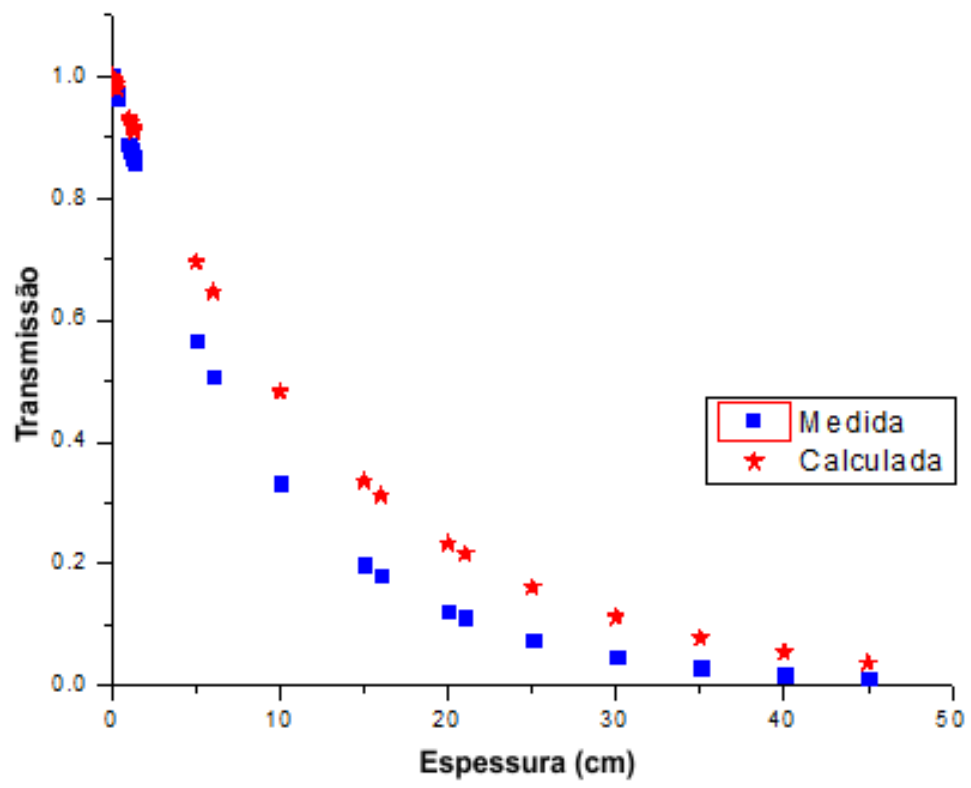

Figura 18: Comparação do transmissão medida e transmissão calculada iniciais para $6 \mathrm{MV}$.

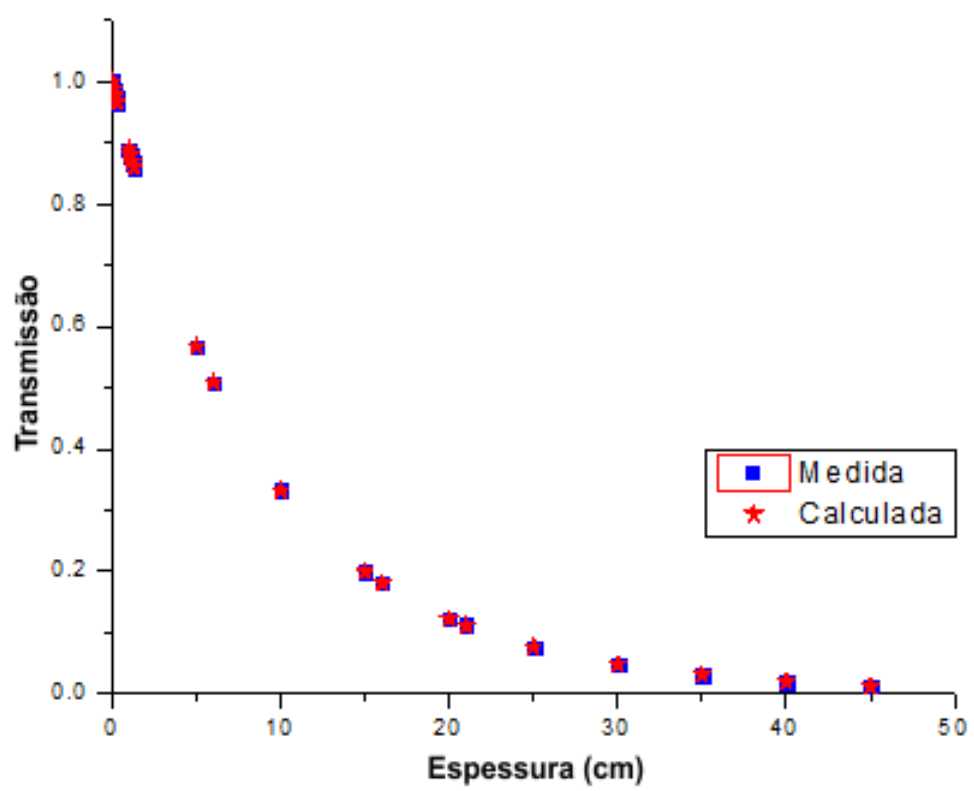

Figura 19: Comparação do transmissão medida e transmissão calculada final para $6 \mathrm{MV}$. 
GSA-1.0 (linha com pontos azul)e o espectro refinado (linha com pontos preto). Na figura 22 finalmente damos o espectro refinado (linha preta com pontos azul), onde se ha extrapolado a curva para obter o $E_{\max }=7.87 \mathrm{MeV}$, este espectro seria ó espectro de fluência de Fótons de $6 \mathrm{MV}$ em função da energia do fóton $E$.

Na figura 23, nós fazemos uma comparação entre o espectro de fluência de fótons de $6 \mathrm{MV}$ obtido pela técnica de GSA, com o programa GSA-1.0, e o espectro obtido do sistema de planejamento $\mathrm{XiO}$ 4.62.00, observa-se uma pequena diferença na região de 3 a $5 \mathrm{MeV}$, entre o espectro do TPS (pontos preto) e o espectro reconstruído pelo programa GSA-1.0 (linha verde com pontos em azul), mais além disso, como se observa, existe um bom acordo entre o espectro obtido pelo uso da técnica de GSA (programa GSA-1.0) e o espectro obtido do planejador TPS XiO 4.62.00, a divergência se deve a inerente aleatoriedade do método de reconstrução usado. Os resultados assim obtidos evidenciam que a técnica de GSA é uma potente ferramenta para a minimização de funções de custo que pode ser usada na reconstrução de espectros de aceleradores lineares clínicos com o objetivo de usar os espectros reconstruídos de base para calcular diferentes quantidades de interes referentes ao feixe clinico como por exemplo a energia media, os porcentagens de doses em profundidade PDD, 0 finalmente os indices de qualidade $T P R_{20 / 10}$.

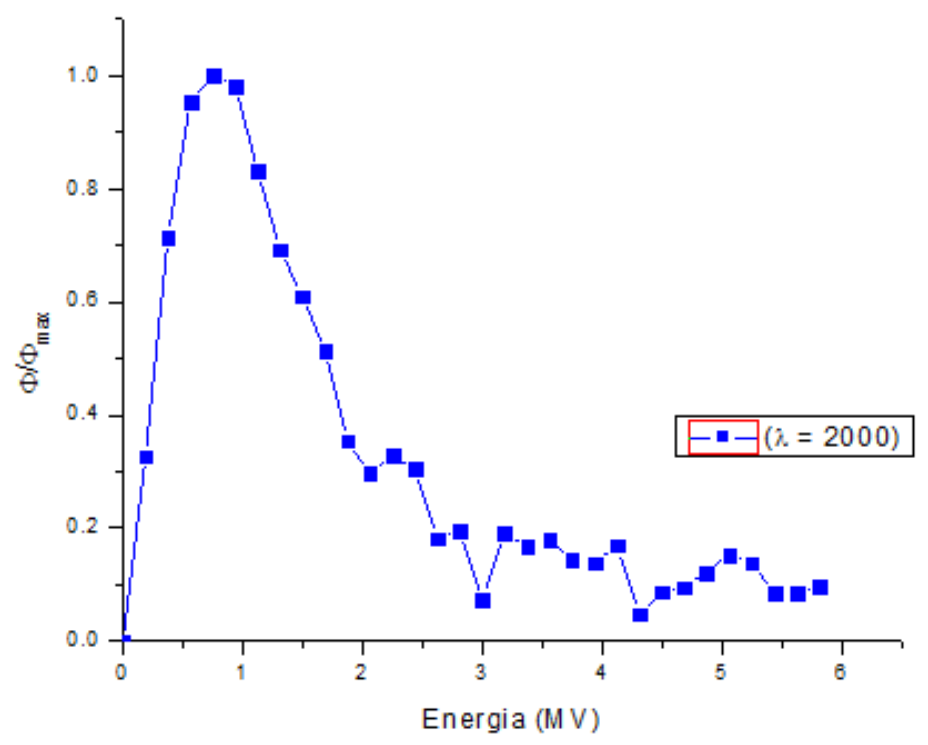

Figura 20: Espectro de fluência de fótons de $6 \mathrm{MV}$ normalizado obtido pela técnica de GSA para Alumínio em função da energia $E$ do fóton .

Como uma comprovação da validade da técnica GSA, nós fazemos a reconstrução do espectro normalizado de fluência de fótons de $15 \mathrm{MV}$ qual se observa na figura 24, que foi reconstruído usando as curvas de transmissão para Alumínio da figura 


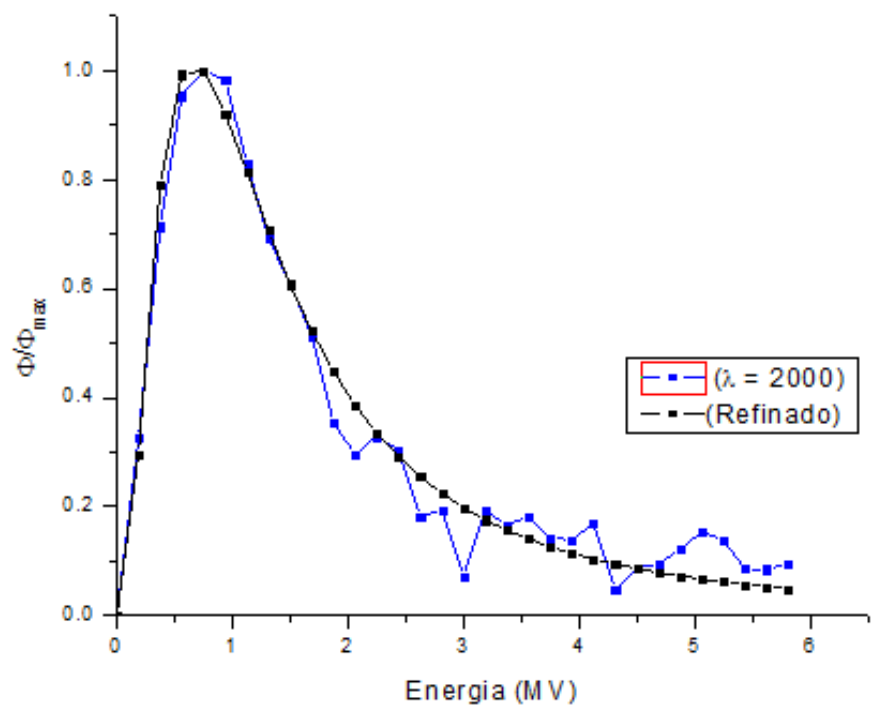

Figura 21: Comparação do Espectro de fluência de fótons de $6 \mathrm{MV}$ refinado (linha com pontos pretos) e o espectro normalizado (linha com pontos azuis) obtido pela técnica de GSA para alumínio em função da energia $E$ do fóton .

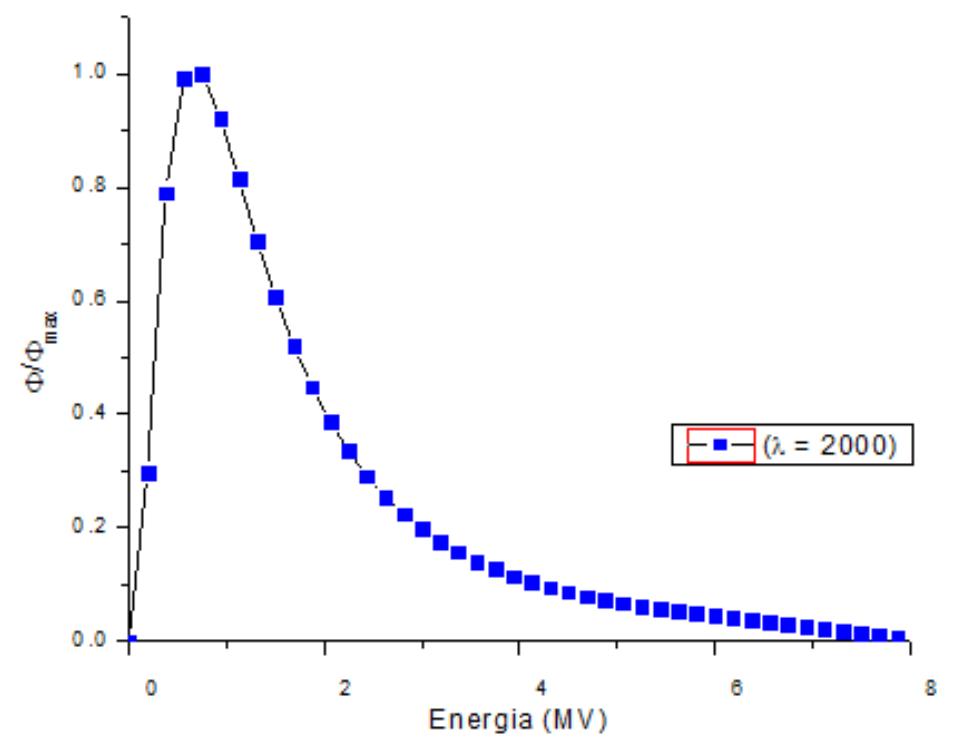

Figura 22: Espectro de fluência de Fótons de $6 \mathrm{MV}$ normalizado obtido pela técnica de GSA para alumínio em função da energia $E$ do fóton depois do refinamento. 


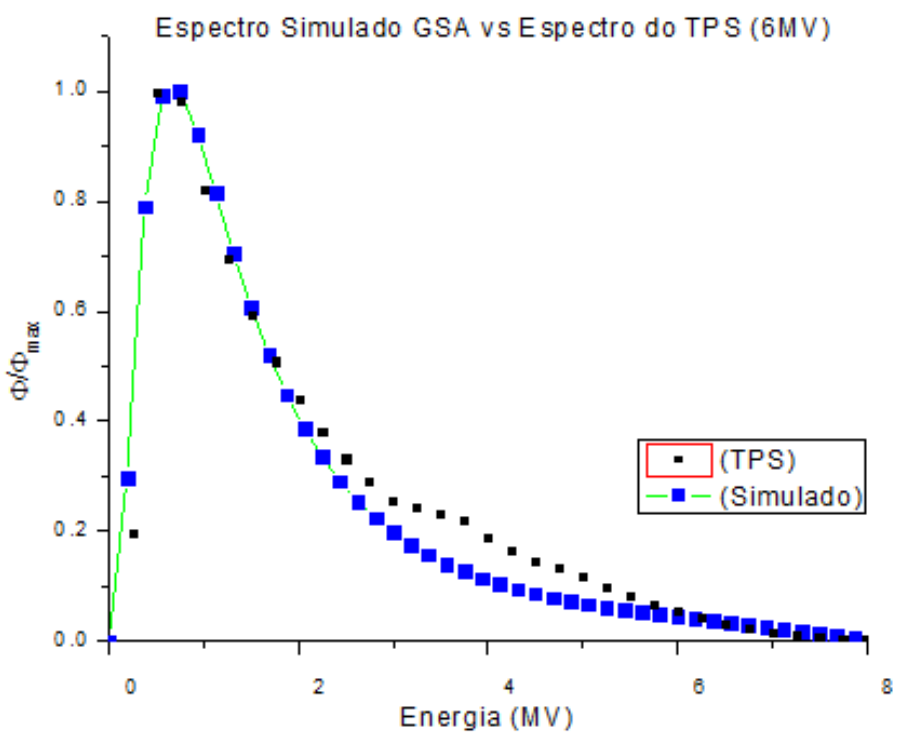

Figura 23: Comparação do espectro de fluência de fótons de $6 \mathrm{MV}$ obtido pela técnica de GSA e o espectro do sistema de planejamentoXiO 4.62.00.

33 (Apêndice E), e os parâmetros da tabela 5. Este espectro passa por um método de refinamento usando o método de Levenberg-Marquardt (19), implementado em Matlab®, a partir da formula analítica melhorada de Schiff (apêndiceD), para extrair a informação espectral como se observa na figura 25 onde se compara o espectro dado pelo programa GSA-1.0 (linha com pontos azul) e seu refinamento (linha com pontos preto). Finalmente na figura 26 observa-se o espectro de fluência de fótons de $15 \mathrm{MV}$ refinado obtido pela técnica de GSA com base nas curvas de transmissão para Alumínio, qual seria o espectro de fluência de fótons para a energia nominal de $15 \mathrm{MV}$ do acelerador linear ONCOR em função da energia $E$ do fóton. A eficiência do processo GSA é considerada com o ajuste da transmissão inicial dada na figura 27 e o ajuste da transmissão ao final do processo de calculo com o programa GSA1.0 dada na figura 28, observas-e que o programa GSA1.0 fez um bom ajuste da transmissão medida e a transmissão calculada para a energia de $15 \mathrm{MV}$.

\begin{tabular}{lcc} 
Tabela 5: Parâmetros para reconstrução do espectro de & $15 \mathrm{MV}$. \\
\hline Item & Representação & Valor \\
\hline Número de canales & $\mathrm{k}$ & 33 \\
Numero de iterações & $t_{\max }$ & 200 \\
Número de soluciones de ensaio & $n_{r}$ & 100 \\
Parâmetro de generalização & $\tilde{q}_{v}$ & 1,6 \\
Parâmetro de regularização & $\lambda$ & 0,0005 \\
Coeficiente de esfriamento & $\alpha$ & 0,9 \\
\hline Energia média (MV) & $\alpha$ & \multicolumn{2}{c}{4,1} \\
\hline
\end{tabular}




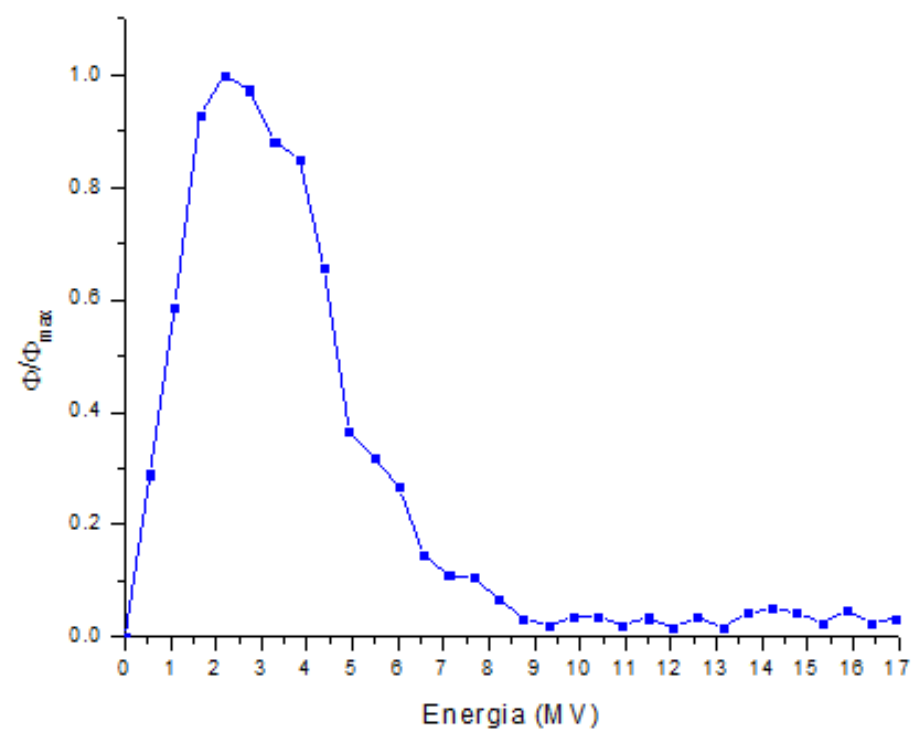

Figura 24: Espectro de fluência de fótons de $15 \mathrm{MV}$ normalizado obtido pela técnica GSA para alumínio em função da energia $E$ do fóton.

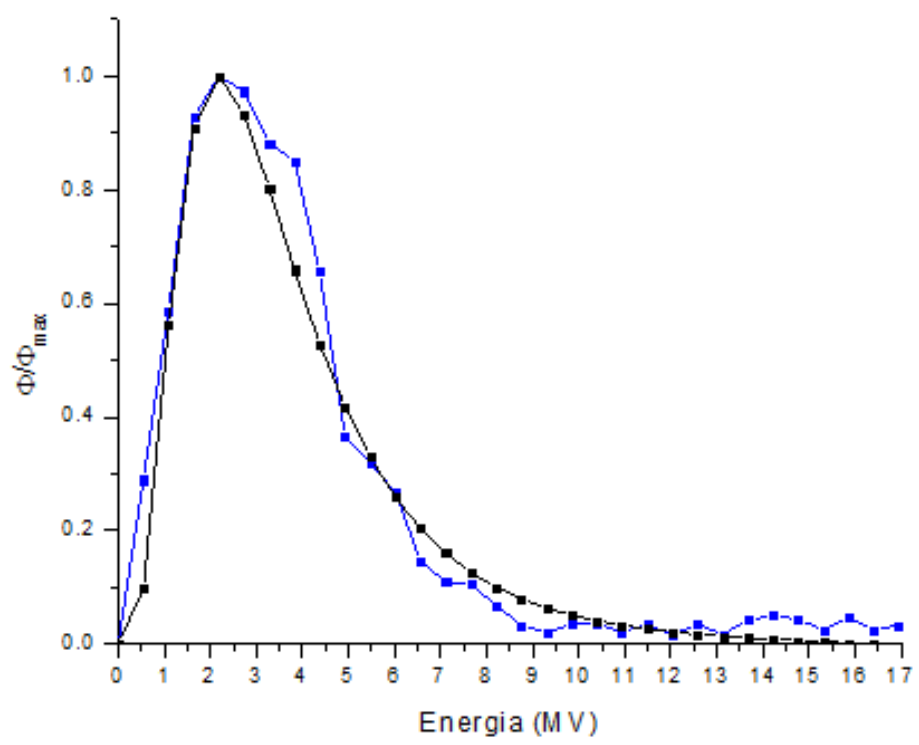

Figura 25: Espectro de fluência de Fótons de $15 \mathrm{MV}$ normalizado obtido pela técnica GSA (linha com pontos em azul) para alumínio em função da energia $E$ do fóton, e seu espectro refinado (linha com pontos preto). 


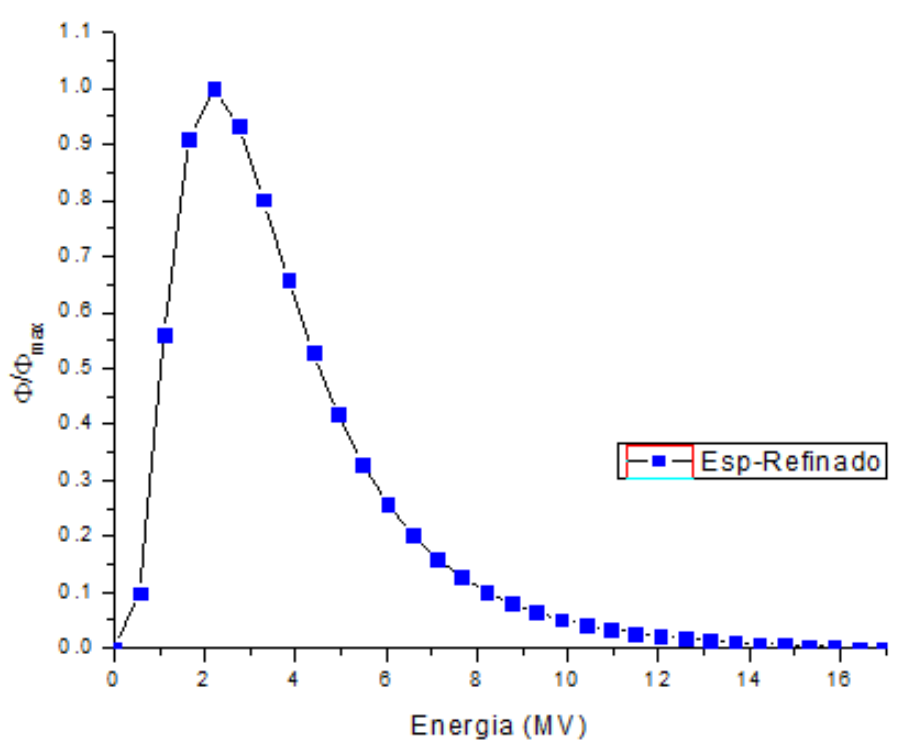

Figura 26: Espectro de fluência de fótons de $15 \mathrm{MV}$ normalizado obtido pela técnica GSA para Alumínio em função da energia $E$ do fóton depois do refinamento.

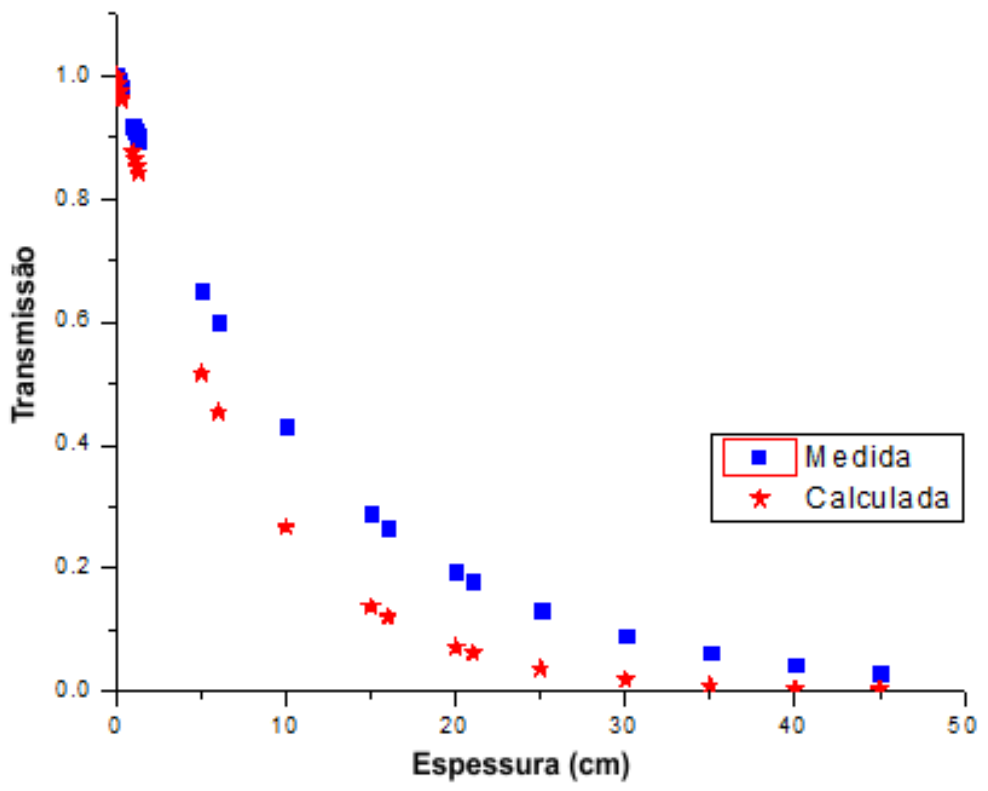

Figura 27: Comparação do transmissão medida e transmissão calculada iniciais para $15 \mathrm{MV}$. 


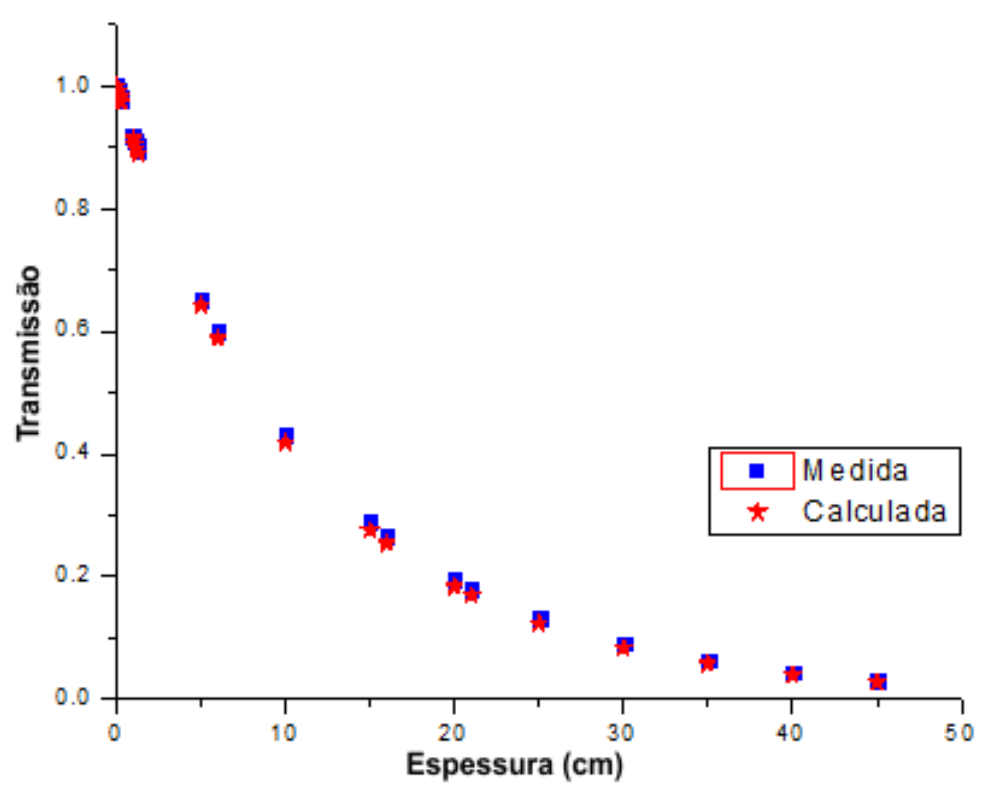

Figura 28: Comparação do transmissão medida e transmissão calculada final para $15 \mathrm{MV}$.

Depois de obter os espectros para $6 \mathrm{MV}$ e $15 \mathrm{MV}$ e as correspondentes energias medias nós fazemos uso da simulação Monte Carlo considerando uma fonte espectral e um phantom de agua de $40 \times 40 \times 51 \mathrm{~cm}^{3}$ para calcular as porcentagens de doses profundas usando o programa PENELOPE. Os resultados da comparação da PDD medida (pontos em azul) e a PDD simulada com o software PENELOPE (linha verde com pontos cor magenta) para o espectro de $6 \mathrm{MV}$ reconstruído com a técnica de GSA e mostrados na figura 29. Assim mesmo a comparação da PDD medida (pontos em azul) e a PDD simulada com o software PENELOPE (linha verde com pontos cor magenta) para o espectro de $15 \mathrm{MV}$ reconstruído com a técnica de GSA e mostrados na figura 30. Como se pode apreciar nas figuras da reconstrução de PDD para $6 \mathrm{MV}$ e $15 \mathrm{MV}$ são obtidas com muita fidelidade o qual e um bom indicador para poder calcular os $T P R_{20 / 10}$ a partir dos PDD simulados.

Os $T P R_{20 / 10}$, são calculados usando o $P D D_{20,10}$, do modo como e proposto no protocolo IAEA-TRS398 [4], a partir da equação

$$
T P R_{20,10}=1,2661 P D D_{20,10}-0,0595
$$

Em que $P D D_{20,10}$ é o quociente dos porcentagens de doses en profundidade para as profundezas de $20 \mathrm{~cm}$ e $10 \mathrm{~cm}$ para um tamanho de campo de $10 \mathrm{~cm} \times 10 \mathrm{~cm}$, definido na superfície do phantom a uma distancia fonte superfície (SSD) de $100 \mathrm{~cm}$. Os 


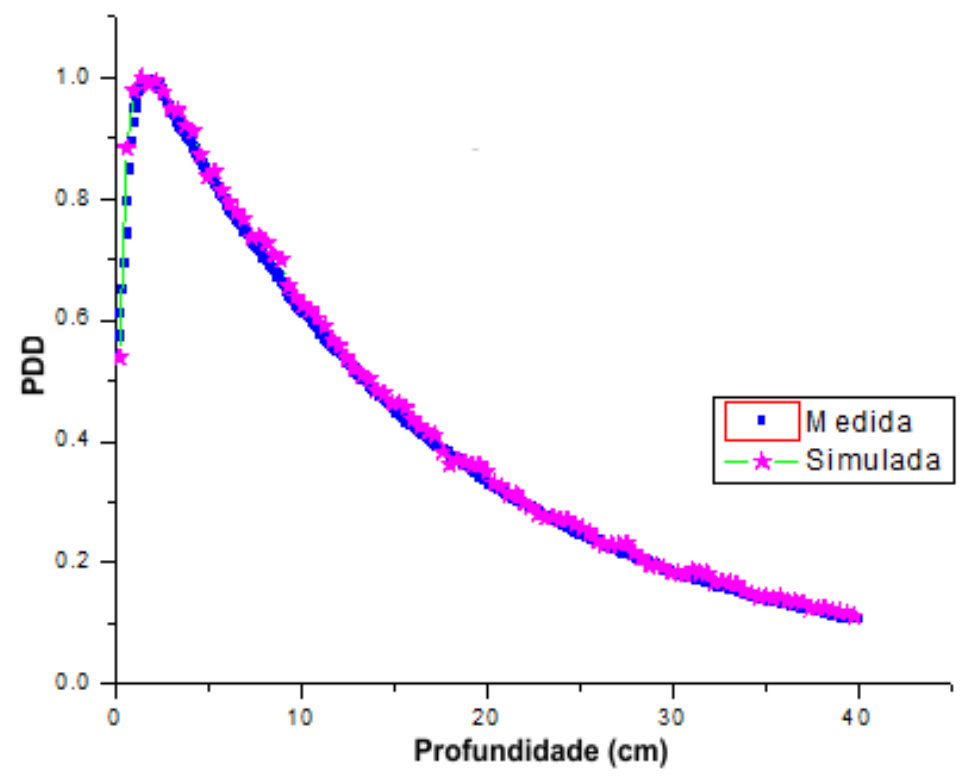

Figura 29: Comparação da PDD medida (pontos em azul) e calculada (linha verde com pontos cor magenta) com PENELOPE para o espectro reconstruído de $6 \mathrm{MV}$.

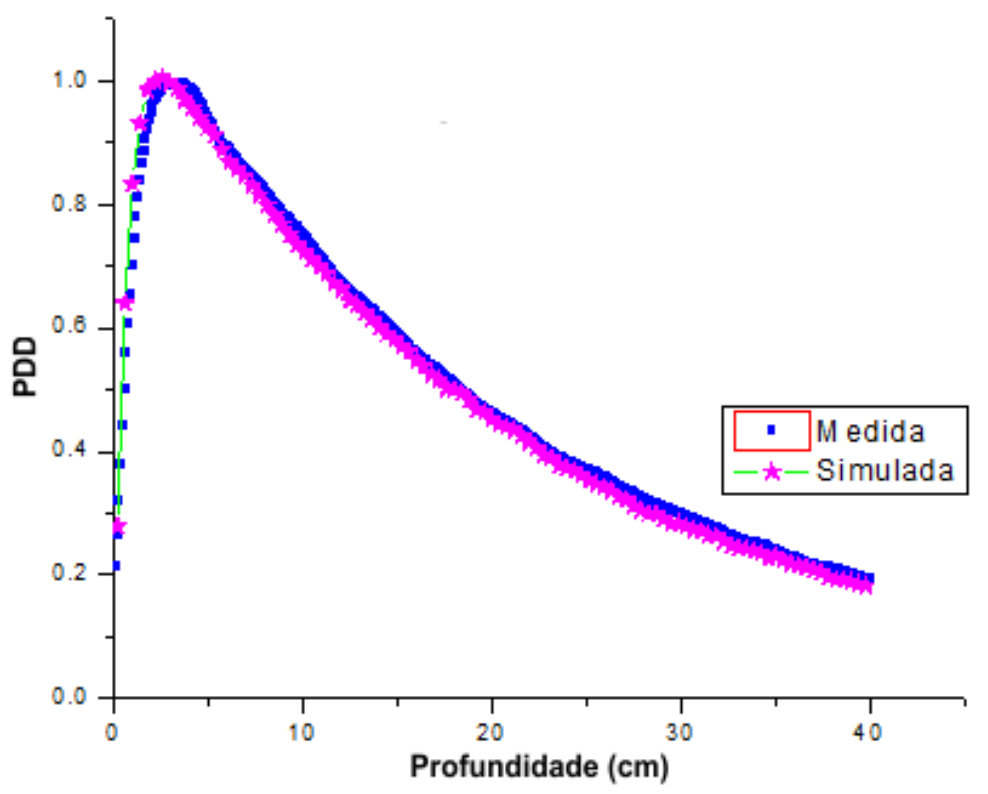

Figura 30: Comparação da PDD medida(pontos em azul) e calculada (linha verde com pontos cor magenta) com PENELOPE para o espectro reconstruído de $15 \mathrm{MV}$. 
cálculos de $T P R_{20,10}$ para as energias de $6 \mathrm{MV}$ e $15 \mathrm{MV}$ são dados na tabela 6 . Estes resultados foram comparados com os dados de $T P R_{20,10}^{\text {ref }}$ usados no serviço de radioterapia do Hospital das Clinicas da Faculdade de Filosofia Ciências e Letras da Universidade de São Paulo de Ribeirão Preto observando-se um bom acordo com os resultados obtidos num erro de calculo menor a $1 \%$.

\begin{tabular}{|c|c|c|}
\hline & 697 & 1501 \\
\hline Energia & $6 \mathrm{MV}$ & $15 \mathrm{MV}$ \\
\hline$P D D_{20,10}$ & 0,57838 & 0,65588 \\
\hline$T P R_{20,10}$ & 0,673 & 0,771 \\
\hline$T P R_{20,10}^{\mathrm{ref}}$ & 0,673 & 0,768 \\
\hline
\end{tabular}

Para o calculo de erros nós consideramos a diagonal da matriz de covariança que correspondem a variância de cada termo do espectro de fluência calculado $g_{i}$ considerada como o desvio padrão de cada componente do vetor espectro de fluência calculado com relação da media $g_{m e d}$ em $N=25$ repetições de acordo com a equação

$$
g_{\text {med }}=\frac{1}{N} \sum_{i=1}^{N} g_{i}
$$

Então o erro de $g_{i}$ e dado pela seguinte equação 3.3:

$$
\Delta g_{i}=\left[\frac{1}{N(N-1)} \sum_{i=1}^{N}\left(g_{i}-g_{m e d}\right)^{2}\right]^{1 / 2}
$$

O calculo dos erros de acordo com a equação 3.3 não excede o 5\%, o que é um bom indicador para a validação da reconstrução dos espectros. 


\section{Conclusões}

Foram realizados cálculos do espectro de fluência de fótons de um acelerador linear de uso clinico para as energias de $6 \mathrm{MV}$ e $15 \mathrm{MV}$, usando a técnica de GSA realizando uma serie de provas ao programa de reconstrução qual em todo momento não apresentou falhas.

A técnica de GSA é uma potente ferramenta pra reconstrução de espectros de aceleradores lineares de uso clinico, não requer um conhecimento rigoroso da geometria e os materiais do cabeçote do acelerador que são necessários para implementar uma simulação Monte Carlo, já que usa um método inverso com base nos dados de transmissão o qual torna mais acessível para o cálculo de grandezas de interesse relativas ao feixe clinico com grande precisão como energia media, porcentagens de doses profunda PDD, e o índice de qualidade do feixe $T P R_{20 / 10}$.

Em nossos cálculos empregamos um método de recuperação da informação física depois de aplicar a técnica de GSA através do refinamento dos espectros usando a fórmula melhorada de Schiff, qual resultou uma ótima ferramenta que reduz a incerteza e suaviza o espectro, resultando em espectros de boa qualidade que podem ser utilizados no âmbito clinico. 


\section{Referências}

1 KHAN, F. M. The physics of radiation therapy. 3. ed. Philadelphia, PA: Lippincott Williams \& Wilkins, 2003.

2 LILLICRAP, S. C. et al. Code of Practice for high-energy photon therapy dosimetry based on the NPL absorbed dose calibration service. Physics in Medicine and Biology, v. 35, n. 10, p. $1355-1360,1990$.

3 ALMOND, P. R. et al. AAPM's TG-51 protocol for clinical reference dosimetry of high-energy photon and electron beams. Medical Physics, v. 26, n. 9, p. 1847-1870, 1999.

4 INTERNATIONAL ATOMIC ENERGY AGENCY. Absorbed dose determination in external beam radiotherapy: an international code of practice for dosimetry based on standards of absorbed dose to water, Technical Report Series No. 398. Vienna: IAEA, 2000.

5 PAPANIKOLAOU, N.; STATHAKIS, S. Dose-calculation algorithms in the context of inhomogeneity corrections for high energy photon beams. Medical Physics, v. 36, n. 10, p. 4765-4775, 2009.

6 HISSOINY, S.; OZELL, B.; DESPRÉS, P. A convolution-superposition dose calculation engine for GPUs. Medical Physics, v. 37, n. 3, p. 1029-1037, 2010.

7 DISHER, B. et al. An in-depth Monte Carlo study of lateral electron disequilibrium for small fields in ultra-low density lung: implications for modern radiation therapy. Physics in Medicine and Biology, v. 57, n. 6, p. 1543-1559, 2012.

8 TAKAHASHI, W. et al. Evaluation of heterogeneity dose distributions for Stereotactic Radiotherapy (SRT): comparison of commercially available Monte Carlo dose calculation with other algorithms. Radiation Oncology, v. 7, p. 20-27, 2012.

9 HUANG, P.-H.; KASE, K. R.; BJÄRNGARD, B. E. Spectral characterization of 4 MV Bremsstrahlung by attenuation analysis. Medical Physics, v. 8, n. 3, p. 368-374, 1981.

10 CATALA, A. et al. Reconstruction of $12 \mathrm{MV}$ bremsstrahlung spectra from measured transmission data by direct resolution of the numeric system AF=T. Medical Physics, v. 22, n. 1, p. 3-10, 1995.

11 HUSSAIN, S. Artificial neural network nodel for spectral construction of a linear accelerator megavoltage photon beam. In: 2010 International Conference on Intelligent Systems, Modelling and Simulation (ISMS). [S.I.: s.n.], 2010. 
12 NISBET, A. et al. Spectral reconstruction of clinical megavoltage photon beams and the implications of spectral determination on the dosimetry of such beams. Physics in Medicine and Biology, v. 43, n. 6, p. 1507-1521, 1998.

13 TSALLIS, C.; STARIOLO, D. A. Generalized simulated annealing. Physica A: Statistical Mechanics and its Applications, v. 233, n. 1-2, p. 395-406, 1996.

14 ATTIX, F. H. Introduction to radiological physics and radiation dosimetry. Weinheim: Wiley-VCH, 2004.

15 PODGORŠAK, E. B. Radiation Physics for Medical Physicists. Germany: Springer-Verlag Berlin Heidelberg, 2006.

16 FOLLOWILL, D. S. et al. Neutron source strength measurements for varian, siemens, elekta, and general electric linear accelerators. Journal of Applied Clinical Medical Physics, v. 4, n. 3, p. 189-194, 2003.

17 FACURE, A. et al. Neutron dose rate evaluation for medical linear accelerators. Radiation Protection Dosimetry, v. 111, n. 1, p. 1-3, 2004.

18 FLETCHER, R. Practical methods of optimization. 2. ed. New York: John Wiley \& Sons, 1987.

19 KELLEY, C. Iterative Methods for Optimization. North Carolina: Society for Industrial and Applied Mathematics, 1999. Disponível em: $<$ http://epubs.siam.org/doi/abs/10.1137/1.9781611970920>.

20 RUSSELL, S. J.; NORWING, P. Artificial intelligence : a modern approach. Upper Saddle River, N.J: Prentice Hall/Pearson Education, 2003. ISBN 0137903952.

21 JAYNES, E. T. Information theory and statistical mechanics. Physical Review, v. 106, n. 4 , p. 620-630, 1957.

22 MARTINEZ, A. S.; GONZÁLEZ, R. S.; TERÇARIOL, C. A. S. Generalized probability functions. Advances in Mathematical Physics, 2009.

23 MENIN, O. H. Eficácia em problemas inversos: generalização do algoritmo de recozimento simulado e função de regularização aplicados a tomografia de impedância elétrica e ao espectro de raios $X$. Tese (Doutorado) - Faculdade de Filosofia, Ciências e Letras de Ribeirão Preto, Universidade de São Paulo, 2014.

24 KIRKPATRICK, S.; GELLAT, C.; VECCHI, M. Optimization by simulated annealing. Science, v. 31, n. 43, p. 5661-5672, 1983.

25 CEPERLEY, D.; ALDER, B. Quantum Monte Carlo. Science, v. 231, p. 555, 1986.

26 GEMAN, S.; GEMAN, D. IEEE Trans. Pattern Anal. Machine Intell., p. 721, 1984.

27 SZU, H.; HARTLEY, R. Fast simulated annealing. Phisics Letters A, v. 122, n. 3,4, 1987.

28 TSALLIS, C.; MENDES, R. S.; PLASTINO, A. R. The role of constraints within generalized nonextensive statistics. Physica A, v. 261, p. 534-554, 1998. 
29 YAMANO, T. Some properties of q-logarithm and q-exponential functions in Tsallis statistics. Physica A, v. 305, p. 486-496, 2002.

30 ARRUDA, T. J. et al. Arithmetical and geometrical means of generalized logarithmic and exponential functions: generalized sum and product operators. Physics Letters A, v. 372, p. 2578-2582, 2008.

31 SILVA, R.; DRUGOWICH, J. R.; MARTINEZ, A. S. Generalized Metropolis dynamics with a generalized master equation: An approach for time-independent and time-dependent Monte Carlo simulations of generalized spin systems. Physical Review E, v. 85, p. 066707, 2012.

32 SELTZER, S. M. Calculation of photon mass energy-transfer and mass energy-absorption coefficients. Radiation Research, v. 136, p. 147-170, 1993.

33 Zong-Yi Hou and Qi-Nian Jin. Tikhonov regularization for nonlinear ill-posed problem. Nonlinear Analysis, Theory, Methods \& Applications, v. 28, n. 11, p. 1799-1809, 1997.

34 VAUHKONEN, M. et al. Tikhonov regularization and prior information in electrical impedance tomography. IEEE Transactions on Medical Imaging,, v. 17, n. 2, April 1998.

35 SHEIKH-BAGHERI, D.; ROGERS, D. W. O. Monte Carlo calculation of nine megavoltage photon beam spectra using the BEAM code. Medical Physics, v. 29, n. 391, 2002.

36 DENG, J.; CHANG, C.; YANG, Z. An exact random number generator for visiting distribution in GSA. International Journal of Simulation: Systems, Science \& Technology, v. 6, n. 12-13, p. 54-61, 2005.

37 ALI, E. S. M.; MCEWEN, M. R.; ROGERS, D. W. O. Unfolding linac photon spectra and incident electron energies from experimental transmission data, with direct independent validation. Medical Physics, v. 39, n. 11, p. 6585-6596, 2012.

38 MATSUMOTO, M.; KURITA, Y. Twisted GFSR generators II. ACM Transactions on Modeling and Computer Simulation, v. 4, p. 254-266, 1994.

39 HUANG, K. Statistical mechanics. New York: NY: Wiley, 1987.

40 CROKIDAKIS, N. et al. Finite-size analysis of a two-dimensional Ising model within a nonextensive approach. Physics Review E, v. 80, p. 051101, 2009.

41 BORGES, E. P. A possible deformed algebra and calculus inspired in nonextensive thermostatistics. Physica A: Statistical Mechanics and its Applications, v. 340, p. 95 101, 2004. ISSN 0378-4371. News and Expectations in Thermostatistics. Disponível em: <http://www.sciencedirect.com/science/article/pii/S0378437104004029>.

42 NIVANEN, L.; MÉHAUTÉ, A. L.; WANG, Q. A. Generalized algebra within a nonextensive statistics. Reports on Mathematical Physics, v. 52, n. 3, p. 437 - 444, 2003. ISSN 0034-4877. Disponível em: $<$ http://www.sciencedirect.com/science/article/pii/S003448770380040X >. 
43 INGBER, L. Simulated annealing: Practice versus theory. Mathematical and Computer Modelling, v. 18, n. 11, p. 29-57, 1993.

44 THISTLETON, W. et al. Generalized box-müller method for generating q-qaussian random deviates. IEEE Transaction on Information Theory, v. 53, p. 4805-4810, 2007.

$45 \mathrm{LI}, \mathrm{G}$. et al. Photon energy spectrum reconstruction based on monte carlo and measured percentage depth dose in accurate radiotherapy. Progress in Nuclear Science and Technology, v. 2, p. 160-164, 2011.

46 DESOBRY, G. E.; BOYER, A. L. Bremsstrahlung review: an analysis of the Schiff spectrum. Medical Physics, v. 18, n. 497, 1991.

47 JALBOUT, W. T.; SPYROU, N. M. Spectral reconstruction by scatter analysis for a linear accelerator photon beam. Physics in Medicine and Biology, v. 51, n. 9, p. 2211-2224, 2006.

48 PRESS, W. H. Numerical Recipes in C: The Art of Scientific Computing. New York: Cambridge University Press, 1992. 


\section{APÊNDICE A - Mecânica estatística e critério de Metropolis}

Em mecânica estatística, um sistema termodinâmico é composto por diferentes micro-estados associados a um macro-estado termodinâmico do sistema que é caracterizados pelo espaço de fase associado em ensemble micro-canônico (mecânica dos micro-estados) e ensemble canônico pra caracterizar macro-estados. De acordo com isso define-se a entropia como uma propriedade fundamental do sistema termodinâmico que caracteriza o ensemble micro-canônico é definida através de um princípio variacional que determina que, num sistema isolado, o estado de equilíbrio termodinâmico do sistema é aquele estado macroscópico para o qual a entropia é máxima (Principio de Máxima Entropia (21)). Num sistema em equilíbrio com energia entre $E$ e $E+\Delta E$, todos $N$ micro-estados acessíveis são igualmente prováveis, o que significa que um micro-estado pode ser obtido a partir de inúmeros micro-estados diferentes (39); se define um ensemble canônico como um conjunto de micro-estados onde a probabilidade $P_{j}$ de encontrar o sistema num micro-estado $j$ e dada pela equação A.1, o que significa que se um sistema esta em equilíbrio a uma dada temperatura T, a probabilidade de encontrá-lo num dado micro-estado especifico $j$ é proporcional a peso de Boltzmann $e^{-E_{j} / k_{B} T}$, onde considerando que a função de partição do sistema é $\sum_{j=1}^{N} E_{j} e^{-E_{j} / k_{B} T}$, podemos escrever a a probabilidade $P_{j}$ como

$$
P_{j}=\frac{e^{-E_{j} / k_{B} T}}{\sum_{j} e^{-E_{j} / k_{B} T}}
$$

$E_{j}$ é a energia do sistema no micro-estado $j$ e $k_{B}$ é a constante de Boltzmann. Com isso, podemos calcular a média como:

$$
\langle E\rangle_{N}=\frac{1}{Z} \sum_{j=1}^{N} E_{j} e^{-E_{j} / k_{B} T}
$$


Um sistema termodinâmico em equilíbrio satisfaze o postulado de igual probabilidade a priori (39), que diz que se um sistema esta em equilíbrio termodinâmico todos os estados acessíveis tem a mesma probabilidade, isso se pode derivar de critérios de ergodicidade já que se consideramos que um sistema é ergódico se a fração de tempo que ele passa em uma região restrita do espaço de fase acessível é proporcional ao volume dessa região, e não as posições particulares na superfície de energia ocupadas pelo sistema em um determinado tempo então um sistema ergódico satisfaze esse postulado. O postulado de igual probabilidade a priori (39) permite determinar a probabilidade de encontrar o sistema em um micro-estado compatível com os vínculos macroscópicos, e a partir da probabilidade podemos determinar valores médios de observáveis como energia, magnetização, etc.

De acordo com o critério de Metropolis(40), as configurações aleatórias geradas são escolhidas com probabilidade proporcional a $e^{-E_{j} / k_{B} T}$. O equilíbrio termodinâmico é obtido através de um processo iterativo no qual, a cada passo se faz modificações aleatórias na configuração do sistema e calcula-se a diferença $\Delta E=E_{2}-E_{1}$, entre a energia $E_{2}$ da nova configuração e a energia $E_{1}$ da configuração anterior. Caso $\Delta E \leq 0$, se aceita com certeza a nova configuração. No entanto, mesmo quando $\Delta E>0$, a nova solução não é descartada de imediato, podendo ser aceita com certa probabilidade $e^{-\Delta E / k_{B} T}$ qual depende da diferença de energias entre os estados $E_{1}$ e $E_{2}$ em conseqüência a probabilidade de aceitação para o critério de Metropolis se expressa como:

$$
P_{\text {acepta }}= \begin{cases}1 & \text { Se } \Delta E \leq 0 \\ e^{\frac{-\Delta E}{k_{B} T}} & \text { outro. }\end{cases}
$$

Uma conseqüência importante do principio de ergodicidade é que a média temporal, sobre um tempo suficientemente longo, da o mesmo resultado que a média de ensemble calculada a partir das configurações do sistema de acordo com o peso de Boltzmann pela equação A.2,

No algoritmo de metropolis se faz médias temporais em lugar de médias de ensemble é uma condição para sua validade e que o sistema seja ergódico, e que uma sequencia aleatória de transições leve ao macro-estado de equilíbrio. Para lograr o propósito de atingir o equilíbrio do sistema a partir de um micro-estado iniciai arbitrário e cumprir as dois condições se recorre ao principio de balance detalhado PBD (31), escolhendo as probabilidades de transição que satisfazem o PBD com $P(i)$ dada pela 
distribuição de Boltzmann. O principio de balance detalhado representa uma condição suficiente para que uma distribuição $P(i)$ seja uma distribuição no equilíbrio e pode descrever-se dados dois micro-estados $i$ e $j$ com probabilidades de transição $A(i \leftarrow j)$ sendo a probabilidade por unidade de tempo do sistema atingir o micro-estado $i$ a partir do micro-estado $j$ é $A(j \leftarrow i)$ sendo a probabilidade por unidade de tempo do sistema atingir o micro-estado $j$ a partir do micro-estado $i$ na equação A.4 como:

$$
A(j \leftarrow i) P(i)=A(i \leftarrow j) P(j)
$$

em que $A(i \leftarrow j)$ e a probabilidade de transição do estado $j$ para o estado $i A(j \leftarrow i) \mathrm{e}$ a probabilidade de transição do estado $i$ para o estado $j P(i)$ e $P(j)$ as probabilidades de encontrar o sistema nos micro-estados $i$ e $j$, respectivamente.

\section{A.1 Algoritmo de Metropolis}

O algoritmo de metropolis pode se expressar como segue:

1. Sortear um micro-estado $i$ com a densidade de probabilidade apropriada ao modelo físico. Encontramos a probabilidade de sortear $i$ dado que o sistema esta em $j \mathrm{P}(\mathrm{i} / \mathrm{j})$.

2. Se a diferença de energia entre o estado $i$ e o estado $j$ e $\Delta E \leq 0$ aceita-ce $i$ como novo estado. Ir ao item4; se $\Delta E>0$ ir ao item 3.

3. Se $\Delta E=E_{i}-E_{j}>0$; sorteamos um numero $r$ com distribuição uniforme entre 0 e 1; se $r \leq \exp (-\Delta E / k B T)$ aceita-se a transição; se $r>\exp (-\Delta E / k B T)$ rejeitasse a transição e retornasse ao item1.

4. Calcula-se as macro-variáveis requeridas respeito às variáveis microscópicas e guardasse os resultados.

5. Depois um numero relativamente grande de sorteios que deve ser escolhido caso a caso se recalculam as macro-variáveis que foram guardas conforme ao item 4.

Após um numero suficientemente grande de iterações no algoritmo de Metropolis se calcula a média temporal como $\langle E\rangle_{N}=\frac{1}{N} \sum_{i=1}^{N} E_{i}$, em que $E_{i}$ é a energia do sistema no $i$-ésimo passo e $N$ é o número de passos executados. Desta forma, obtemos uma média temporal da energia do sistema que, de acordo com o teorema ergódico, no equilíbrio termodinâmico, é igual à média configuracional dada pela equação A.2. 
Essa equivalência ergódica entre as médias configuracional e temporal fundamenta o algoritmo de Metropolis, pois a distribuição de Boltzmann obedece ao principio do balanço detalhado (PBD). Como se sabe, o PBD é a condição suficiente para que um sistema atinja uma distribuição de equilíbrio termodinâmico.

\section{A.2 Critério de Metropolis generalizado}

A partir do trabalho de Crokidakis et al.(40), baseado na estatística não-extensiva de Tsallis aplicada ao modelo de spin de Ising para calcular susceptibilidade magnética e calor específico em função da temperatura; Silva, Drugowich e Martinez(31), propuseram a reformulação da equação mestre padrão e o algoritmo de Metropolis generalizado, redefinindo as taxas de transição de um spin entre dois estados diferentes para satisfazer o critério de balanço detalhado PBD como:

seja a equação mestre

$$
d P\left(E^{(a)}, t\right) / d t=\sum_{\sigma_{i}^{(b)}}\left\{w\left[\sigma_{i}^{(b \rightarrow a)}\right] P\left(E^{(b)}, t\right)-w\left[\sigma_{i}^{(a \rightarrow b)}\right] P\left(E^{(a)}, t\right)\right\}
$$

em que $w\left[\sigma_{i}^{(b \rightarrow a)}\right]=w\left[\sigma_{i}^{(b)} \rightarrow \sigma_{i}^{(a)}\right]$ é a taxa de transição do $i$-ésimo spin desde $\sigma_{i}^{(b)}$ a $\sigma_{i}^{(a)}$ quais sao as configurações de spin antes e depois da transição é $E^{(a)}$ é $E^{(b)}$ e a energia do sistema antes e depois da transição respectivamente. Quando $t \rightarrow \infty$, $d P\left(E^{(a)}, t\right) / d t=0$ e uma condição para o equilíbrio. a condição suficiente mais no necessaria e conhecida como a condição de balanço detalhado conduce a:

$$
w\left[\sigma_{i}^{(b \rightarrow a)}\right] P\left[E^{(b)}\right]-w\left[\sigma_{i}^{(a \rightarrow b)}\right] P\left[E^{(a)}\right]=0
$$

A partir de este critério e considerando $P[E]=P(E, t \rightarrow \infty)$ a distribuição de Boltzmann $P\left(E_{j}\right)=e^{-\beta E_{j}} / \sum_{k} e^{-\beta E_{k}}$, em que $\beta=\left(k_{B} T\right)^{-1}$, o uso do critério de Metropolis conduz a:

$$
w\left[\sigma_{i}^{(b \rightarrow a)}\right]=\min \left\{1, \exp \left[-\beta\left(E^{a}-E^{b}\right)\right]\right\}
$$

Para generalizar o critério de Metropolis escrevemos a distribuição de BoltzmannGibss generalizada como:

$$
P_{1-q}\left(E_{i}\right)=\frac{\left[e_{1-q}\left(-\beta^{\prime} E_{i}\right)\right]^{q}}{\sum_{i=1}^{\Omega}\left[e_{1-q}\left(-\beta^{\prime} E_{i}\right)\right]^{q}}
$$


em que $\beta^{\prime}=\beta / \Sigma_{i=1}^{\Omega}\left\{\left[e_{1-q}\left(-\beta E_{i}\right)\right]^{q}+(1-q) \beta\langle E\rangle_{1-q}\right\}$, a energia média generalizada $\langle E\rangle_{1-q}=\sum_{i=1}^{\Omega} E_{i} P_{1-q}\left(E_{i}\right)$, e $\Omega$ é o numero de estados acessíveis do sistema.

fazendo uso das funções q̃-generalizadas (apêndice A.3) é a generalização dos operadores algébricos (apêndice A.4), eles conseguem, e reformulam o critério de aceitação como:

$$
w\left[\sigma_{i}^{(b \rightarrow a)}\right]=\frac{P_{1-q}\left[E^{(a)}\right]}{P_{1-q}\left[E^{(b)}\right]}=\left\{\frac{e_{1-q}\left[-\beta^{\prime} E^{(a)}\right]}{e_{1-q}\left[-\beta^{\prime} E^{(b)}\right]}\right\}^{q}
$$

das equações para os parâmetros generalizados obtemos

$$
\frac{P_{1-q}\left[E^{(a)}\right]}{P_{1-q}\left[E^{(b)}\right]}=e_{1-q}\left\{-\beta^{\prime}\left[E^{(a)} \ominus_{1-q} E^{(b)}\right]\right\}
$$

em conseqüência empregando a equação A.9 e a probabilidade de Boltzmann generalizada podemos descrever a evolução do sistema com a nova equação mestre generalizada:

$$
\frac{d P_{1-q}\left[E^{(a)}\right]}{d t}=\sum_{\sigma_{i}^{(b)}}\left\{w\left[\sigma_{i}^{(b \rightarrow a)}\right] \otimes_{\tilde{q} / q} P_{q}\left[E^{(b)}\right] \ominus_{\tilde{q} / q} w\left[\sigma_{i}^{(a \rightarrow b)}\right] \otimes_{\tilde{q} / q} P_{q}\left[E^{(a)}\right]\right\}
$$

Então a o principio de balanço detalhado (condição suficiente para o equilíbrio) para a equação mestre generalizada pode ser expressa como:

$$
w\left[\sigma_{i}^{(b \rightarrow a)}\right] \otimes_{\tilde{q} / q} P_{q}\left[E^{(b)}\right] \ominus_{\tilde{q} / q} w\left[\sigma_{i}^{(a \rightarrow b)}\right] \otimes_{\tilde{q} / q} P_{q}\left[E^{(a)}\right]=0
$$

ou em seu defeito se pode expressar como

$$
w\left[\sigma_{i}^{(b \rightarrow a)}\right] \oslash_{\tilde{q} / q} w\left[\sigma_{i}^{(a \rightarrow b)}\right]=P_{q}\left[E^{(a)}\right] \oslash_{\tilde{q} / q} P_{q}\left[E^{(b)}\right]
$$

o novo critério de metropolis generalizado como:

$$
\begin{aligned}
w\left[\sigma_{i}^{(b \rightarrow a)}\right] & =\min \left\{1,\left[e_{\tilde{q}}\left(-\beta^{\prime} E^{(a)}\right)\right]^{q} \oslash_{\tilde{q} / q}\left[e_{\tilde{q}}\left(-\beta^{\prime} E^{(b)}\right)\right]^{q}\right\} \\
& =\min \left\{1,\left[e_{\tilde{q}}\left(-\beta^{\prime}\left(E^{(a)}-E^{(b)}\right)\right)\right]^{q}\right\}
\end{aligned}
$$

De este modo se recupera a localidade para usar o principio do balanço detalhado de energia com o novo algoritmo de metropolis (31). a implementado do novo algoritmo es a mesma como o casso do algoritmo de metropolis A.1 e e implementado em nosso algoritmo GSA dado no diagrama de blocos da figura 17. 


\section{A.3 Funções Generalizadas}

Exponencial Generalizada $\bigcirc q$-logaritmo e $q$-exponencial sao definidos (29), (22) por:

$$
\ln _{q} x=\frac{x^{1-q}-1}{1-q}, \quad \exp _{q} x= \begin{cases}{[1+(1-q) x]^{1 /(1-q)}} & \text { Se } 1+(1-q) x \geq 0 \\ 0 & \text { outro. }\end{cases}
$$

onde $\lim _{q \rightarrow 1} \ln _{q} x=\ln x$, e, $\lim _{q \rightarrow 1} e_{q}^{x}=e^{x}$, além do uso das inversas $e_{q}^{\ln _{q} x}=\ln _{q} e_{q}^{x}=x$.

Propriedades da Exponencial Generalizada

$$
\begin{gathered}
e_{\tilde{q}}=e_{\tilde{q}}(1)=(1+\tilde{q})^{1 / \tilde{q}} \\
\left(e_{q}^{f(x)}\right)^{a}=e_{1-(1-q) / a}^{a f(x)} \\
\left(e_{q}^{f(x)}\right)^{q}=\frac{d}{d x} e_{q}^{f(x)} / f^{\prime}(x) \\
\left(e_{q}^{x} e_{q}^{y}\right)^{1-q}=\left(e_{q}^{x+y}\right)^{1-q}+(1-q)^{2} x y \\
d e_{\tilde{q}}^{(k x)} / d x=k\left[e_{\tilde{q}}^{(k x)}\right]^{1-\tilde{q}}=k e_{\tilde{q} /(1-\tilde{q})}[(1-\tilde{q}) k x]
\end{gathered}
$$

\section{Gaussiana Generalizada Standard}

$$
\begin{gathered}
G_{\tilde{q}, a}(x)=\frac{\sqrt{\tilde{q}} \Gamma(1 / \tilde{q})}{\Gamma(1 / \tilde{q}-1 / 2)} \frac{e_{-\tilde{q}}\left[-(x / a)^{2} / 2\right]}{\sqrt{2 \pi a^{2}}} \\
\left\langle x^{2 n}\right\rangle_{\tilde{q}, a, 1 / 2}=\left(\frac{2 a^{2}}{\tilde{q}}\right)^{n} \frac{\Gamma(1 / 2+n) \Gamma(1 / \tilde{q}-1 / 2-n)}{\sqrt{\pi} \Gamma(1 / \tilde{q}-1 / 2)}
\end{gathered}
$$

a variança e finita unicamente para $\tilde{q}<2 / 3$

$$
\sigma_{\tilde{q}, a}^{2}=\left\langle x^{2}\right\rangle_{\tilde{q}, a}=\frac{2 a^{2}}{2-3 \tilde{q}}
$$

q-meia e q-variança de uma Generalizada

$$
\begin{gathered}
\bar{\mu}_{q} \equiv\langle x\rangle_{q} \equiv \frac{\int x[p(x)]^{q} d x}{\int[p(x)]^{q} d x} \\
\bar{\sigma}_{q}^{2} \equiv\left\langle\left(x-\bar{\mu}_{q}\right)^{2}\right\rangle_{q} \equiv \frac{\int\left(x-\bar{\mu}_{q}\right)^{2}[p(x)]^{q} d x}{\int[p(x)]^{q} d x}
\end{gathered}
$$




\section{A.4 Generalização dos Operadores Algébricos}

Aqui definimos as operações $\tilde{q}$-soma, $\tilde{q}$-subtração, $\tilde{q}$-produto e $\tilde{q}$ - divisão, com base as propriedades de funções $\tilde{q}$-generalizadas, especificamente o $\tilde{q}$-logaritmo (Eq. 2.9) e $\tilde{q}$-exponencial (Eq. 2.10) [ (41), (42)], que são validas para qualquer valor de $\tilde{q}$, cabe mencionar que quando $\tilde{q}=0$ se recupera o logaritmo e exponencial tradicionais.

$$
\begin{gathered}
a \oplus_{\tilde{q}} b=a+b+\tilde{q} a b, \\
a \ominus_{\tilde{q}} b=\frac{a-b}{1+\tilde{q} b}, \\
a \otimes_{\tilde{q}} b=\left[a^{\tilde{q}}+b^{\tilde{q}}-1\right]_{+}^{1 / \tilde{q}}, \\
a \oslash_{\tilde{q}} b=\left[a^{\tilde{q}}-b^{\tilde{q}}+1\right]^{1 / \tilde{q}},
\end{gathered}
$$

Da mesma forma se pode definir as operações:

$$
\begin{gathered}
\exp _{\tilde{q}}(a) \exp _{\tilde{q}}(b)=\exp _{\tilde{q}}\left(a \oplus_{\tilde{q}} b\right), \\
\ln _{\tilde{q}}(a b)=\ln _{\tilde{q}}(a) \oplus_{\tilde{q}} \ln _{\tilde{q}}(b), \\
\ln _{\tilde{q}}\left(a \otimes_{\tilde{q}} b\right)=\ln _{\tilde{q}}(a)+\ln _{\tilde{q}}(b), \\
\exp _{\tilde{q}}(a) \otimes_{\tilde{q}} \exp _{\tilde{q}}(b)=\exp _{\tilde{q}}(a+b), \\
\ln _{\tilde{q}}\left(\frac{a}{b}\right)=\ln _{\tilde{q}}(a) \ominus_{\tilde{q}} \ln _{\tilde{q}}(b), \\
\frac{\exp _{\tilde{q}}(a)}{\exp _{\tilde{q}}(b)}=\exp _{\tilde{q}}\left(a \ominus_{\tilde{q}} b\right), \\
\ln _{\tilde{q}}\left(a \oslash_{\tilde{q}} b\right)=\ln _{\tilde{q}}(a)-\ln _{\tilde{q}}(b),
\end{gathered}
$$

\section{A.5 Convergência do método de GSA}

Para mostrar a convergência do método de Annealing basta supor que o produto de probabilidades de não gerar um estado de equilíbrio $x$ para todos os tempos de recozido sucessivos a $k_{0}$ e zero (43).

$$
\prod_{k=k_{0}}^{\infty}\left(1-g_{k}\right)=0
$$


este equação e equivalente a dizer que a partir do tempo $k_{0}$ a probabilidade de encontrar o mínimo e mantida em um o que significa que:

$$
\sum_{k=k_{0}}^{\infty} g_{k}=\infty
$$

em conseqüência considerando a distribuição de probabilidade de Tsallis generalizada $g_{(k)}$ e um esquema de dece a temperatura dado na equação A.40

$$
T_{v}^{(t)}=T_{v}^{(0)} \frac{\ln _{\tilde{q}_{v}}(2)}{\ln _{\tilde{q}_{v}}(t+1)}
$$

Cumpre-se que:

$$
\sum_{k=k_{0}}^{\infty} g_{k} \geq c \sum_{k=k_{0}}^{\infty} \exp _{\tilde{q}}\left(-\log _{\tilde{q}}(k+1)\right)=c \sum_{k=k_{0}}^{\infty} 1 /(k+1)=\infty
$$

sendo que $c=T_{v}^{(0)} \ln _{\tilde{q}_{v}}(2)$, o que provaria a convergência do método de GSA.

Outra prova pode ser feita usando o metodo o método dado pó D.Henderson et al. com um teorema:

"Seja $P_{k}(i, j)$ a probabilidade de ir de uma solução $x(j)$ a uma solução $x(i)$ em uma iteração interna num laço $k$ e seja $P_{k}^{m}(i, j)$ a a probabilidade de ir de uma solução $x(j)$ a uma solução $x(i)$ em $m$ laços internos. se a cadeia de Markov associada $P_{k}^{m}(i, j) \mathrm{e}$ irreducivel e aperiodica com muitas soluções finitas então $\lim _{m \rightarrow \infty} P_{k}^{m}(i, j)=\pi_{k}(i)$ existe para tudo $i, j \in \Omega$ e $k$ iterações. de outro modo $\pi_{k}(i)$ e a única solução estritamente positiva de:"

$$
\pi_{k}(i)=\sum_{j \in \Omega} \pi_{k}(j) P_{k}(i, j), \vee j \in \Omega
$$

em que

$$
\sum_{j \in \Omega} \pi_{k}(j)=1
$$




\section{APÊNDICE B - Método de reconstrução dos espectros}

Nos adotamos o método proposto por Nisbet et al.(12), quem fez uso de um método de caracter inverso para obter o espectro de fluência de fótons a partir da doses absorvida no meio. A doses absorvida num meio,

$$
D_{\text {med }}=\int_{E=0}^{E_{\max }} E \Phi^{\prime}(E)\left(\mu_{e n} / \rho\right) d E,
$$

em que $\left(\mu_{e n} / \rho\right)$ é o coeficiente de absorção em energia mássico do material atenuador, $\Phi^{\prime}$ é a fluência de fótons, é $E$ é sua energia. A doses absorvida ao meio pode se expressar como:

$$
D_{\text {med }}=M N_{K} C_{w, \lambda}
$$

em que $M$ é a leitura da câmara de ionização, $N_{K}$ é o fator de calibração da câmara em termos de kerma no ar, $C_{w, \lambda}$ é o fator de conversão de doses a kerma. Então a leitura da câmara pode se obter como:

$$
M=\frac{1}{N_{K} C_{w, \lambda}} \int_{E=0}^{E_{\max }} \Phi^{\prime}(E)\left(\mu_{e n} / \rho\right) E d E .
$$

A fração $T_{x}$ do feixe fe fótons primário transmitido através de uma espessura $x$ do material atenuador, e dado por

$$
T_{x}=\frac{M_{x}}{M_{0}},
$$

onde $M_{x}$, e a leitura da câmara para um feixe atenuado pó uma espessura $x$ de naterial atenuador, e $M_{0}$ e a leitura da câmara para um feixe sem atenuação.

As medições de atenuação foram feitas em condições de feixe estreito de maneira que a contribuição do espalhamento não e considerada. Ademais a fluência de fótons diferencial $\Phi^{\prime}(E)$ para um feixe de fótons atenuado por uma espessura $x$ de material, pode se expressar como o produto da fluência de fótons diferencial para um feixe de 
fótons não atenuado $\Phi^{\prime}(E)_{0}$ e a atenuação exponencial devido ao material atenuador.

$$
\Phi^{\prime}(E)=\Phi^{\prime}(E)_{0} \exp \left[-(\mu / \rho)_{a t t} x \rho\right],
$$

em que $(\mu / \rho)_{a t t}$ é o coeficiente de atenuação para o material atenuador e $\rho$ é a densidade.

Assim mesmo se a atenuação através da parede da câmara e a capa de equilíbrio eletrônico(build-up) e tomada em conta, e se $n$ medidas com diferentes espessuras de material atenuador são feitas, a fluência de fótons diferencial se expressa como

$$
\Phi^{\prime}(E)_{x}=\Phi^{\prime}(E)_{0} \exp \left(-\left\{\left(\frac{\mu}{\rho}\right)_{\text {att }} x_{n}+\sum_{i=1}^{h}\left[-\left(\frac{\mu}{\rho}\right)_{\text {med }_{i}} \rho_{\text {med }_{i}} t_{\text {med }_{i}}\right]\right\}\right)
$$

em que $x_{n}=\sum_{j=0}^{n} \rho_{j} t_{j}$ é a suma dos produtos densidade $\rho_{j}$ é a espessura $t_{j}$ de cada folha de material atenuante formando o material atenuador; $(\mu / \rho)_{\text {med }}$ é o coeficiente de atenuação mássico para o meio i-ésimo na parede da câmara (e capa de buildup), e $\rho_{\text {med }}$ e $t_{m e d}$ são a densidade e espessura do meio i-ésimo respetivamente, $h$ é o numero de diferentes meios, sendo dois, a parede de grafito da câmara e o material da capa de build-up de Perspex(acrilico).

Usando as equações B.3, B.4, B.6, e fazendo discreto o domínio da energia, em $k$ canais de energia, onde $E(s)$ e o limite inferior e $E(s+1)$, e o limite superior do canal de energia $s$, Nisbet et al.(12), obtém a transmissão para uma leitura particular da câmara de ionização $T_{n}$ dada como

$$
T_{n}=\frac{\sum_{s=0}^{k-1} a_{n, s} \tilde{\Phi}^{\prime}(s)_{0}}{\sum_{s=0}^{k-1} a_{0, s} \tilde{\Phi}^{\prime}(s)_{0}}, \text { para } n=0,1, \ldots, m-1,
$$

onde $m$ e o numero de medidas de atenuação.

O coeficiente $a_{n, s}$ e dado como:

$$
a_{n, s}=\int_{E(s)}^{E(s+1)}\left(\frac{\mu_{e n}}{\rho}\right) \exp \left(-\left\{\left(\frac{\mu}{\rho}\right)_{\text {att }} \sum_{j=0}^{n} \rho_{j} t_{j}+\sum_{i=1}^{h}\left[\left(\frac{\mu}{\rho}\right)_{\text {med }_{i}} \rho_{\text {medi }_{i}} t_{\text {med }_{i}}\right]\right\}\right) E d E
$$

e o coeficiente $a_{0, s}$ :

$$
a_{0, s}=\int_{E(s)}^{E(s+1)}\left(\frac{\mu_{e n}}{\rho}\right) \exp \left(-\left\{\sum_{i=1}^{h}\left[\left(\frac{\mu}{\rho}\right)_{\text {medi }_{i}} \rho_{\text {med }_{i} t_{\text {med }_{i}}}\right]\right\}\right) E d E
$$


O objetivo e resolver a equação B.7 para os termos de fluência na equação matricial usando a técnica de GSA é reconstruir o espectro de fluência para o feixe de fótons. Para fazer isso o espectro e dividido em um numero de $k-1$ canais para os que cada um dos elementos $a_{n, s}$, e $a_{0, s}$ são calculados por integração numérica. De acordo com a proposta de Nisbet et al.(12) nos construímos uma função de custo dada pela equação B.10, definida como o erro entre a transmissão experimental e a transmissão calculada mais um termo qual é dado por uma função de regularização de Tikhonov multiplicada por um parâmetro de regularização $\lambda$ :

$$
f\left(\phi_{\text {trial }}\right)=\frac{1}{m} \sum_{n=0}^{m-1}\left[T^{(n)}-S^{(n)}\right]^{2}+\frac{\lambda}{k-2} \sum_{s=1}^{k-1}\left|\hat{\phi}_{\text {trial }}^{(s)}-\hat{\phi}_{\text {trial }}^{(s-1)}\right| .
$$

Onde a para construir a função de custo $f\left(\phi_{\text {trial }}\right)$, usamos $\hat{\phi}_{\text {trial }}$ que e uma fluência de ensaio normalizada dada por Menin(23), obtida a partir de dividir cada um dos elementos de $\phi_{\text {trial }}$ pelo máximo calculado $\max \left(\phi_{\text {trial }}\right) . T^{(n)}$ e a transmissão calculada na equação B.7 e $S^{(n)}$ e a transmissão medida, $\lambda$ e um parâmetro de regularização, $m$ e o numero de medidas feitas de transmissão, e $k$ e o número de canais de energia para a reconstrução do espectro.

Devido a que a temperatura controla a estocasticidade do processo de otimização GSA, foram usados dois esquemas de resfriamento. O resfriamento geométrico para a temperatura de aceitação $T_{a}$, dado pela equação

$$
T^{(t)}=\alpha^{t} T_{a}^{(0)}
$$

em que $\alpha \in(0,1)$ e a taxa de esfriamento. E outro esquema de resfriamento da temperatura visitante dada pela equação $\mathrm{B} .12$, onde $\ln _{\tilde{q}_{v}}$ e a função logaritmo generalizado.

$$
T_{v}^{(t)}=T_{v}^{(0)} \frac{\ln _{\tilde{q}_{v}}(2)}{\ln _{\tilde{q}_{v}}(t+1)}
$$

A temperatura inicial de aceitação, $T_{a}^{(0)}$, se calculo fazendo correr a simulação em um corto numero $n$ de passos prévio, para exploração do espaço de soluções, e para assim conhecer a maxima variação da função de custo da equação B.10, $\operatorname{com} \Delta f_{\text {prev }}=$ $\max \left(f\left(x_{i}\right)-\min \left(f\left(x_{i}\right)\right)\right)$, com $x_{i} \in D$ e $i=1, . . n$, e logo usando a equação 2.22 para calcular a probabilidade iniciai de aceitar novas soluções $p_{0}$, calculamos a temperatura de aceitação iniciai dada por

$$
T_{a}^{(0)}=-\frac{\Delta f_{\text {prev }}}{\ln _{\tilde{q}_{a}}\left(p_{0}\right)}
$$




\section{APÊNDICE C - Critérios para obtenção de soluções de ensaio GSA}

Para obter as soluções de ensaio a ser usadas no algoritmo de GSA é importante ter em conta a geração de soluções a partir do método de Box-Müller, e o usso de um método de regularização como restrição a ser imposta para função a ser minimizada de forma a produzir um problema de aproximação bem-comportado, detalhamos o uso de uma função em $\mathrm{C}++$ para obter a $\tilde{q}$-gaussiana e o método de regularização de Tikhonov usados neste trabalho na continuação:

\section{C.1 Pseudo-Código para o Método de Box-Müller Ge- neralizado}

O método de Box-Müller generalizado foi obtido do trabalho de Thistleton et al.(44), e foi usado para construir a $\tilde{q}$-Gaussiana deviate, a partir da qual nos obtivemos nosso método GSA, e é dado na seguinte sub-rutina $\mathrm{C}++$, como

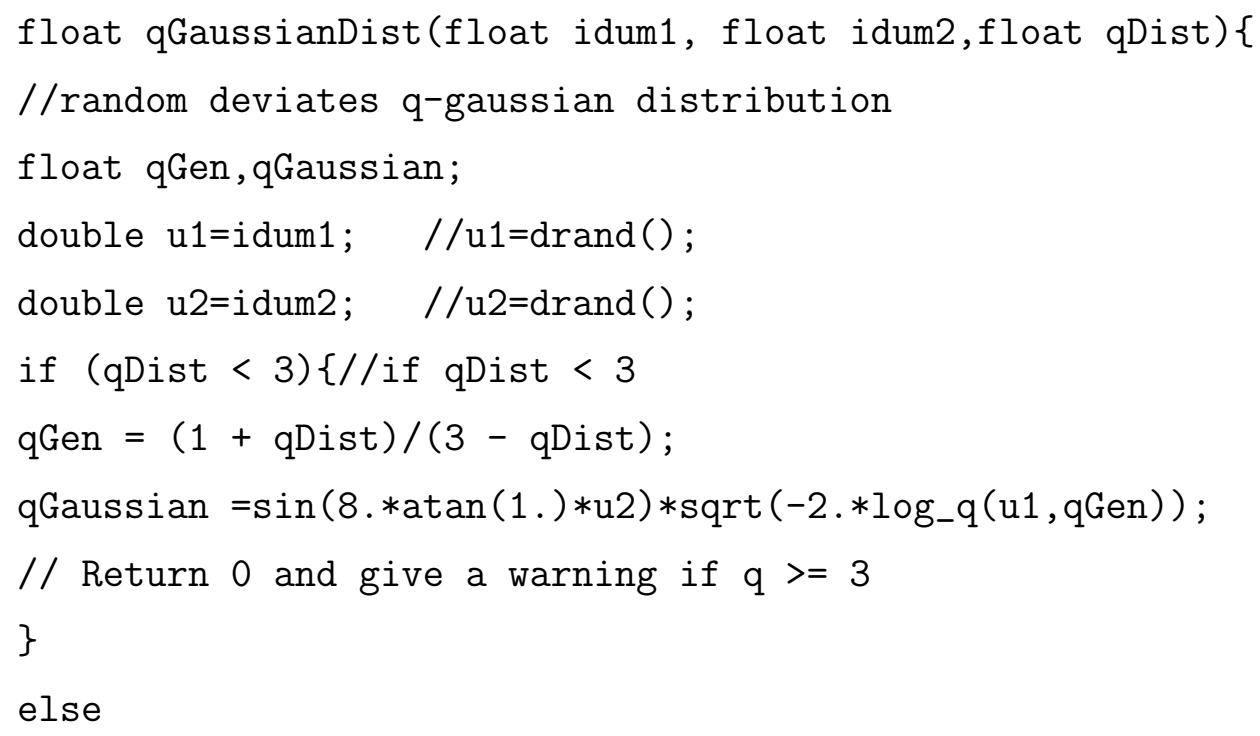




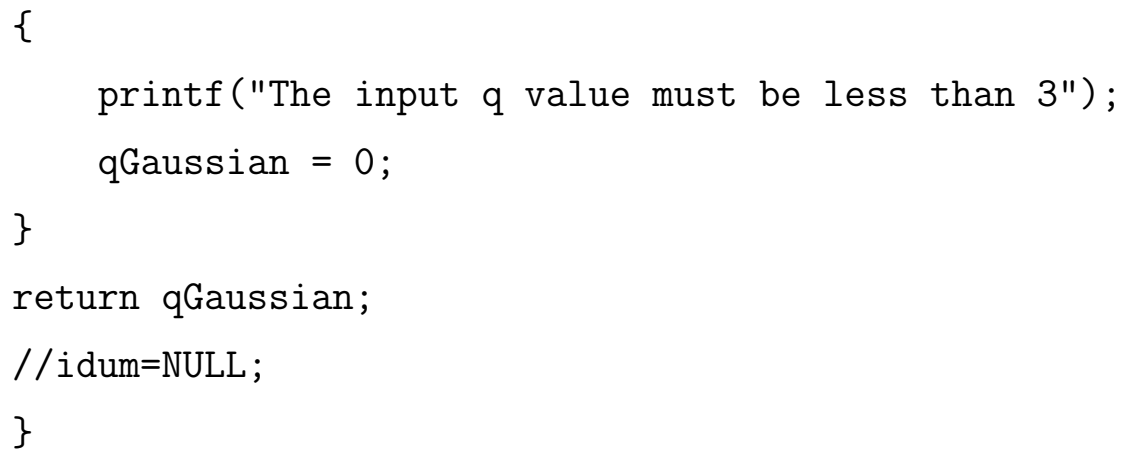

\section{C.2 Regularização de Tikhonov}

O emprego de um método de regularização permite a obtenção de um problema de aproximação bem-comportado, a partir de um mal-comportado, pela incorporação de restrições de suavidade junto ao modelo de aproximação [ (33), (34)]. Este processo converge para um problema de otimização que deve minimizar uma função-objetivo $F(x)$ dada pela equação C.1:

$$
F(x)=\left\|s(x)-y^{\varepsilon}\right\|^{2}+\lambda R(u)
$$

em que $s(x)$ e a função desconhecida que queremos encontrar e $y^{\varepsilon}$ sao as possíveis soluções de ensaio para $\mathrm{s}(\mathrm{x}), \lambda$ é o parâmetro de regularização, e nos usamos 0 parâmetro de Regularização de Tikhonov: o operador é expresso por:

$$
R(u)=\sum_{k=0}^{p} \mu_{k}\left\|u^{(k)}\right\|_{2}^{2}
$$

em que $u^{(k)}$ denota a k-ésima derivada (diferença) e $\mu_{k}>0$. Em geral $\mu_{k}=\delta_{i j}$ e ó delta de Kronecker. e a técnica é chamada de regularização de Tikhonov de ordem$j$. O efeito da regularização de Tikhonov-0 é reduzir oscilações na função u (busca por funções suaves). Já na regularização de 1a ordem torna $u(1) \rightarrow 0 u$ é aproximadamente constante. Como este problema é mal-condicionado, a escolha de uma solução particular dentre as infinitas soluções possíveis está vinculada à definição apropriada da função de suavidade $R$. Pode-se observar que quando $\lambda \rightarrow 0$, o termo de fidelidade dos dados na função objetivo é superestimado, enquanto que para $\lambda \rightarrow \infty$ toda a informação contida no modelo matemático é perdida. 


\section{APÊNDICE D - Reconstrução e refinamento dos espectros}

Atualmente existem três maneiras para obter o espectro de fótons de um acelerador linear, que consistem em modelamento da fonte usando simulação Monte Carlo, medição pó espectrometria Compton e reconstrução pó métodos matemáticos como a transformada de Laplace, recozimento simulado ou outro método numérico que usa dados de medições de transmissão o dados da medição da curva de doses em profundidade PDD. E provado que a reconstrução de espectros baseado em dados de PDD pode conduzir a grandes erros pela lenta variação do PDD com o espectro; o método Monte Carlo a provado sua efetividade na reconstrução de espectros mais requer muito conhecimento da geometria e os materiais presentes na estrutura da fonte de radiação e o caminho dos fótons, nos propomos um método prático e de fácil uso na rotina clinica em base ao calculo usando dados de transmissão e usando o algoritmo de recozimento Simulado generalizado (GSA) para o calculo do espectro de fótons, e no casso de necessitar um refinamento do espectro obtido utilizar a formula de Schiff melhorada(45).

Schiff desarrolho uma formula para o espectro de fluência de fótons para um modelo de LINAC simplificado (45-47) baseado num modelo matemático no linear e num método analítico melhorado que usa a seguinte formula:

$$
\left\{\begin{array}{l}
\phi(E)=\frac{e^{-\mu(E) t}}{E}\left[\frac{T-E}{T}(\ln \eta-1)+\left[\frac{E}{T}\right]^{2}(\ln \eta-0.5)\right], \\
\eta=\left[\left(\frac{0.511 E}{2 T(T-E)}\right)^{2}+\left(\frac{Z^{1 / 3}}{111}\right)^{2}\right] .
\end{array}\right.
$$

em que $T$ e a energia total do electron incidente sobre o alvo (target), $t$ e o espessura hipotética de material alvo equivalente em atenuação ao sistema de filtração (alvo, filtro aplanador, etc) é $\mu(E)$ e o coeficiente de atenuação linear do material alvo, e $Z$ e o numero atômico efetivo de todos os materiais atenuantes. Li et al.(45) introduz 
um termino de forma log-gaussiano para adaptar esta formula a LINAC comerciais da seguinte equação:

$$
f(E)=c e^{-\ln ^{2}\left(E / E_{p}\right) / 4 a^{2}}
$$

em que $E_{p}$ e o valor pico $a$ e á largura a metade do pico e $c$ é um coeficiente de normalização. Logo a formula melhorada de Schiff resulta:

$$
\left\{\begin{array}{l}
\phi(E)=\frac{c e^{-\mu(E) t-\ln ^{2}(E / E p) / 4 a^{2}}}{E} \times \\
{\left[\frac{T-E}{E}(\ln \eta-1)+\left[\frac{E}{T}\right]^{2}(\ln \eta-0.5)\right]} \\
\eta=\left[\left(\frac{0.511 E}{2 T(T-E)}\right)^{2}+\left(\frac{Z^{1 / 3}}{111}\right)^{2}\right]
\end{array}\right.
$$

em que o ajuste dos dados deve ser realizado em função a seis parâmetros definidos quais são: T, Z, t, a, c, Ep 


\section{APÊNDICE E - Dados para obtenção curva de transmissão}

\section{E.1 Coeficiente de atenuação}

Na Figura 31 observa-se o coeficiente de atenuação $\mu / \rho$ e coeficiente de atenuação mássico $\mu_{e n} / \rho$ para Alumínio obtido de 32

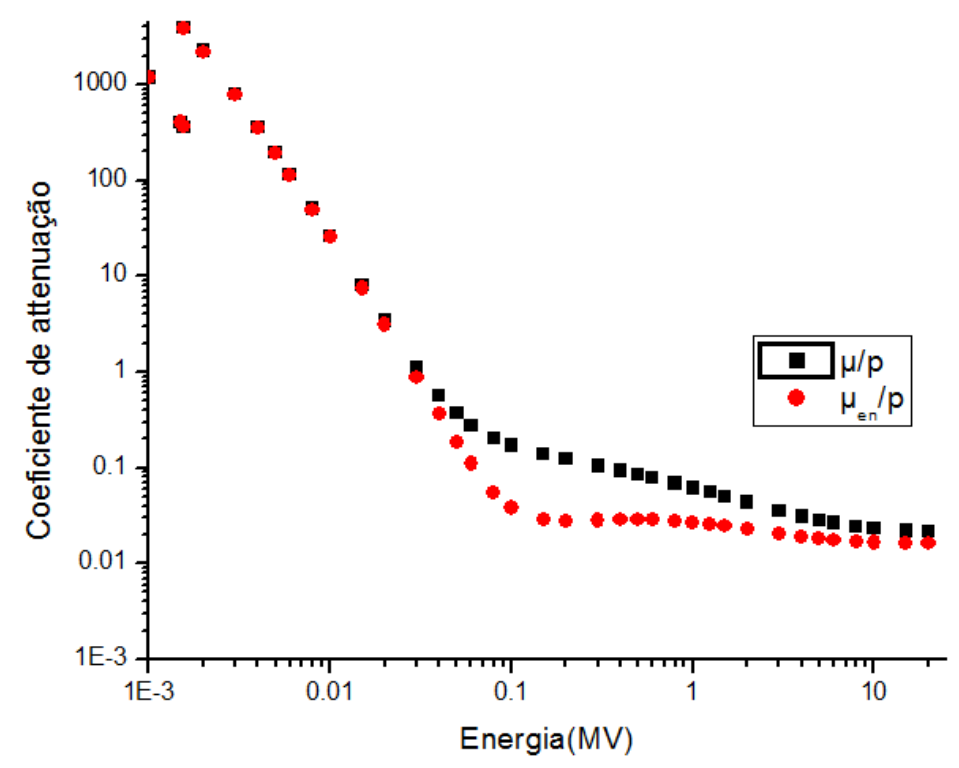

Figura 31: Coeficiente de atenuação e coeficiente de atenuação mássico para alumínio em função da energia do fóton $h v$ na faixa de 0 a $20 \mathrm{MV}$.

Na Figura 32 observa-se a transmissão relativa $T_{x}$ em Alumínio em função da espessura $x(\mathrm{~cm})$ de alumínio para fótons de $6 \mathrm{MV}$ que foram medidas com a câmara de ionização FARMER e o eletrômetro IBADOSE1. Na Figura 33 observa-se a transmissão relativa $T_{x}$ em Alumínio em função da espessura $x(\mathrm{~cm})$ de alumínio para fótons de $15 \mathrm{MV}$ que foram medidas com a câmara de ionização FARMER e o eletrômetro IBADOSE1. Na Figura 34 observa-se a transmissão relativa $T_{x}$ em Alumínio em função 


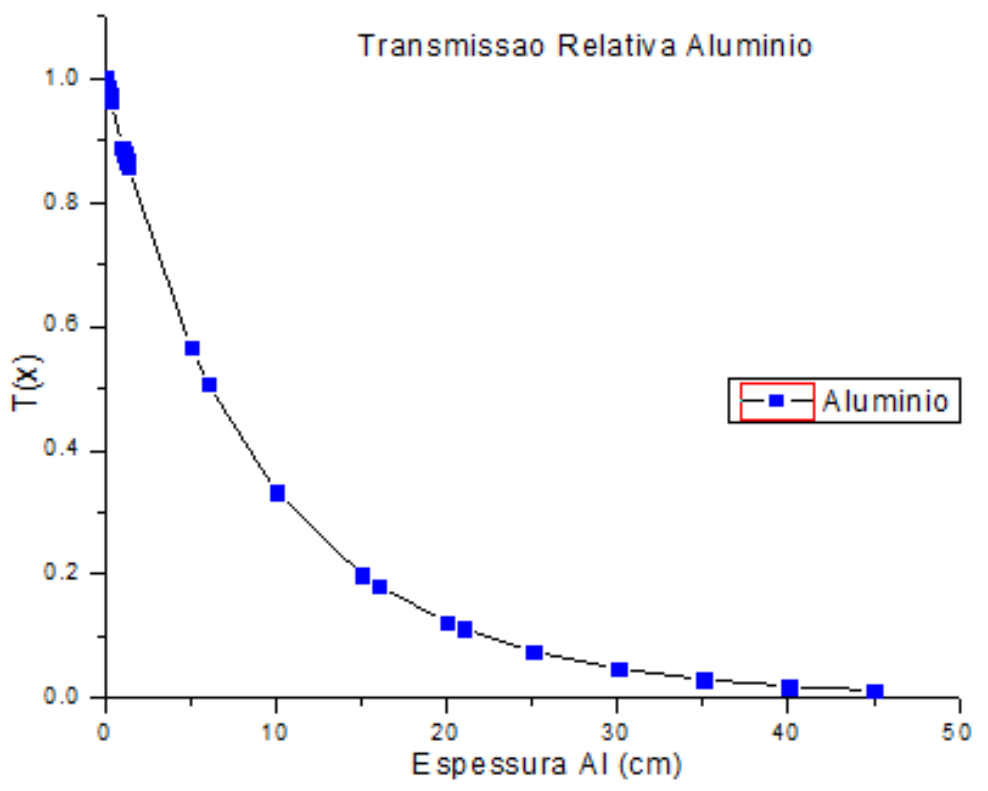

Figura 32: Transmissão relativa $T_{x}$ em alumínio em função da espessura $x(\mathrm{~cm})$ de alumínio para fótons de $6 \mathrm{MV}$ que foram medidas com a câmara de ionização FARMER e o eletrômetro IBADOSE1

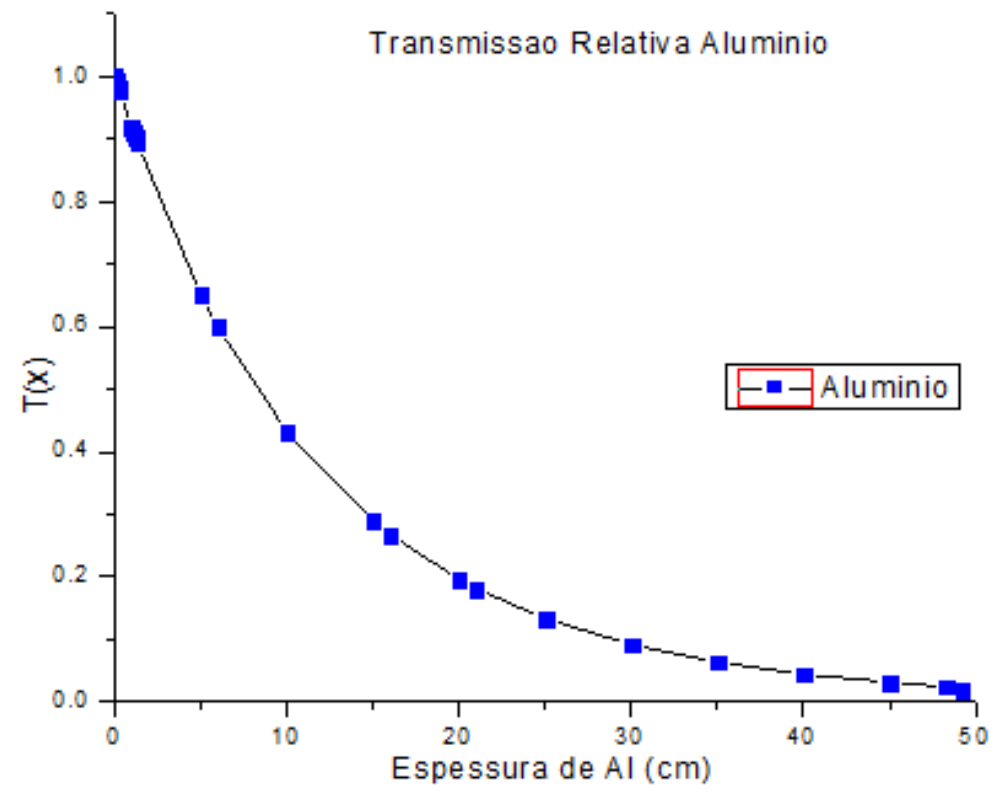

Figura 33: Transmissão relativa $T_{x}$ em alumínio em função da espessura $x(\mathrm{~cm})$ de alumínio para fótons de $15 \mathrm{MV}$ que foram medidas com a câmara de ionização FARMER e o eletrômetro IBADOSE1 
da espessura $x(\mathrm{~cm})$ de Cobre para fótons de $6 \mathrm{MV}$ que foram medidas com a câmara de ionização FARMER e o eletrômetro IBADOSE1. Na Figura 35 observa-se a trans-

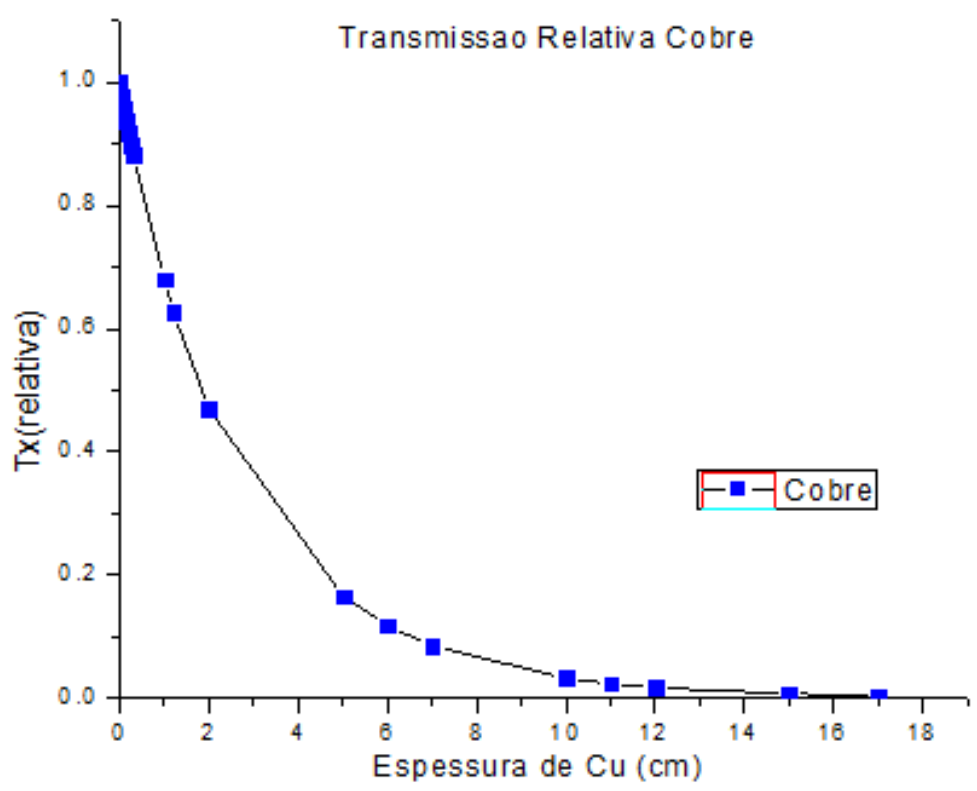

Figura 34: Transmissão relativa $T_{x}$ em cobre em função da espessura $x(\mathrm{~cm})$ de cobre para fótons de $6 \mathrm{MV}$ que foram medidas com a câmara de ionização FARMER e o eletrômetro IBADOSE1

missão relativa $T_{x}$ em Cobre em função da espessura $x(\mathrm{~cm})$ de Cobre para fótons de $15 \mathrm{MV}$ que foram medidas com a câmara de ionização FARMER e o eletrômetro IBADOSE1. Na Figura 36 observa-se a transmissão relativa $T_{x}$ em Chumbo em função da espessura $x(\mathrm{~cm})$ de Chumbo para fótons de $6 \mathrm{MV}$ que foram medidas com a câmara de ionização FARMER e o eletrômetro IBADOSE1. Na Figura 37 observa-se a transmissão relativa $T_{x}$ em Chumbo em função da espessura $x(\mathrm{~cm})$ de Chumbo para fótons de $15 \mathrm{MV}$ que foram medidas com a câmara de ionização FARMER e o eletrômetro IBADOSE1. Na Figura 38 observa-se uma comparação da transmissão relativa $T_{x}$ em Alumínio, cobre e Chumbo em função da espessura $x(\mathrm{~cm})$ para cada material para fótons de $6 \mathrm{MV}$ que foram medidas com a câmara de ionização FARMER e o eletrômetro IBADOSE1. Na Figura 39 observa-se a comparação da transmissão relativa $T_{x}$ em Alumínio, cobre e Chumbo em função da espessura $x(\mathrm{~cm})$ para cada material para fótons de $15 \mathrm{MV}$ que foram medidas com a câmara de ionização FARMER e o eletrômetro IBADOSE1. 


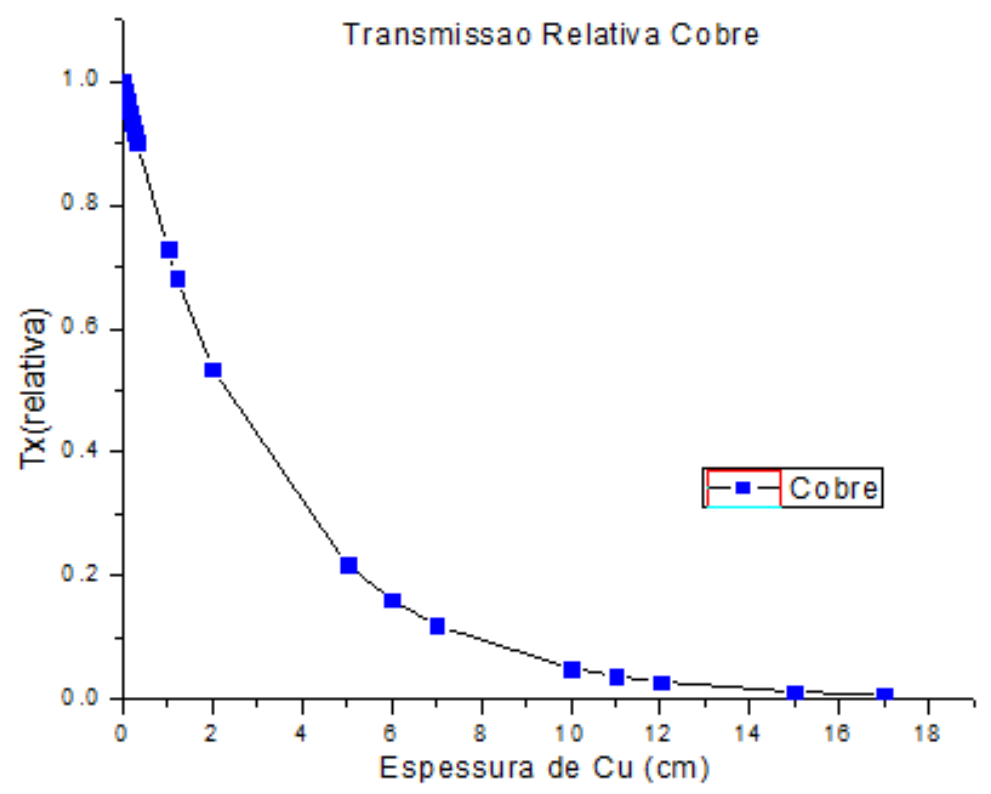

Figura 35: Transmissão relativa $T_{x}$ em cobre em função da espessura $x(\mathrm{~cm})$ de cobre para fótons de $15 \mathrm{MV}$ que foram medidas com a câmara de ionização FARMER e o eletrômetro IBADOSE1

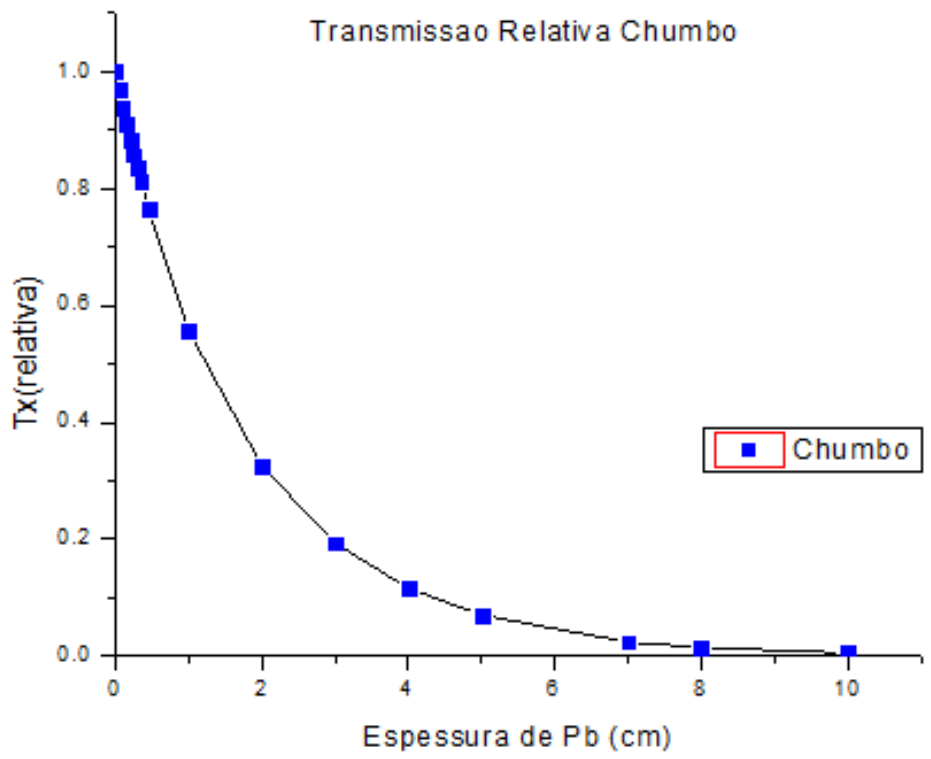

Figura 36: Transmissão relativa $T_{x}$ em chumbo em função da espessura $x(\mathrm{~cm}) \mathrm{de}$ chumbo para fótons de $6 \mathrm{MV}$ que foram medidas com a câmara de ionização FARMER e o eletrômetro IBADOSE1 


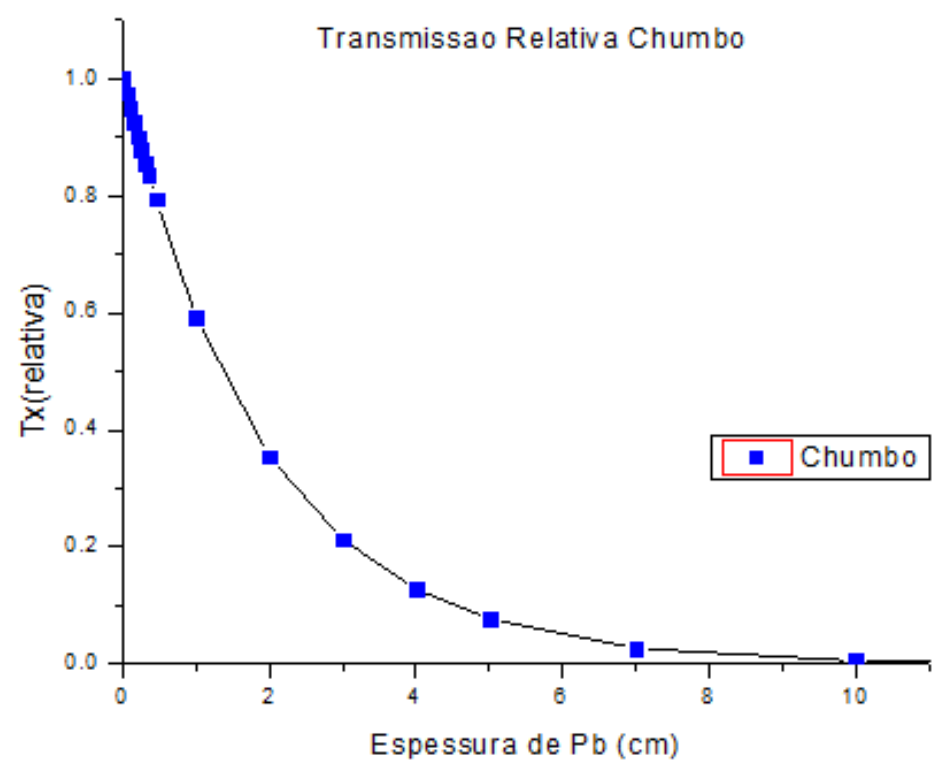

Figura 37: Transmissão relativa $T_{x}$ em chumbo em função da espessura $x(\mathrm{~cm})$ de chumbo para fótons de $15 \mathrm{MV}$ que foram medidas com a câmara de ionização FARMER e o eletrômetro IBADOSE1

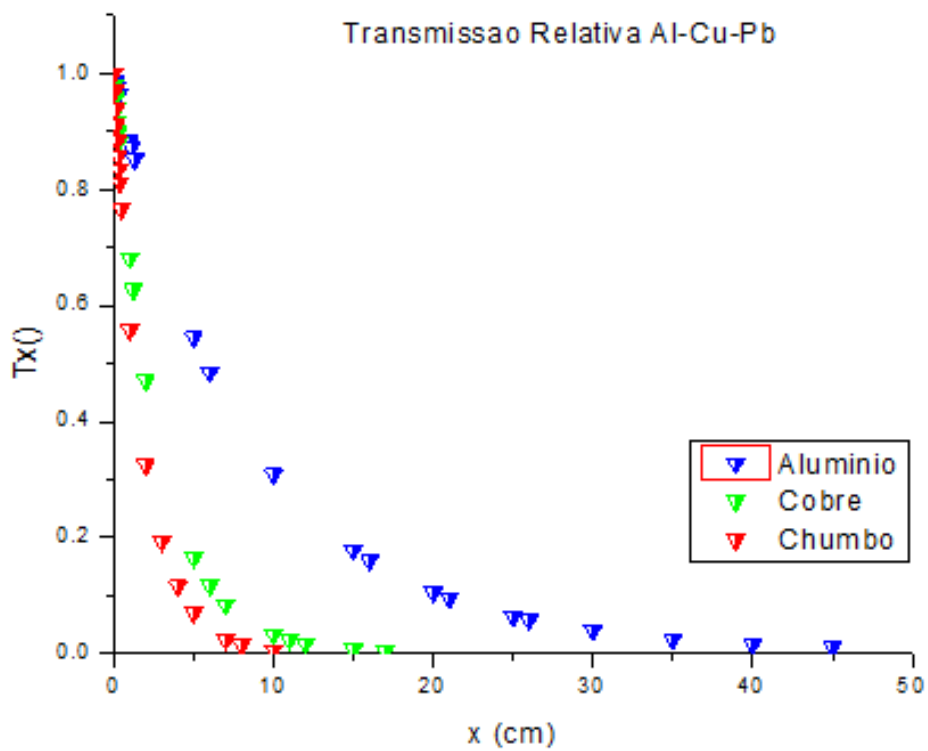

Figura 38: Comparação da transmissão relativa $T_{x}$ em alumínio, cobre e chumbo em função da espessura $x(\mathrm{~cm})$ para cada material para fótons de $6 \mathrm{MV}$ que foram medidas com a câmara de ionização FARMER e o eletrômetro IBADOSE1. 


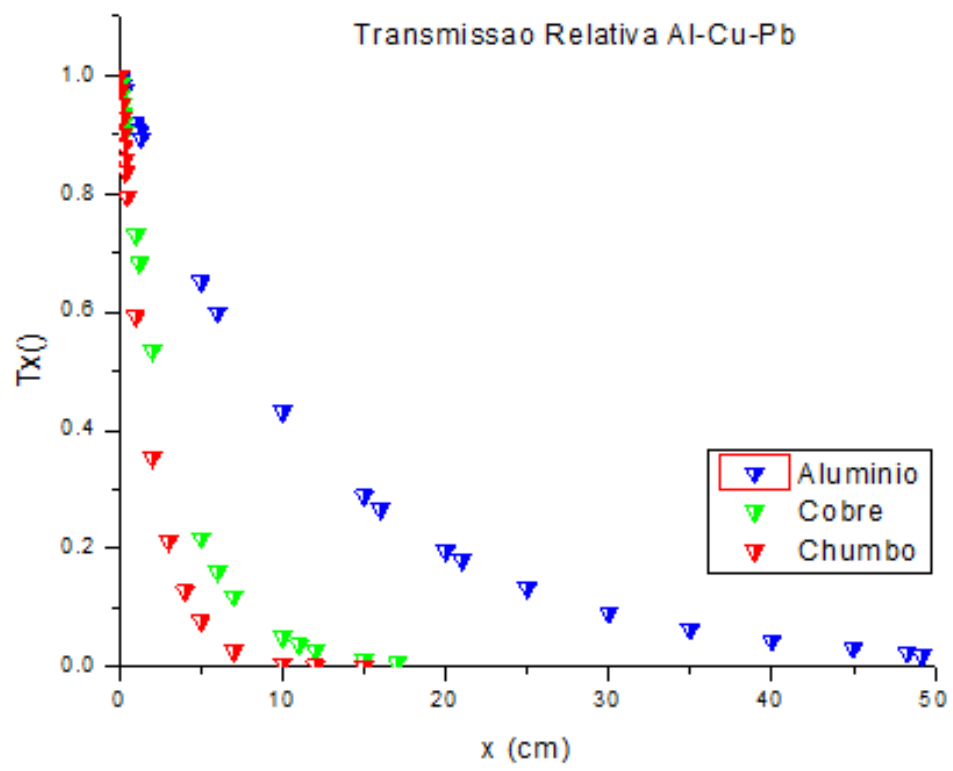

Figura 39: Transmissão relativa $T_{x}$ em chumbo em função da espessura $x(\mathrm{~cm})$ de chumbo para fótons de $15 \mathrm{MV}$ que foram medidas com a câmara de ionização FARMER e o eletrômetro IBADOSE1 


\section{APÊNDICE F - Distribuições de probabilidade e universo soluções para $6 \mathrm{MV}$}

\section{F.1 Distribuições}

Com o propósito de testar a obtenção de distribuições de probabilidade nos obtivemos as distribuições de probabilidade exponencial, normal e $\tilde{q}$-Normal com o fim de verificar o bom funcionamento do programa, estas distribuições sao dadas nas seguintes figuras: Na figura 40 observa-se a obtenção das distribuições de probabili-

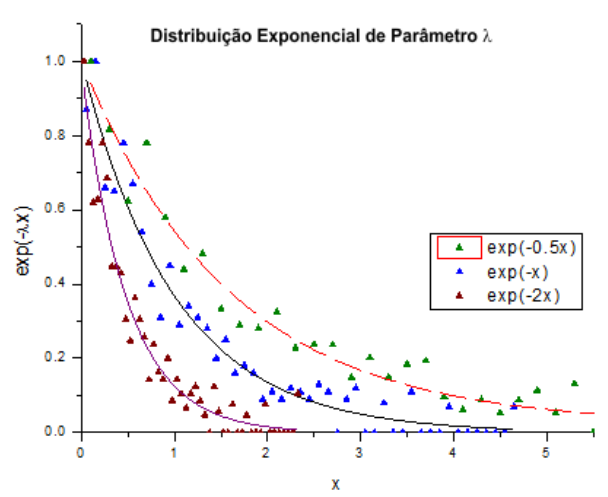

Figura 40: Distribuição exponencial de parâmetro $\lambda$ gerada com rand

dade exponencial para $\exp (-0.5 x), \exp (-x), \exp (-2 x)$ com as correspondentes ajustes ao valor teórico usando um gerador de números aleatórios simples como o rand. $\mathrm{Na}$ figura 41 observa-se a obtenção das distribuições de probabilidade exponencial para $\exp (-0.5 x), \exp (-x), \exp (-2 x), \exp (-4 x)$ com o gerador de números aleatórios ran2 de Numerical Recipes (48). Seguidamente apresentamos a comparação do histograma da distribuição de probabilidade $\exp (-x)$, com o valor teórico correspondente na figura 42.

Então usando o método de box müller, construímos a distribuição normal-variate na figura 43, é a normal-deviate 44, construída com o gasdev de Numerical Recipes (48). 


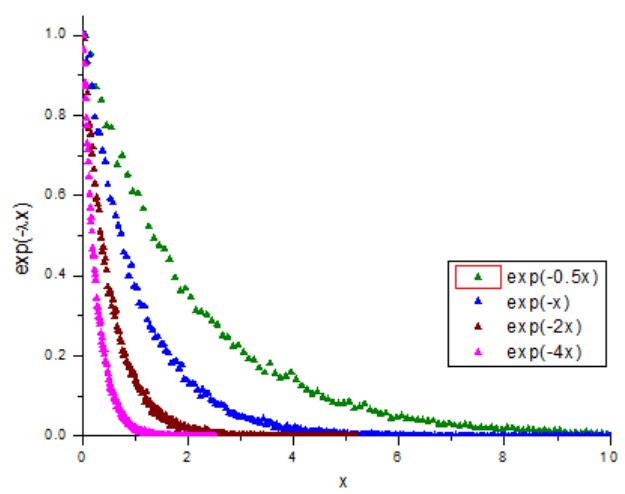

Figura 41: Distribuição exponencial de parâmetro $\lambda$ gerada com ran2

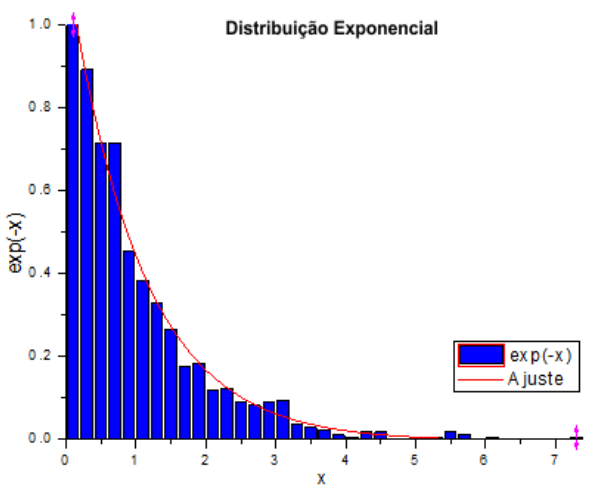

Figura 42: Distribuição exponencial

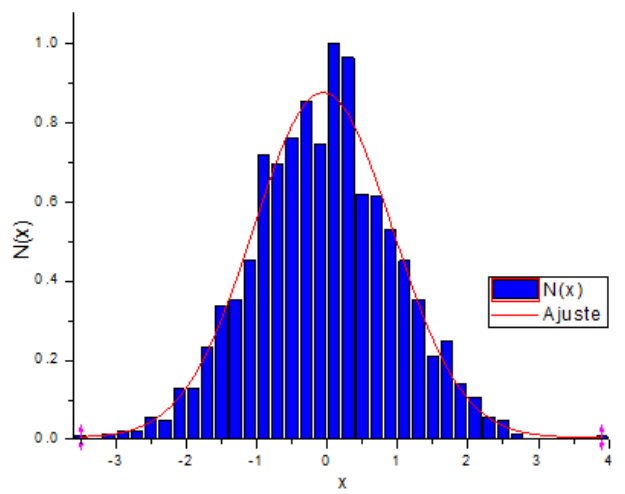

Figura 43: Distribuição Normal-variate 


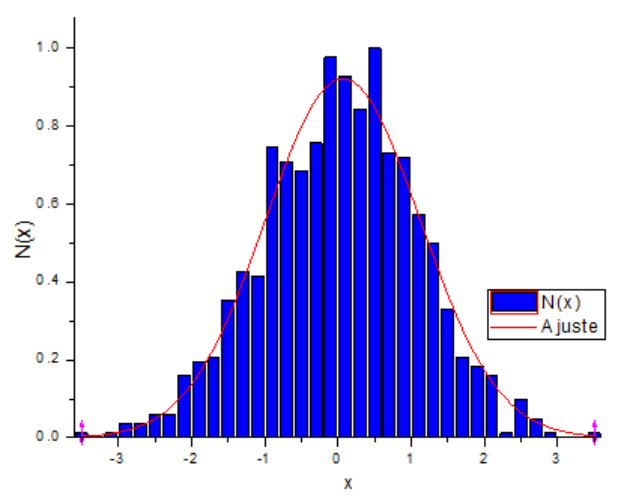

Figura 44: Distribuição Normal-variate obtida de gasdev

A partir das funções $\tilde{q}$-logaritmo e $\tilde{q}$-exponencial se obtém a função $\tilde{q}$-Normal dada na figura 45

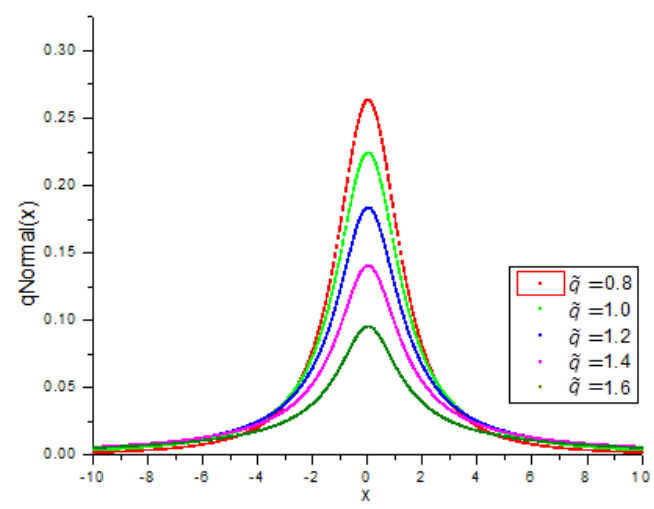

Figura 45: Função $\tilde{q}$-Normal em função do parâmetro $\tilde{q}$

Para nosso propósito normalizamos ao máximo cada função q̃-Normal para cada cada valor do parâmetro q̃, os quais sao mais fácil de comparar com nossa distribuição q-Normal deviate obtida com o método de Box Muller generalizado dado no [apêndice C.1], os valores normalizados sao dados na figura 46 .

Finalmente obtivemos a distribuição q -Normal a partir do método de box muller generalizado, [apêndice C.1], a qual e usada para gerar soluções candidatas para nosso modelo na figura 47.

A partir dessas considerações e do usso da distribuição q̃-Normal padrão para gerar soluções candidatas em nosso modelo nos construímos o universo de possíveis soluções para o espectro de fluência de fótons de $6 \mathrm{MV}$ para diferentes valores do parâmetro $\tilde{q}$ e variando o parâmetro $\lambda$. como se mostra nas figuras a continuação:

Observasse nas figuras [48 - 53], para o espectros de fluência para $6 \mathrm{MV}$, que no existe uma variação importante quando variamos ó parâmetro $\lambda$, o qual e uma 


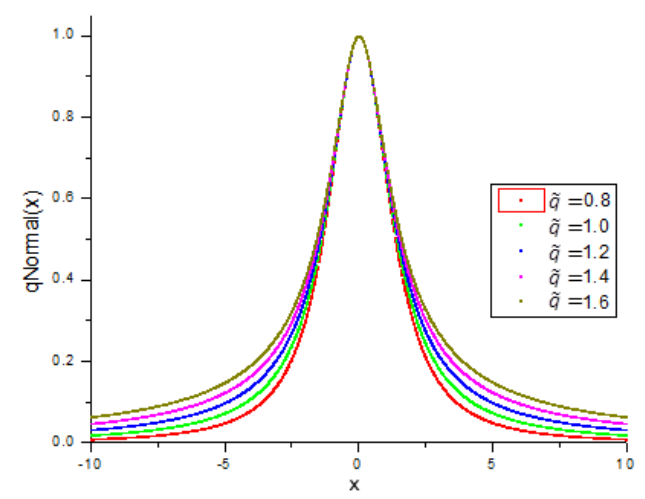

Figura 46: Função q̃-Normal em função do parâmetro q̃ normalizados ao máximo de cada distribuição

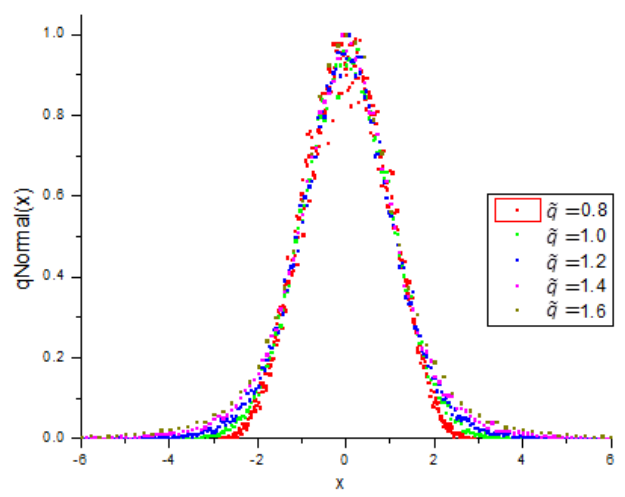

Figura 47: Distribuição de probabilidade $\tilde{q}$-Normal padrão em função do parâmetro $\tilde{q}$ normalizados ao máximo de cada distribuição

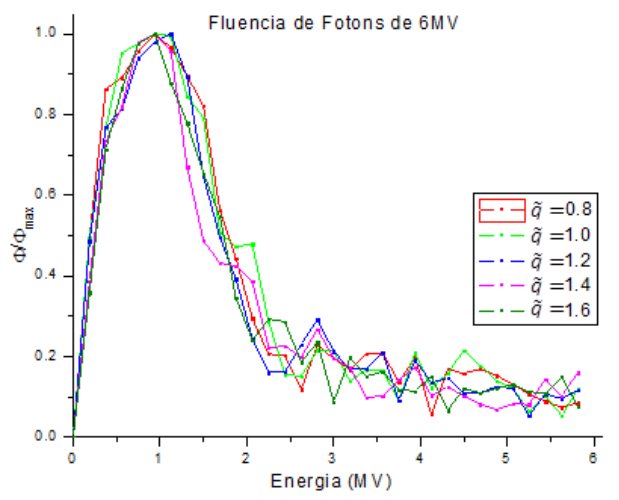

Figura 48: Espectros de fluência para $\lambda=0.0005, k=33$, tmax $=200, n r=100, \alpha=0.9$ 


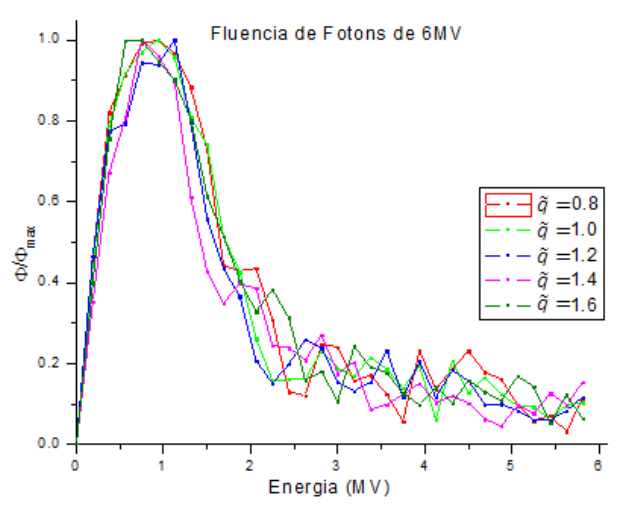

Figura 49: Espectros de fluência para $\lambda=2000, k=33, \operatorname{tmax}=200, n r=100, \alpha=0.9$

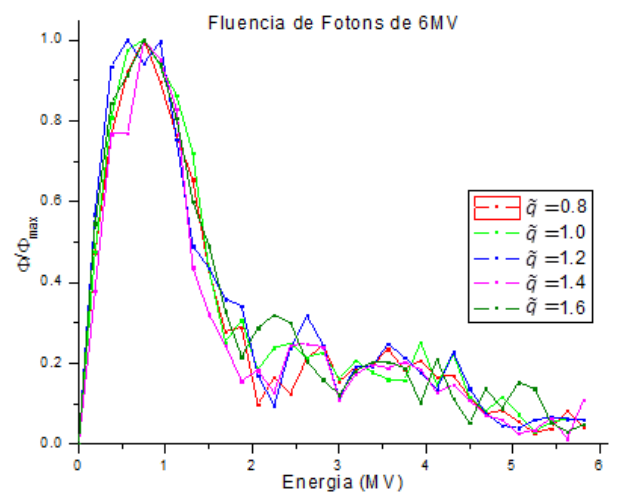

Figura 50: Espectros de fluência para $\lambda=0.0005, k=33, \operatorname{tmax}=500, n r=100, \alpha=0.9$

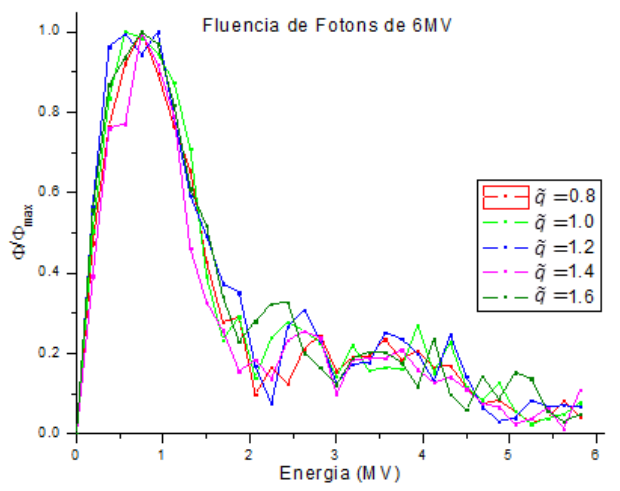

Figura 51: Espectros de fluência para $\lambda=2000, k=33, \operatorname{tmax}=500, n r=100, \alpha=0.9$ 


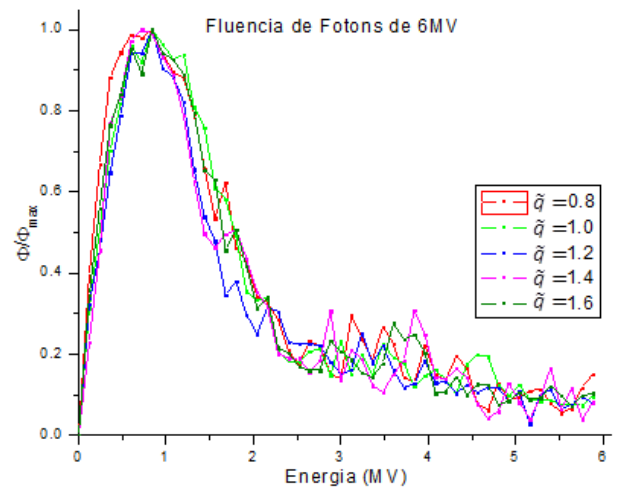

Figura 52: Espectros de fluência para $\lambda=0.0005, k=51$, tmax $=500, n r=100, \alpha=0.9$

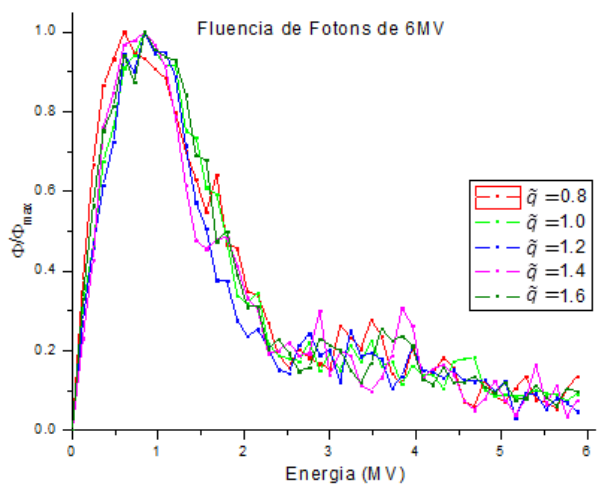

Figura 53: Espectros de fluência para $\lambda=2000, k=51, \operatorname{tmax}=500, n r=100, \alpha=0.9$ 
boa condição para a unicidade e convergência das soluções, indicando que a implementação do algoritmo foi adequada, além do ruido aleatório inerente devido ao método aleatório usado, e as condições de seleção do parâmetro de regularização de Tikhonov[ (33), (34)]. Todas as soluções para o espectro de fluência de fótons foram obtidas com nosso programa GSA1.0 escrito em em $\mathrm{C}++$ e usando um novo gerador de números aleatórios de tipo Mersenne Twister (MT) para gerar números pseudo-aleatórios dado no artigo de Matsumoto e Kurita(38). 


\section{APÊNDICE G - Espectros obtidos pela técnica GSA com base nas curvas de transmissão}

\section{G.1 Validação da reconstrução do espectro de fluência de fótons}

Para fazer as provas iniciais do método GSA na reconstrução de espectros nos usamos o trabalho de Catala et al.(10) quem reconstruiu o espectro de fluência de fótons para um acelerador de $12 \mathrm{MV}$ considerando o efeito da capa de build-up nas medições de transmissão e na obtenção do espectro. Ele considerou as medidas de transmissão para uma capa de build-up de $2.6 \mathrm{~cm}$ de diâmetro de material Alumínio,e uma câmera de ionização FARMER 2581 de $0,32 \mathrm{~mm}$ de raio e volume de 0.6 cc para suas medições de transmissão os espectros de fluência de $12 \mathrm{MV}$ reconstruído pra os dados de transmissão nesse trabalho com diferentes numero de canais $k=51$ em cor vinho, $k=101$ em cor azul e o espectro refinado para ambos se mostra a continuação na figura 54 como pra garantir a unicidade da solução mostramos os espectros finais extrapolados obtidos pela técnica de GSA para $k=51$ em linha verde com pontos em azul, $k=101 \mathrm{em}$ linha verde com pontos em cor vinho na figura 55. Se observa um bom acordo de nossos resultados pra o espectro de fluência obtidos para esse espectro e o obtido pó Catala et al.(10). Nas seguintes provas nos usamos as curvas de transmissão reconstruídas a partir do espectro de um acelerador linear Varian de $4 \mathrm{MV}, 10 \mathrm{MV}$ e um acelerador Electa de $6 \mathrm{MV}$ obtidos da referência 35 com o propósito de usar as curvas de transmissão para reconstruir o espectro con a técnica de GSA essas curvas foram obtidas num programa em $\mathrm{C}++$ que calcula a transmissão a partir do espectro dado e a espessura dos atenuadores, nas figuras mostramos as curvas de transmissão calculadas: o seguinte proba para nosso algoritmo GSA1.0 foi reconstruir o espectro de un acelerador linear Varian de $4 \mathrm{MV}$ a partir da curva de 


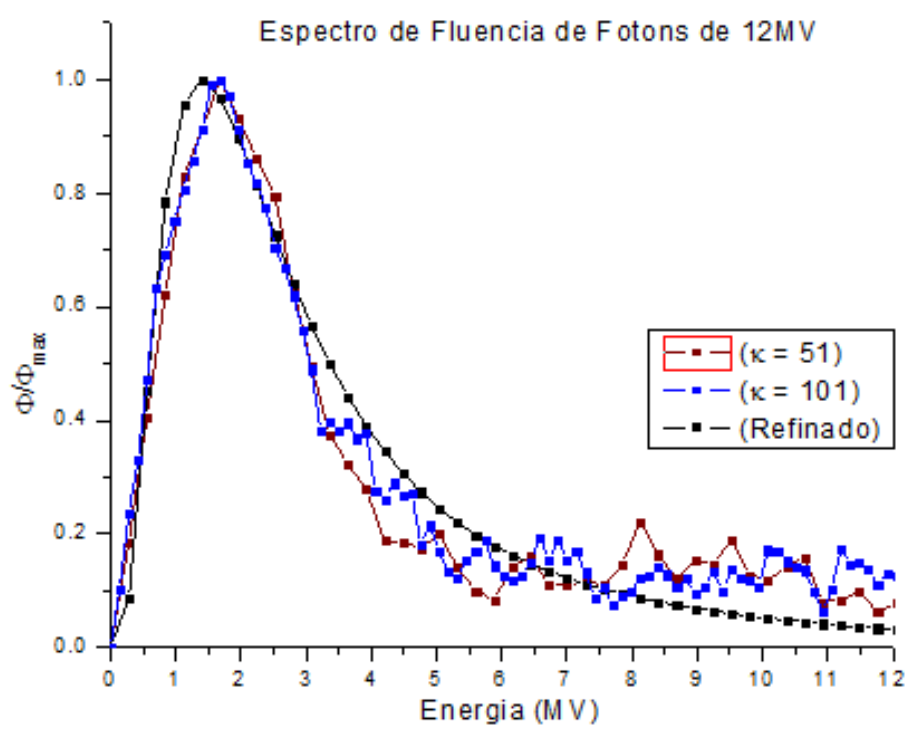

Figura 54: Espectro de fluência de fótons de $12 \mathrm{MV}$ normalizado obtido pela técnica de GSA para Alumínio em função da energia do fóton $E$

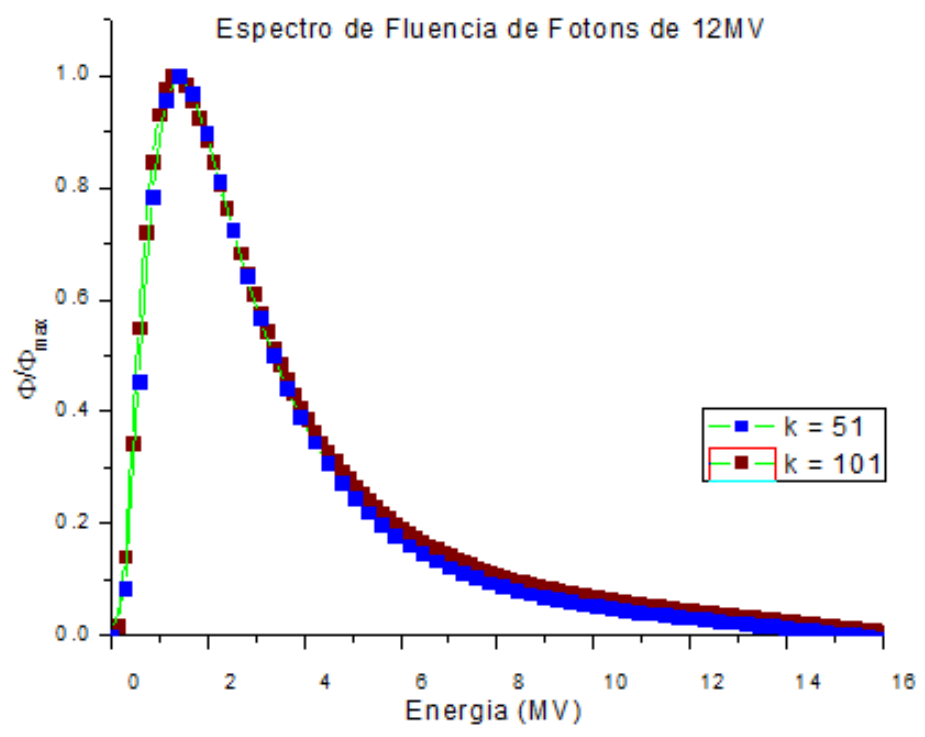

Figura 55: Espectro de fluência de Fótons de $12 \mathrm{MV}$ normalizado obtido pela técnica de GSA para alumínio em função da energia do fóton $E$ 


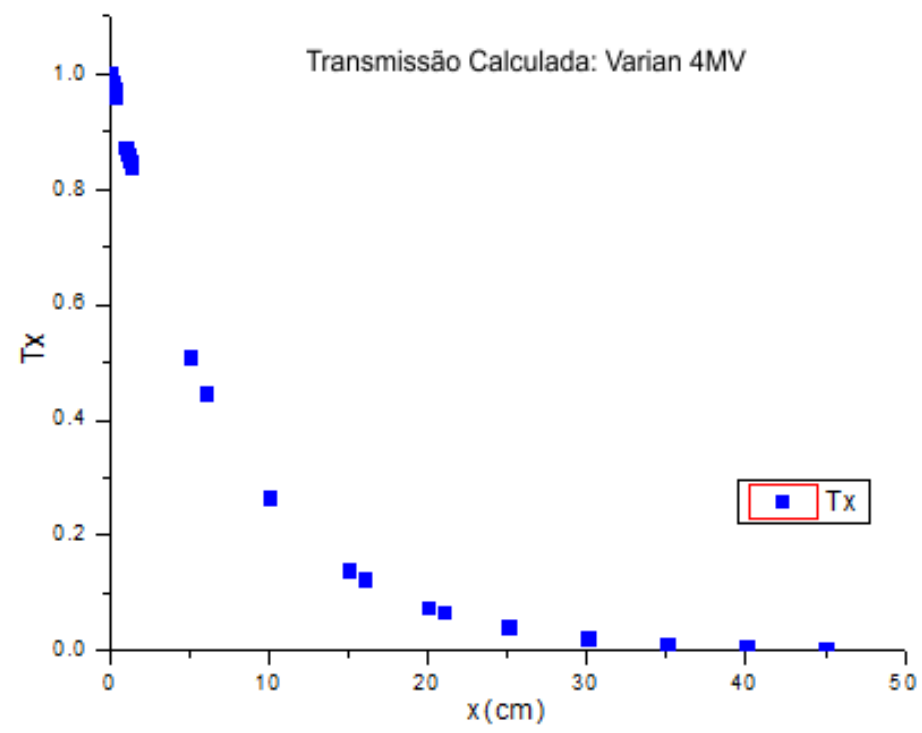

Figura 56: Transmissão calculada para blocos de alumínio de diferentes espessuras para fótons de um acelerador linear Varian de $4 \mathrm{MV}$ normalizado

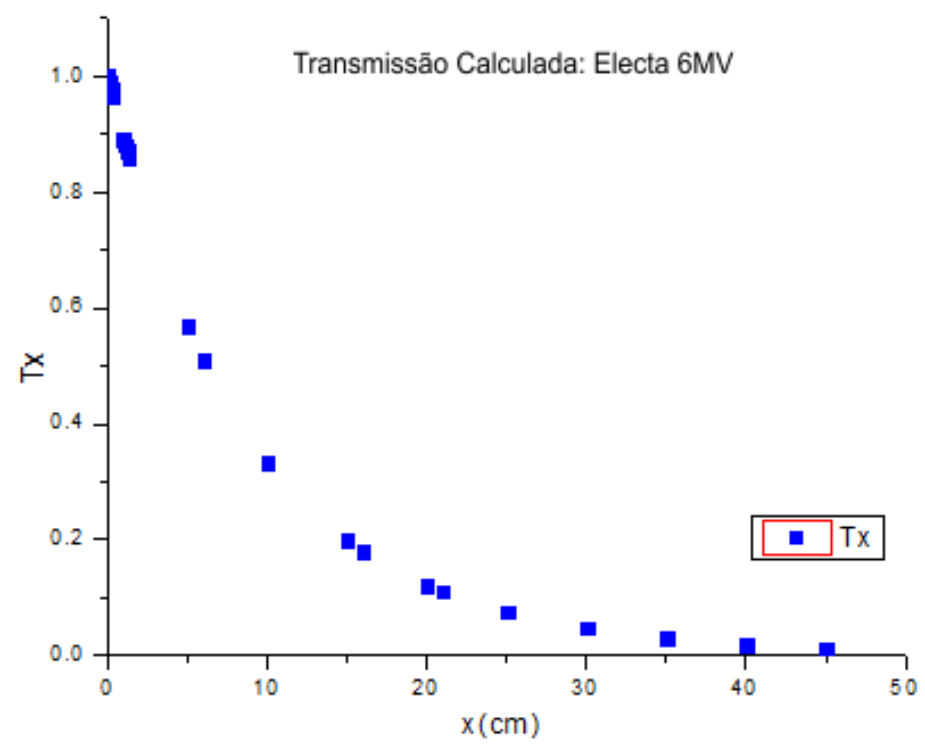

Figura 57: Transmissão calculada para blocos de alumínio de diferentes espessuras pra fótons de um acelerador linear Electa de $6 \mathrm{MV}$ normalizado 


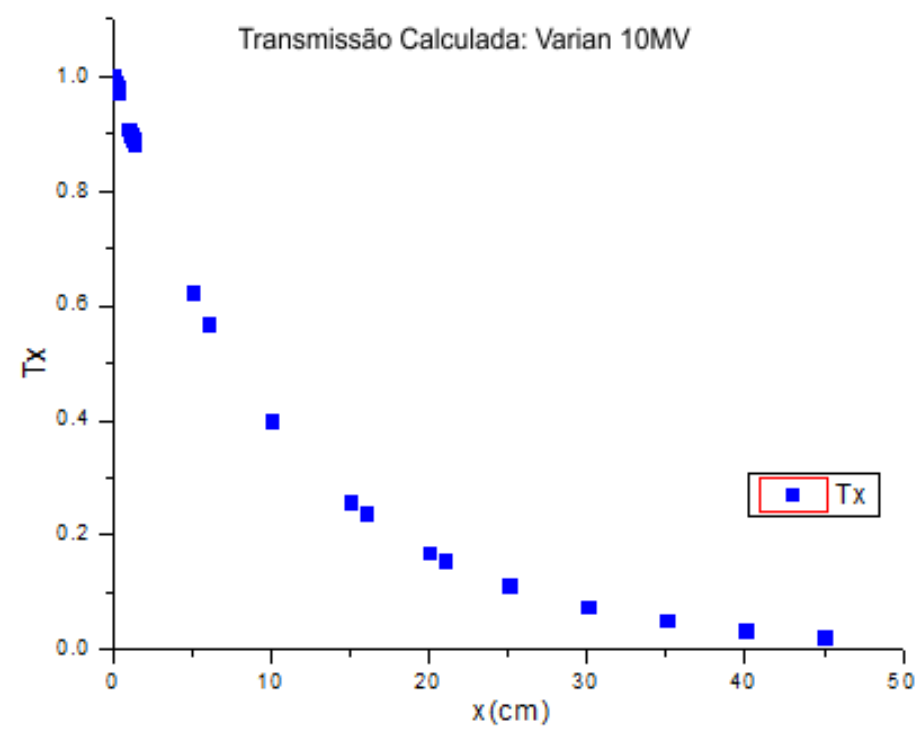

Figura 58: Transmissão calculada para blocos de alumínio de diferentes espessuras pra fótons de um acelerador linear Varian de $10 \mathrm{MV}$ normalizado

transmissão simulada previamente com um programa em $\mathrm{C}++$ dada na figura 56 a continuação observa-se a reconstrução para um numero de canais de $k=33$ (pontos cor preto)e $k=51$ (pontos cor azul)comparado com o espectro teórico em estrelas cor vinho, obtido do trabalho de SHEIKH-BAGHERI e Rogers(35) na figura 59. na

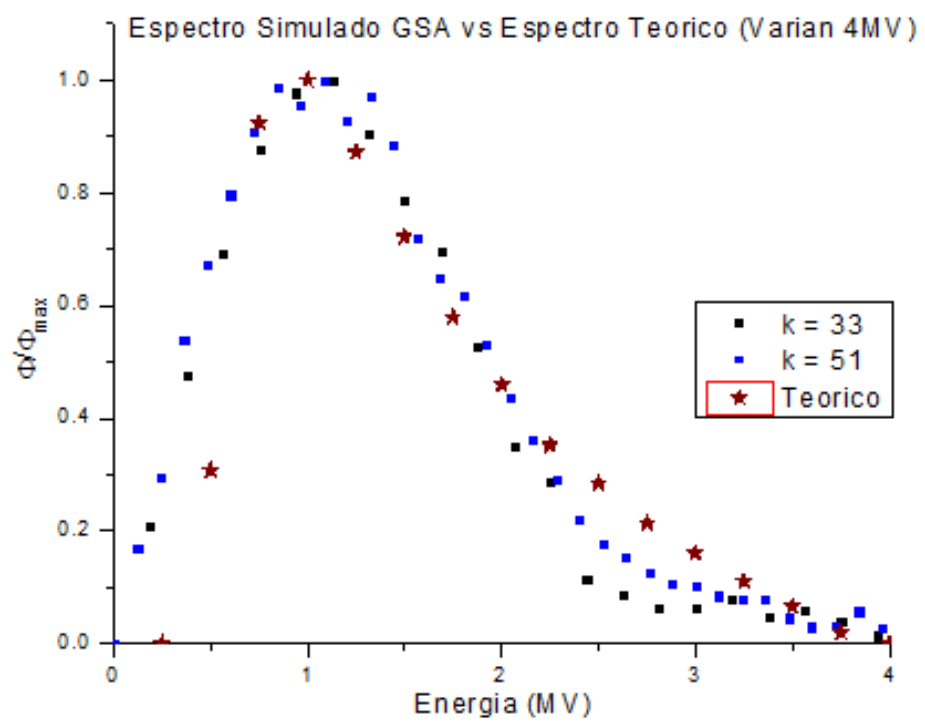

Figura 59: Espectro de fluência de fótons de para um acelerador linear Varian de $4 \mathrm{MV}$ normalizado obtido pela técnica de GSA para alumínio em função da energia do fóton E

figura 60 observa-se a dispersão de valores da reconstrução com nosso algoritmo GSA1.0 para o espectro de un acelerador linear Electa de 6MV a partir da curva de transmissão simulada previamente com um programa em $\mathrm{C}_{++}$dada na figura 57 a 
continuação observa-se a reconstrução para um número de canais de $k=33$ (pontos cor Azul)e $k=51$ (pontos cor vinho)comparado com o espectro teórico em pontos cor preto, obtido do trabalho de SHEIKH-BAGHERI e Rogers(35). outra reconstrução foi

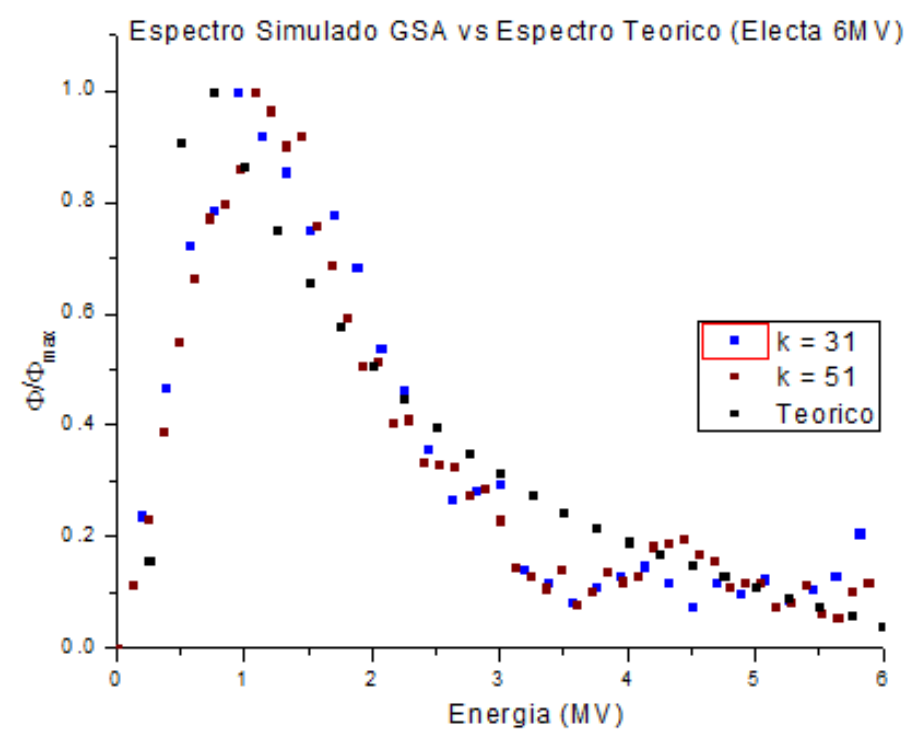

Figura 60: Espectro de fluência de fótons de para um acelerador linear Electa de $6 \mathrm{MV}$ normalizado obtido pela técnica de GSA para alumínio em função da energia do fóton E

feita para o espectro de un acelerador linear Varian de $10 \mathrm{MV}$ com nosso algoritmo GSA1.0 a partir da curva de transmissão simulada previamente com um programa em $\mathrm{C}++$ dada na figura 58 a continuação observa-se a reconstrução para um numero de canais de $k=51$ (triângulos cor vinho)e $k=71$ (pontos cor-de-rosa), $k=101$ (quadrados cor azul)e comparado com o espectro teórico em quadrados cor preto, obtido do trabalho de SHEIKH-BAGHERI e Rogers(35) na figura 61. Observas-e que mesmo no tenha os parâmetros adequados para a reconstrução se obtém uma boa aproximação com respeito ao espectro teórico. Em conseqüência e viável reconstruir o espectro de fluência de fótons aplicando a técnica de GSA, nas seguintes gráficas mostramos nossos resultados obtidos a partir das medições de transmissão e o uso do método proposto na seção 2.2 para as energias de $6 \mathrm{MV}$ e $15 \mathrm{MV}$. Finalmente apresentamos os espectros refinados correspondentes a cada casso existe bom acordo com os respectivos espectros teóricos 


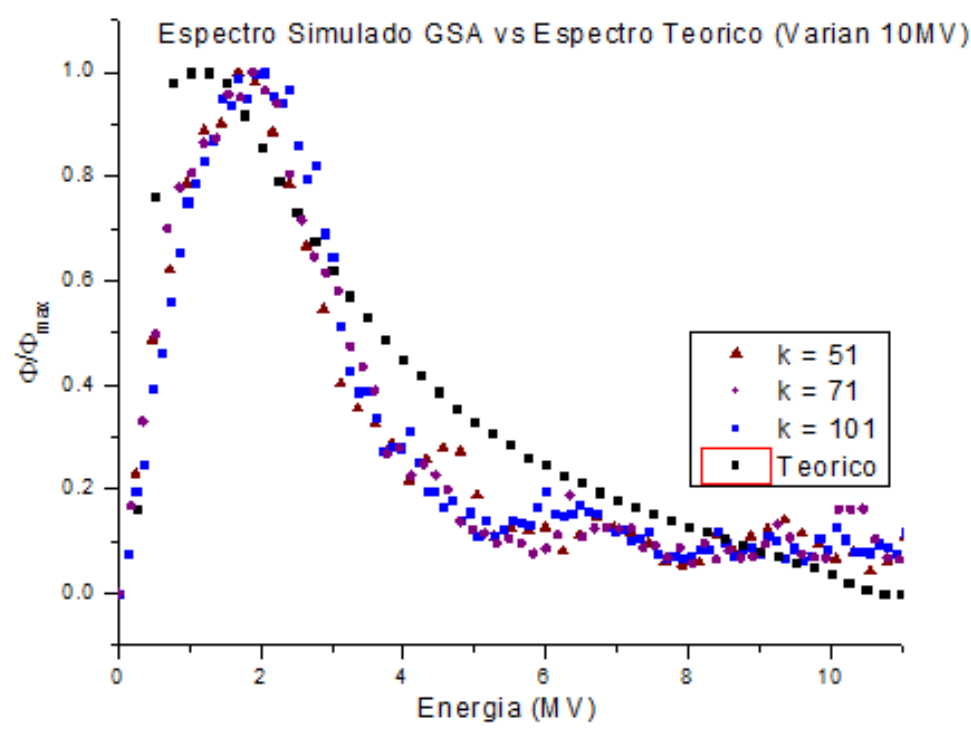

Figura 61: Espectro de fluência de fótons de para um acelerador linear Varian de $10 \mathrm{MV}$ normalizado obtido pela técnica de GSA para alumínio em função da energia do fóton E

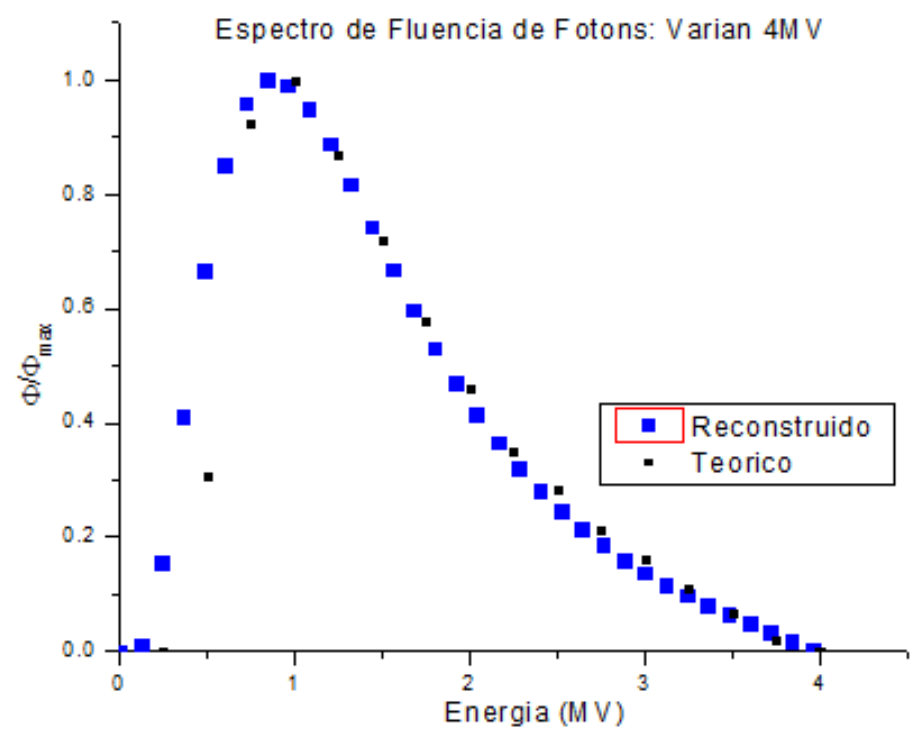

Figura 62: Espectro de fluência de fótons de para um acelerador linear Varian de $4 \mathrm{MV}$ normalizado obtido pela técnica de GSA para alumínio em função da energia do fóton E comparado com o espectro teórico 


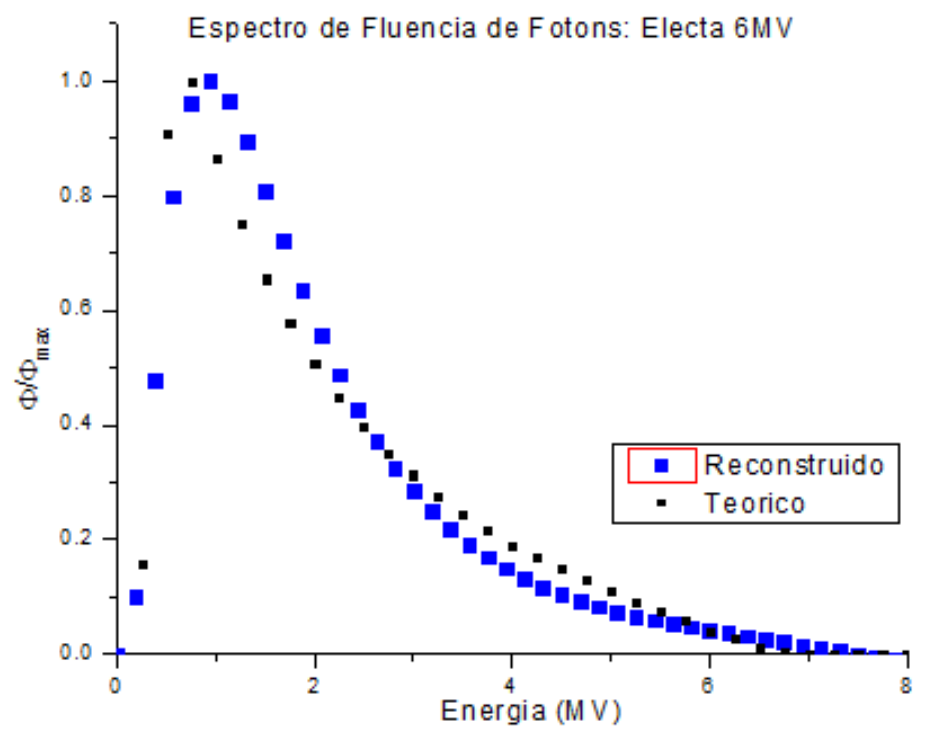

Figura 63: Espectro de fluência de fótons de para um acelerador linear Electa de $6 \mathrm{MV}$ normalizado obtido pela técnica de GSA para alumínio em função da energia do fóton Ecomparado com o espectro teórico

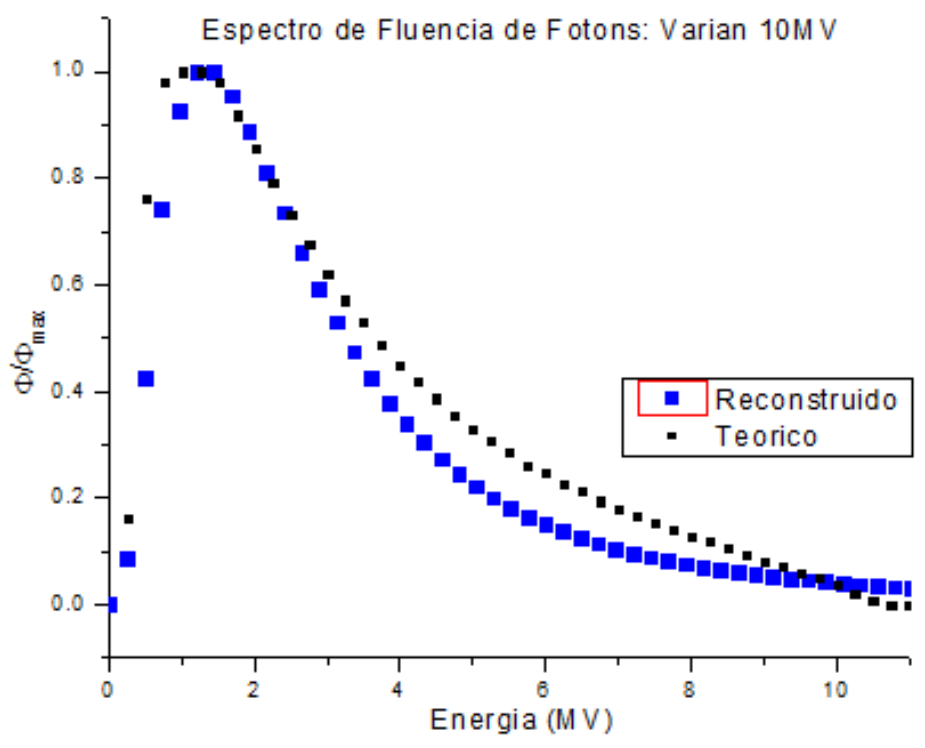

Figura 64: Espectro de fluência de fótons de para um acelerador linear Varian de $10 \mathrm{MV}$ normalizado obtido pela técnica de GSA para alumínio em função da energia do fóton $E$ comparado com o espectro teórico 


\section{G.2 Espectro de fluência de fótons de $6 \mathrm{MV}$}

Na Figura 65 observa-se o Espectro de fluência de Fótons de $6 \mathrm{MV}$ normalizado obtido pela técnica de GSA com base nas curvas de transmissão para Alumínio em função da energia do fóton $E$. Na Figura 66 observa-se o Espectro de fluência de Fótons de 6MV normalizado obtido pela técnica de GSA com base nas curvas de transmissão para Alumínio em função da energia do fóton $E$, esse espectro a sido refinado para obter em pontos preto o espectro resultante. Finalmente na Figura 67 observa-se o Espectro de fluência de Fótons de 6MV normalizado e refinado obtido pela técnica de GSA com base nas curvas de transmissão para Alumínio em função da energia do fóton $E$. na figura 71 observa-se o espectro reconstruído pela técnica

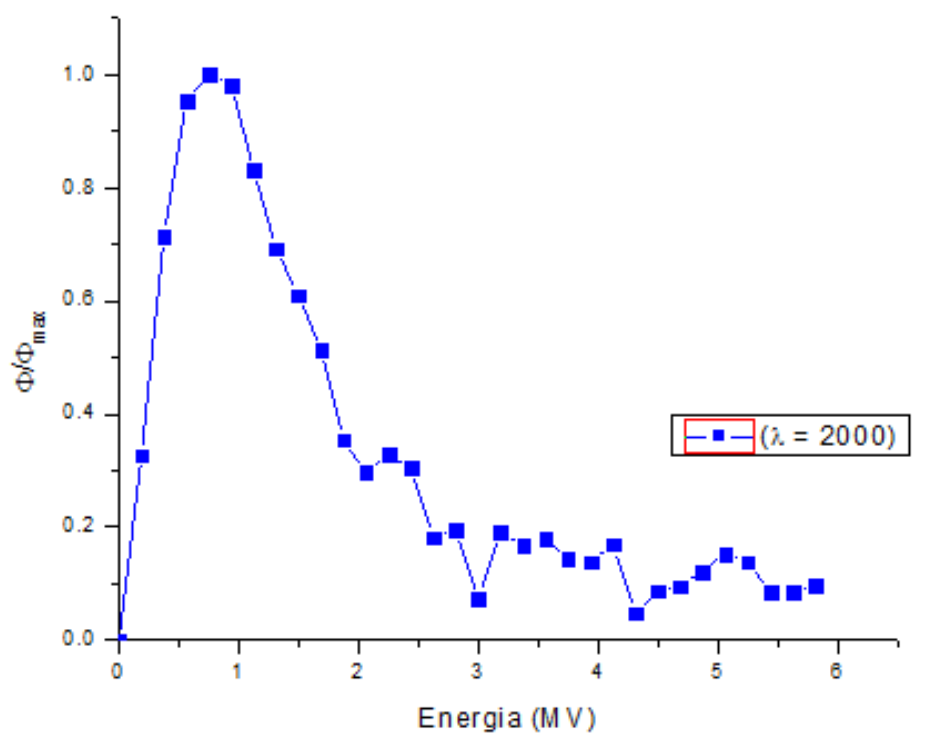

Figura 65: Espectro de fluência de Fótons de $6 \mathrm{MV}$ normalizado obtido pela técnica de GSA para alumínio em função da energia do fóton $E$

de GSA (triângulos em azul)para $k=101, t_{\max }=200 n_{r}=100, \tilde{q}_{v}=1,6 \alpha=0,9$ em que temos variado o número de canais $k$ respeito dos outros espectros obtidos comparado com seu espectro depois do refinamento(linha com pontos em preto). seguidamente apresentamos o espectro final depois do refinamento na figura 72.

\section{G.3 Espectro de fluência de fótons de $15 \mathrm{MV}$}

Na Figura 73 observa-se o Espectro de fluência de Fótons de 15MV normalizado obtido pela técnica de GSA com base nas curvas de transmissão para Alumínio em função da energia do fóton $E$. Na Figura 74 observa-se o Espectro de fluência de 


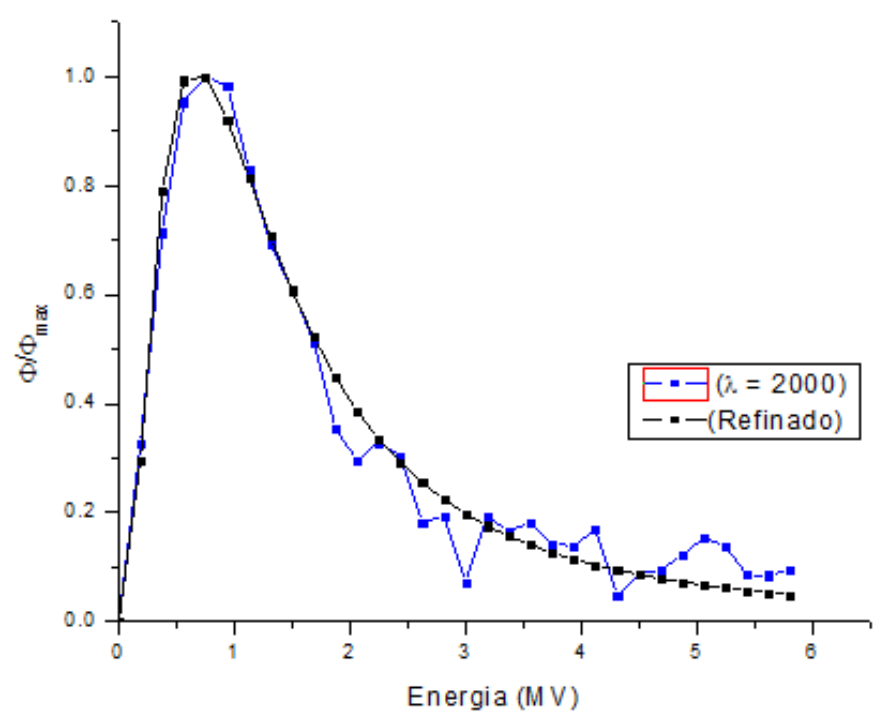

Figura 66: Espectro de fluência de Fótons de $6 \mathrm{MV}$ normalizado obtido pela técnica de GSA para alumínio em função da energia do fóton $E$

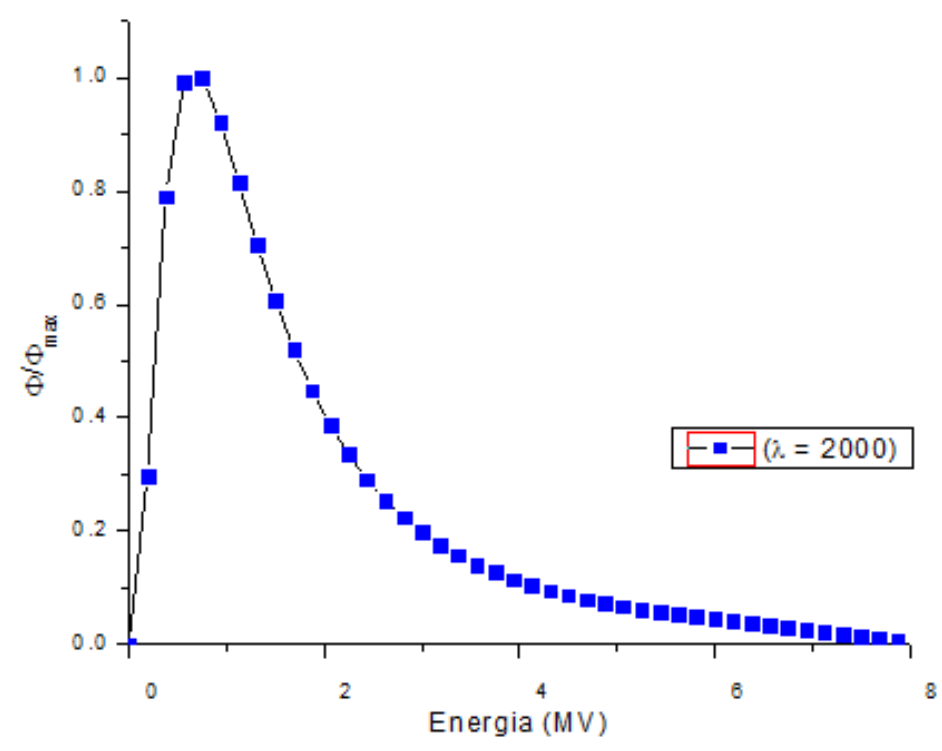

Figura 67: Espectro de fluência de Fótons de $6 \mathrm{MV}$ normalizado obtido pela técnica de GSA para alumínio em função da energia do fóton $E$ depois do refinamento 


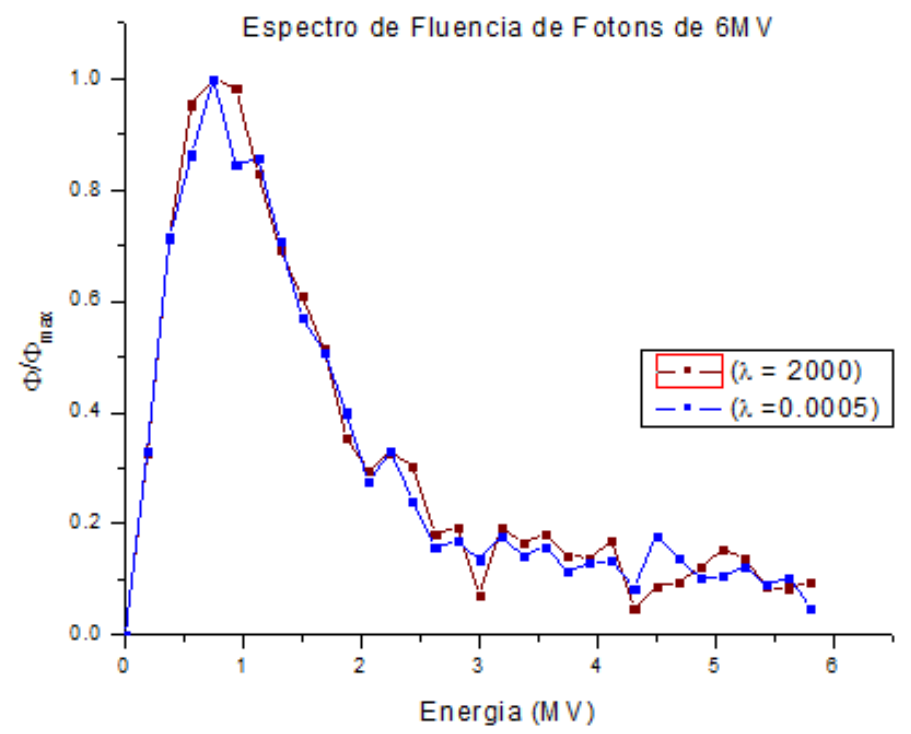

Figura 68: Comparação entre os Espectro de fluência de fótons de $6 \mathrm{MV}$ normalizado obtido pela técnica de GSA para alumínio em função da energia do fóton $E$ para diferentes valores do parametro $\lambda$

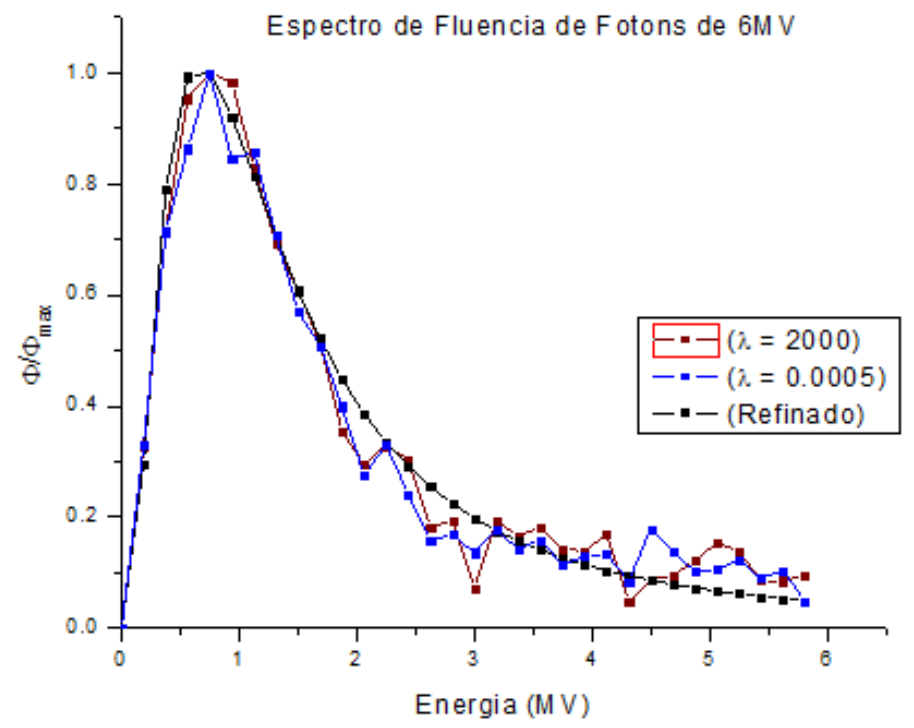

Figura 69: Comparação dos espectros de fluência de fótons de $6 \mathrm{MV}$ normalizado obtido pela técnica de GSA para alumínio em função da energia do fóton $E$ para diferentes valores do parâmetro $\lambda$ com o espectro refinado 


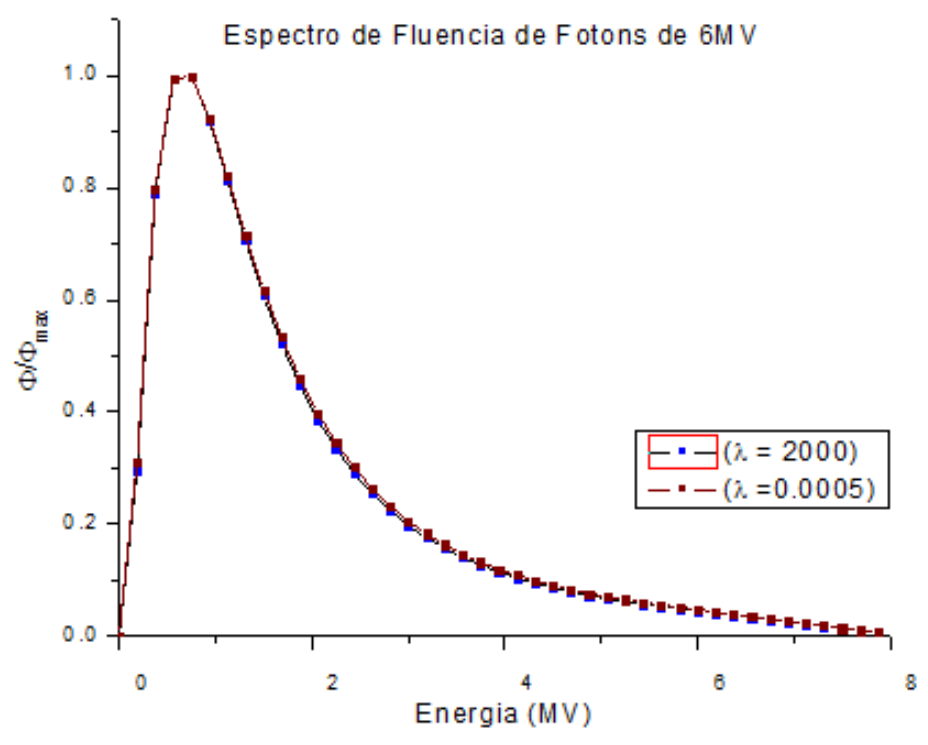

Figura 70: Comparação dos Espectros de fluência de fótons de $6 \mathrm{MV}$ normalizado obtido pela técnica de GSA para alumínio em função da energia do fóton $E$ depois do refinamento para diferentes valores do parametro $\lambda$

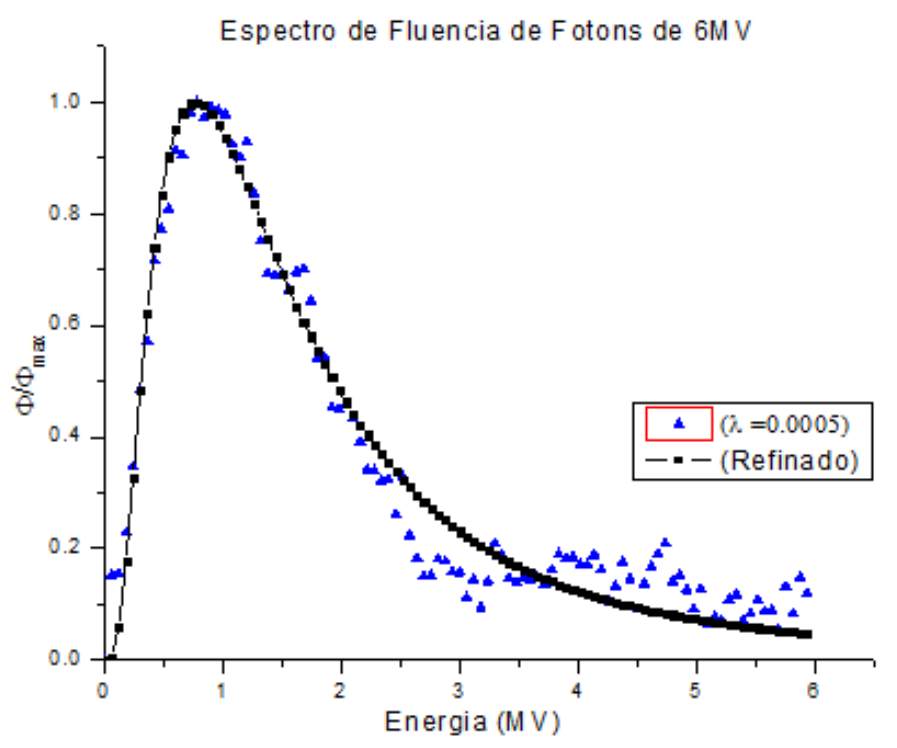

Figura 71: Espectro de fluência de fótons de $6 \mathrm{MV}$ normalizado obtido pela técnica de GSA para Alumínio em função da energia do fóton $E$ (triângulos em azul) para um numero de canais $k=101$, e seu espectro depois do refinamento (linha com pontos em preto) 


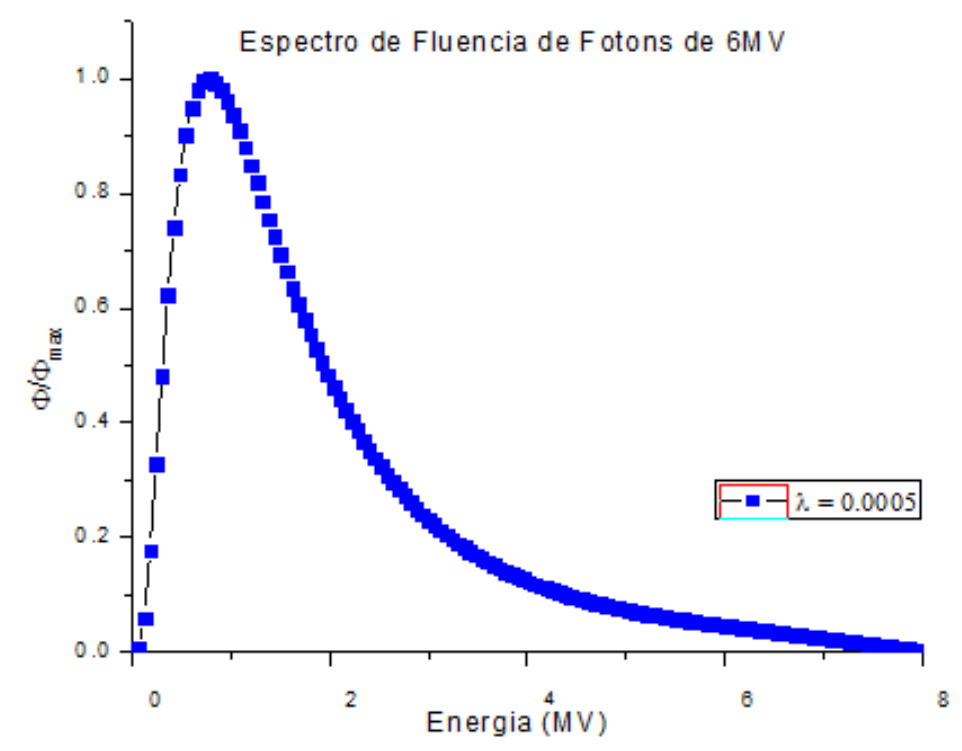

Figura 72: Espectro de fluência de fótons de $6 \mathrm{MV}$ normalizado obtido pela técnica de GSA para alumínio em função da energia do fóton $E$ para um numero de canais $k=101$, depois do refinamento

Fótons de 15MV normalizado obtido pela técnica de GSA com base nas curvas de transmissão para Alumínio em função da energia do fóton $E$, esse espectro a sido refinado para obter em pontos preto o espectro resultante. Finalmente na Figura 75 observa-se o Espectro de fluência de Fótons de 15MV normalizado obtido pela técnica de GSA com base nas curvas de transmissão para Alumínio em função da energia do fóton $E$ depois do refinamento. 


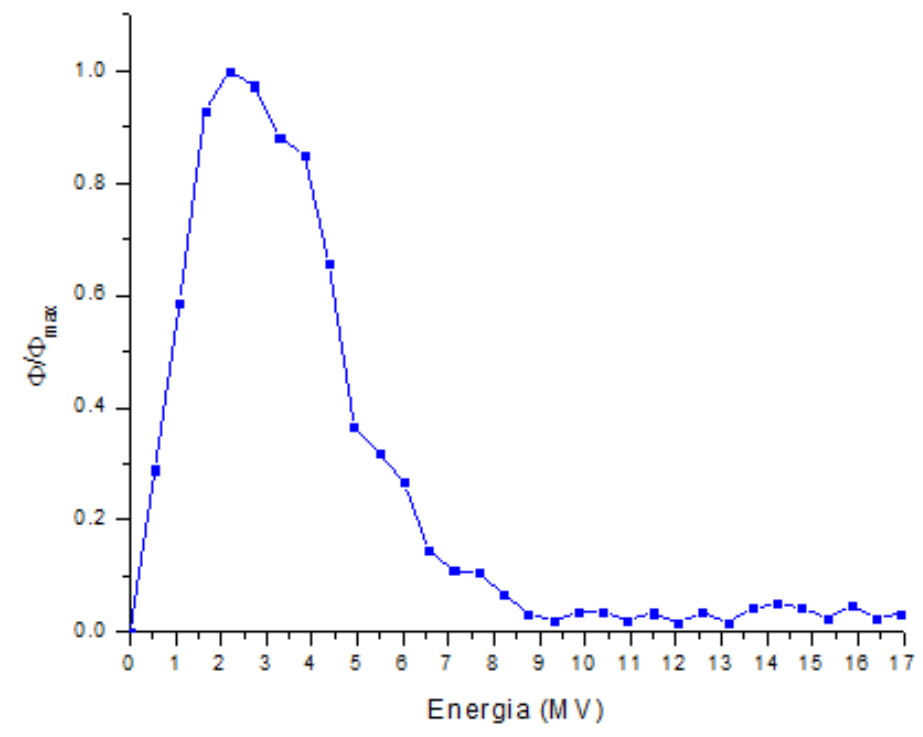

Figura 73: Espectro de fluência de fótons de $15 \mathrm{MV}$ normalizado obtido pela técnica de GSA para alumínio em função da energia do fóton $E$

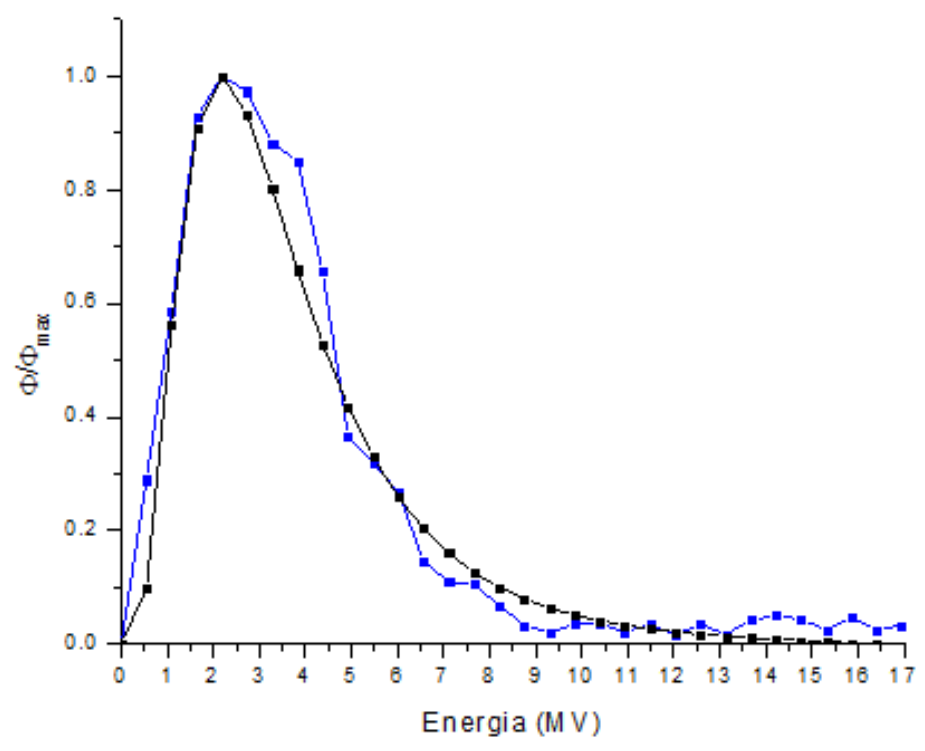

Figura 74: Espectro de fluência de fótons de $15 \mathrm{MV}$ normalizado obtido pela técnica de GSA para alumínio em função da energia do fóton $E$ 


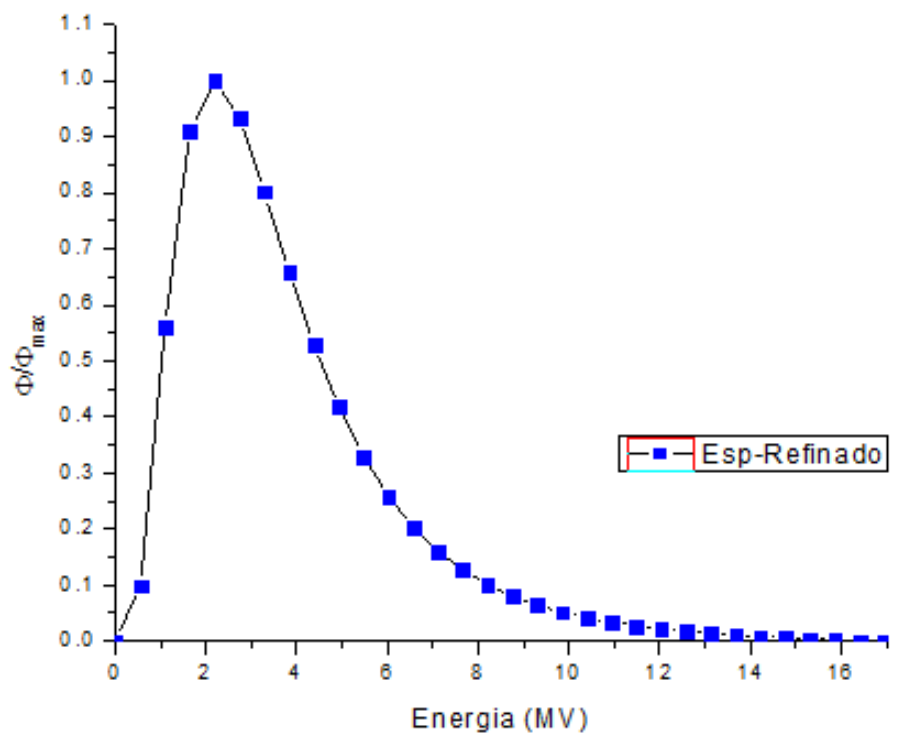

Figura 75: Espectro de fluência de fótons de $15 \mathrm{MV}$ normalizado obtido pela técnica de GSA para alumínio em função da energia do fóton $E$ depois do refinamento 